NBER WORKING PAPER SERIES

\title{
SMOOTH LANDING OR CRASH? \\ MODEL-BASED SCENARIOS OF \\ GLOBAL CURRENT ACCOUNT REBALANCING
}

\author{
Hamid Faruqee \\ Douglas Laxton \\ Dirk Muir \\ Paolo Pesenti \\ Working Paper 11583 \\ http://www.nber.org/papers/w11583
NATIONAL BUREAU OF ECONOMIC RESEARCH
1050 Massachusetts Avenue
Cambridge, MA 02138 \\ August 2005
}

Revised draft of the paper prepared for the NBER Conference on G7 Current Account Imbalances: Sustainability and Adjustment, Newport RI, June 2005. We thank Susana Mursula for invaluable assistance and Nathalie Carcenac for data support. We also thank Nicoletta Batini, Tamim Bayoumi, Rich Clarida, Giancarlo Corsetti, Robert Flood, Thomas Helbling, Michael Kumhof, Gian Maria Milesi-Ferretti, Papa N.Diaye, Alessandro Rebucci, David Robinson, Lars Svensson, and Cedric Tille for comments and suggestions. The views expressed in this paper are those of the authors and should not be attributed to the International Monetary Fund, its Executive Board or its management, the Norges Bank, the Bank of Canada, the Federal Reserve Bank of New York, the Federal Reserve System, or any other institution with which the authors are affiliated. The views expressed herein are those of the author(s) and do not necessarily reflect the views of the National Bureau of Economic Research.

(C2005 by Hamid Faruqee, Douglas Laxton, Dirk Muir and Paolo Pesenti. All rights reserved. Short sections of text, not to exceed two paragraphs, may be quoted without explicit permission provided that full credit, including () notice, is given to the source. 
Smooth Landing or Crash? Model-Based Scenarios of Global Current Account Rebalancing Hamid Faruqee, Douglas Laxton, Dirk Muir and Paolo Pesenti

NBER Working Paper No. 11583

August 2005

JEL No. E66, F32, F47

\section{$\underline{\text { ABSTRACT }}$}

This paper re-examines the implications, risks, and attendant policies surrounding global rebalancing of current accounts through the lens of a dynamic, multi-region model of the global economy. In the baseline scenario, world macroeconomic imbalances of the early 2000 s can be attributed to a combination of six related but distinct tendencies: (i)expansionary U.S. fiscal policy, (ii) declining rate of U.S. private savings, (iii) increased foreign demand for U.S. assets, particularly in Asia, (iv) strong productivity growth in emerging Asia, (v) lagging productivity growth in Japan and the euro area, and (vi) gaining export competitiveness in emerging Asia. The baseline projects stabilizing U.S. public and foreign debt (albeit at higher levels) and a gradual depreciation of the dollar, allowing the U.S. external deficit to gradually move to a sustainable level. An alternative scenario, involving a sudden portfolio reshuffling in the rest of the world, would result in higher U.S. real interest rates, a significantly weaker dollar, with harmful effects on U.S. (and possibly global) growth. More flexible exchange rates in emerging Asia can help reduce variability in both regional output and inflation. Other simulations consider the effects of U.S. fiscal adjustment, as well as growth-enhancing structural reforms in Europe and Japan.

\author{
Hamid Faruqee \\ International Monetary Fund \\ Washington, DC 20431 \\ hfaruqee@imf.org \\ Douglas Laxton \\ International Monetary Fund \\ Washington, DC 20431 \\ dlaxton@imf.org
}

\author{
Dirk Muir \\ Bank of Canada \\ 234 Wellington Street \\ Ottawa, ON K1A 0G9 \\ CANADA \\ dmuir@bank-banque-canada.ca \\ Paolo Pesenti \\ Federal Reserve Bank of New York \\ 33 Liberty Street \\ New York, NY 10045 \\ and NBER \\ paolo.pesenti@ny.frb.org
}




\section{Introduction}

Widening external imbalances have been a defining feature of the global landscape in recent years and, for many, constitute a key macroeconomic risk for the world economy. But the debate is far from settled. Two issues are central. First, is the present global pattern of current account imbalances sustainable and for how long? Second, if these positions require unwinding, can an orderly rebalancing be achieved without substantial disruption to global growth, international trade and capital flows, and under what circumstances?

At the center of concern is the massive U.S. current account deficit and whether its resolution foreshadows a hard landing for the dollar. For example, while the dollar has steadily depreciated (in real effective terms) since 2002, the U.S. deficit and external surpluses elsewhere (e.g., Japan and emerging Asia) have only widened further. How much farther will the dollar need to fall? The cautionary tale of past external adjustments focuses our attention on the wider ramifications of large, unsustainable current account deficits for exchange rates, domestic demand, and growth. ${ }^{1}$ Moreover, the prospect of large, disorderly swings in the value of the dollar - given its dominant role in the international monetary system - presents an additional financial risk with potentially far-reaching consequences, and where the regions that may be most deeply affected lie well beyond U.S. shores.

Leaving the possible fallout aside, how did we arrive at this point? A decade ago, the current account deficit of the United States stood around 100 billion dollars or $1 \frac{1}{2}$ percent of annual output. Over the ensuing ten years, that deficit would balloon six-fold to over 600 billion dollars or $1 \frac{1}{2}$ percent of world output, designating the world's wealthiest nation as its largest external borrower (by far). In terms of U.S. saving and investment, the initial leg of burgeoning deficits was led by brisk capital spending in the mid- to late-1990s, which retreated after the equity bust began around the turn of the century. At that same time, declining national saving - headlined by growing public deficits and mounting debt assumed a lead role in the further expansion of the U.S. current account deficit in the years that followed up to the present day.

In historical perspective, the large U.S. external deficit is unprecedented. With reference to Figure 1 (where $\mu$ is the sample average and $\sigma$ the standard deviation of the current account-to-GDP ratio), over the past half-century, U.S. current accounts have centered around a small deficit over the post-war period (1.12 percent of GDP). But the last decade has borne witness to a remarkable extension of the left tail of this distribution. During the 1980s, an emergence of large U.S. external deficits - also against the backdrop of budgetary deficits and dollar appreciation - were reminiscent of the current episode. However, unlike the past when the counterparts to U.S. deficits were largely confined to other G-7 industrial countries, the current global constellation of external imbalances has expanded the roster of players considerably. ${ }^{2}$

The current episode thus clearly suggests that matters are best viewed from a wider, multilateral perspective, including in terms of the uneven global pattern of growth and demand. A sanguine view of these developments (and their ultimate resolution) typically revolves around three related but distinct considerations: the Lawson doctrine, the 'new

\footnotetext{
${ }^{1}$ The literature on current account reversals and their nexus with growth and other variables is extensive; see for example Milesi-Ferretti and Razin (2000), Edwards (2004), and Freund (2000).

${ }^{2}$ China's reserves increased by $\$ 117$ billion in 2003 , after subtracting $\$ 45$ billion in reserves transferred in the recent bank recapitalization. These funds apparently remain in USD assets. South Korea, Taiwan, and Singapore increased reserves by $\$ 34$ billion, $\$ 44$ billion, and $\$ 14$ billion, respectively.
} 
Bretton Woods' system, and globalization.

Under a generalized interpretation of the Lawson doctrine, ${ }^{3}$ external imbalances are inconsequential, as they merely reflect the market's (optimal) decisions regarding saving and investment. ${ }^{4}$ But two qualifications should be noted. First, this presumes that the public sector's balances remain in good standing. And second, private sector decisions are not distorted by any major market imperfections or failures. Prima facie, the emergence of large budgetary deficits in the United States (at least since 2000) and the role of emerging market economies in prevailing global imbalances raise important caveats to the doctrine's application in the current circumstance. Nevertheless, the view that the current account deficit per se is not a problem, but remains the natural outgrowth of a strong domestic economy relative to persistent weakness in major partners - mainly Japan and Europe has not receded.

Focusing on the important role of emerging markets in understanding global imbalances, the 'new Bretton Woods' hypothesis - advanced by Dooley, Folkerts-Landau and Garber (2003) - posits that the constellation of external imbalances partly reflects the deliberate actions (e.g., de facto pegs) of 'periphery' countries seeking export-led growth as a strategy for economic development. In practical terms, this involves pegging the currency to the U.S. dollar to help domestic exporters safeguard their U.S. market shares and accumulate dollar reserves resulting from any payment imbalances. So long as the periphery, with new entrants waiting in the wings (e.g., India), willingly acquires dollar claims, this arrangement of external imbalances can endure indefinitely. ${ }^{5}$ For its part at the 'center', the United States (i) resurrects its passive exchange rate role as the n-th currency, and (ii) provides liquidity and intermediation to the rest of the world - benefiting by borrowing short (e.g., foreign sales of U.S. treasuries) at favorable terms while lending long profitably (i.e., U.S. FDI) ${ }^{6}$

The third major aspect of the sanguine side of the debate is globalization. A quartercentury after Feldstein and Horioka (1980), saving and investment no longer appear quite so constrained to move in tandem, and the universe of current account imbalances has clearly expanded. ${ }^{7}$ In other words, the mere fact that external imbalances, in many cases, have grown to unprecedented levels can be viewed as a testament to the better functioning and increasing integration of global capital markets. Indeed, the vast amounts of foreign saving mobilized to finance the ample shortfall of U.S. saving relative to investment have broken new ground. With a new-found ability to borrow (and lend), countries belonging to an increasingly integrated global economy can further engage in intertemporal trade to buffer against local shocks, smooth consumption, and raise welfare. A by-product of globalization

\footnotetext{
${ }^{3}$ In the late 1980s, Nigel Lawson, then British Chancellor of the exchequer, argued that the large U.K. current account deficit was a matter of no consequence, given that the public sector balance was in surplus. He also argued that this principle applied only to developed countries, where it was more reasonable to assume that private agents behaved optimally.

${ }^{4}$ See Corden (1994).

${ }^{5}$ Eichengreen (2004) criticizes this assessment, arguing that the 'periphery' is not a cohesive, uniform group, and could quickly unravel when national interests come into conflict with collective ones. The possibility of two viable international currencies - i.e., also the euro - further complicates the picture.

${ }^{6}$ Dooley, Folkerts-Landau, Garber (2004) elaborate on this maturity transformation under the present global alignment. Eichengreen and Adalet (2005) criticizes this too; arguing that being an international financial center and providing intermediation service does not necessitate a large (or any) deficit on the part of the United States.

${ }^{7}$ See Faruqee and Lee (2005).
} 
is that 'valuation' effects - operating on larger gross levels of foreign assets or liabilities can augment the traditional expenditure-switching effects of exchange rate adjustment and thereby facilitate a rebalancing scenario. ${ }^{8}$

So have we entered into a 'brave new world' when thinking about global imbalances? The mainstream view, as lucidly argued by Obstfeld and Rogoff (2000a), would firmly reply 'not yet.' Countervailing arguments note that while the underlying trends toward a more integrated global economy are undeniable, the limitations are also equally clear. Segmented goods markets and pricing to market, incomplete pass-through and 'disconnected' exchange rates, home bias in goods and in assets, and significant trade costs are all emblematic of an international economy still some ways off from an idealized single, global market. ${ }^{9}$ These real-world features and frictions raise cautionary flags about a more complacent view of global imbalances and the large shocks - including uneven economic and fiscal expansions - that have accompanied them. The key question from the mainstream is not 'if' but 'when' (and 'how') the inevitable adjustment will occur. The concern is that the exchange rate changes needed to generate enough expenditure switching may be very large. ${ }^{10}$ The hope is that broader adjustment - diversified across countries and policy instruments may be able to help achieve a more orderly rebalancing and avoid a protectionist backlash. ${ }^{11}$

In sum, as implied by the stylized facts and by the various interpretations of the present episode, the evolution (and resolution) of global imbalances needs to be understood within a coherent multilateral framework. This paper re-examines these multi-faceted issues through the lens of a dynamic, multi-region model of the global economy. The model offers sufficient complexity and richness to furnish a rigorous macroeconomic framework to assess the economic implications, related risks, and policy recommendations associated with the prevailing constellation and the prospect of global rebalancing of current accounts.

Informed by the multilateral analysis, our baseline view is that steady global rebalancing with an orderly unwinding of financial positions and currency realignments - notably a gradual depreciation in the U.S. dollar - can be achieved, although it is not assured. In this instance, the burden of adjustment will largely fall on the United States and emerging Asia in terms of reversing their past (net) national saving trends, requiring committed U.S. fiscal consolidation and aided by greater exchange rate flexibility in Asia that also limited output and inflation variability. Although more uncertain, some 'normalization' of private consumption rates (in opposing directions) in the two regions would further facilitate external adjustment.

Europe and Japan, for their part, could meaningfully contribute to the multilateral adjustment process through stronger pursuit of growth-enhancing structural reforms that align with their own national interests. Led by competition-friendly reforms in product markets and with structural adjustment supported by monetary policy, credible measures tackling deep-seated structural impediments and distortions would boost their growth and investment prospects, thereby contributing to external rebalancing.

\footnotetext{
${ }^{8}$ See Lane and Milesi-Ferretti (2001, 2003, 2004), Tille (2003), WEO (2005). An extreme form of this argument where valuation effects supplant the requisite adjustment in the trade balance is exposited in Gourinchas and Rey (2005).

${ }^{9}$ See, for example, Engel (1993), Engel and Rogers (1996), Rogoff (1996), Obstfeld and Rogoff (2000a,b), Devereux and Engel (2002), Corsetti and Dedola (2002), and Choudhri, et al (2005).

${ }^{10}$ See Engel (2002), Obstfeld (2002) and Corsetti and Pesenti (2005a, b) for a modern view on expenditure switching effects.

${ }^{11}$ See De Rato (2005).
} 
Far less benign adjustment scenarios are also quite conceivable. A more dangerous route, in the absence of underlying, broad-based adjustment in macroeconomic and structural policies, would rely more on the vagaries of global financial markets. If mounting concerns over imbalances triggered sizeable international portfolio shifts, a sudden exit out of U.S. dollar assets could effect more dramatic changes to (interest and) exchange rates, including a significantly weaker U.S. dollar, with harmful knock-on effects for global growth.

A roadmap to the paper is as follows. Sections 2 and 3 outline the structure and calibration of our multi-region model. Section 4 describes the individual key elements needed to construct the central baseline scenario of global rebalancing. Section 5 considers key alternative scenarios and assesses the likely macroeconomic and policy implications. Section 6 concludes.

\section{The structure of the model}

The simulation model we construct in this paper is rather detailed and complex. To simplify the exposition, in this section we limit ourselves to a very synthetic and intuitive overview of the model, highlighting a few formal features of particular relevance for the calibration exercise. Technical details of the theoretical framework are extensively discussed in the Appendix.

The overall structure of the model is illustrated in Figure 2. The world economy consists of four regional blocs ('countries'): US (United States), ${ }^{12}$ JE (Japan and euro area), AS (Emerging Asia), and RC (Remaining Countries). ${ }^{13}$ There is a common stochastic trend for the world economy (the variable $T R E N D$ ), whose gross rate of growth between time $t$ and time $\tau$ is denoted $g_{t, \tau}$. All quantity variables in the model are expressed in detrended terms, that is as ratios relative to TREND. In each country, there are households, firms, and a government. Households consume a (non-tradable) final good and supply differentiated labor inputs to firms. Firms produce final goods, (tradable) intermediate goods, and provide intermediation services. The public sector consumes non-traded goods and services, financed through taxation or borrowing, and manages short-term interest rates through monetary policy. Each sector is described in turn below.

Infinitely-lived households consume a non-tradable final good $(C)$, and each is the monopolistic supplier of a differentiated labor input $(\ell)$ to all domestic firms. ${ }^{14}$ There are two types of households: forward-looking ones (with subscript $F L$ ) and liquidity-constrained ones (with subscript $L C$ ). Liquidity-constrained agents represent a fraction $s_{L C}$ of national households. These households do not have access to capital markets and finance their consumption exclusively through disposable labor incomes. The specification of households' preferences adopts the Greenwood, Hercowitz and Huffman (1988) (GHH) utility function, adjusted for habit formation and preference shocks. Denoting $\mathcal{W}_{t}(j)$ as lifetime expected

\footnotetext{
${ }^{12}$ To avoid confusion, in the text we refer to "US" as the region of the model, and to the "U.S." as the real-world United States.

${ }^{13}$ The choice of regional aggregation is dicussed in Section 3.1 below.

${ }^{14}$ Interpreting $T R E N D_{t}$ as labor-augmenting technical change at time $t, \ell_{t}$ in the model is time devoted to work, assumed to be bounded by endowment, while effective labor is $T R E N D_{t} \ell_{t}$. It follows that the nominal wage (the monetary remuneration for one unit of labor services $\ell_{t}$ ) can be trending both because of nominal inflation and because of real (labor-augmenting) growth.
} 
utility of household $j$, we have:

$$
\mathcal{W}_{t}(j) \equiv \mathrm{E}_{t} \sum_{\tau=t}^{\infty} \beta_{t, \tau} g_{t, \tau}^{1-\sigma} u_{\tau}\left(C_{\tau}(j), \ell_{\tau}(j)\right)
$$

where the instantaneous felicity is proportional to:

$$
u_{t}\left(C_{t}(j), \ell_{t}(j)\right) \propto *\left[\frac{C_{t}(j)-b_{c} C_{j, t-1} / g_{t-1, t}}{1-b_{c} / g_{t-1, t}}-\frac{Z_{V}}{1+\zeta}\left(\frac{\ell_{t}(j)-b_{\ell} \ell_{j, t-1}}{1-b_{\ell}}\right)^{1+\zeta}\right]^{1-\sigma}
$$

In the expressions above $\beta_{t, \tau}$ is the discount rate, possibly different across countries, between time $t$ and time $\tau$. The term $g_{t, \tau}^{1-\sigma}$ in (1) implies that the disutility of labor effort moves with the common trend. As is customary, this feature can be interpreted as technological progress associated with home production activities, here related to the global trend. The parameter $\sigma$ in (1) and (2) is the reciprocal of the elasticity of intertemporal substitution. The parameter $\zeta$ which affects the curvature of labor disutility is the reciprocal of the Frisch elasticity of labor supply. There is habit persistence in consumption with coefficient $0<b_{c}<1$. The term $C_{j, t-1}$ is past per-capita consumption of household $j$ 's peers, (i.e., either forward-looking or liquidity-constrained agents). Similarly, there is habit persistence in leisure with coefficient $0<b_{\ell}<1$. The term $Z_{V}$ is a constant.

Forward-looking households own domestic firms and the domestic capital stock $(K)$, which they rent to domestic firms. The market for capital is competitive. Capital accumulation is subject to adjustment costs, as are wage contracts (i.e., nominal wage rigidities). Labor and capital are immobile internationally. Forward-looking households in each country also own two short-term nominal bonds, one denominated in domestic currency and issued by that country's government, and another denominated in U.S. currency and issued in zero net supply worldwide. There are intermediation costs for national households transacting in the international bond market. No other asset is traded internationally.

On the production side, perfectly competitive firms produce two final goods - a consumption good $(A)$ and an investment good $(E)$. The consumption good is consumed either by domestic households or by the government $\left(G_{C}\right)$. Similarly, demand for the investment good is split between private agents $(I)$ and the public sector $\left(G_{I}\right)$. Final goods are produced by using all available intermediate goods as inputs. Intermediate goods are either non-traded $(N)$ or traded internationally $(T)$. Domestic tradables used by domestic firms are denoted $Q$, imports are denoted $M$. For instance, a firm $x$ produces the consumption good with the following nested constant-elasticity-of-substitution (CES) technology:

$$
\begin{aligned}
& A_{t}(x)^{1-\frac{1}{\varepsilon_{A}}}=\left(1-\gamma_{A, t}\right)^{\frac{1}{\varepsilon_{A}}} N_{A, t}(x)^{1-\frac{1}{\varepsilon_{A}}} \\
& +\gamma_{A, t}^{\frac{1}{\varepsilon_{A}}}\left[\nu_{A}^{\frac{1}{\mu_{A}}} Q_{A, t}(x)^{1-\frac{1}{\mu_{A}}}+\left(1-\nu_{A}\right)^{\frac{1}{\mu_{A}}} M_{A, t}(x)^{1-\frac{1}{\mu_{A}}}\right]^{\frac{\mu_{A}}{\mu_{A}-1}}\left(1-\frac{1}{\varepsilon_{A}}\right)
\end{aligned}
$$

The three intermediate inputs used in the production of the consumption good $A$ are a basket $N_{A}$ of nontradable goods, a basket $Q_{A}$ of domestic tradable goods, and a basket $M_{A}$ of imported goods. The elasticity of substitution between tradables and nontradables is $\varepsilon_{A}>0$, and the elasticity of substitution between domestic and imported tradables is $\mu_{A}>0$. The weights of the three inputs in production are, respectively, $1-\gamma_{A}, \gamma_{A} \nu_{A}$ and $\gamma_{A}\left(1-\nu_{A}\right)$.

To handle the different goods produced in different countries, the variable $M_{A}$ denotes a combination of different baskets of goods imported from the rest of the world. To model realistic dynamics of import volumes - such as delayed and sluggish adjustment to changes 
in relative prices - we assume that imports are subject to short-term adjustment costs (discussed in detail in the Appendix). More precisely, referring to a generic country as $C O$, and to the importing country as $H$, firm $x^{H}$ 's imports $M_{A}^{H}\left(x^{H}\right)$ are a CES function of baskets of goods imported from the other countries, or:

$$
M_{A, t}^{H}\left(x^{H}\right)^{1-\frac{1}{\rho_{A}^{H}}}=\sum_{C O \neq H}\left(b_{A}^{H, C O}\right)^{\frac{1}{\rho_{A}^{H}}}\left(M_{A, t}^{H, C O}\left(x^{H}\right)\left(1-\Gamma_{M A, t}^{H, C O}\left(x^{H}\right)\right)^{1-\frac{1}{\rho_{A}^{H}}}\right.
$$

In the expression above $\rho_{A}^{H}$ is the elasticity of import substitution across countries; a higher value for $\rho_{A}^{H}$ implies that it is easier for firm $x^{H}$ to substitute imports from one country with imports from another. The weights $b_{A}^{H, C O}$ (summing up to one) determine the composition of the import basket across countries. $M_{A}^{H, C O}\left(x^{H}\right)$ denotes imports from country $C O$ by firm $x^{H}$ located in country $H$, and. $\Gamma_{M A}^{H, C O}\left(x^{H}\right)$ denotes the associated adjustment costs.

Intermediate goods are available in different varieties, each produced by a single firm under conditions of monopolistic competition worldwide. The prices of intermediate goods are subject to adjustment costs (nominal price rigidities). These goods are produced with domestic labor inputs and domestic capital. For instance, the nontradable variety $n$ is produced with the following CES technology:

$$
N_{t}(n)=Z_{N, t}\left[\left(1-\alpha_{N}\right)^{\frac{1}{\xi_{N}}} \ell_{t}(n)^{1-\frac{1}{\xi_{N}}}+\alpha_{N}^{\frac{1}{\xi_{N}}} K_{t}(n)^{1-\frac{1}{\xi_{N}}}\right]^{\frac{\xi_{N}}{\xi_{N}-1}}
$$

Firm $n$ uses labor $\ell(n)$ and capital $K(n)$ to produce $N(n)$ units of its variety. $\xi_{N}>0$ is the elasticity of input substitution, and $Z_{N}$ is a sectoral productivity shock common to all producers of nontradables. ${ }^{15}$

Finally, the government purchases the two national final goods, as well as nontradable services $G_{N}$. As treasury, the government finances the excess of its expenditures over net taxes by borrowing from the domestic private sector. As central bank, the government manages the national short-term nominal interest rate. Monetary policy is specified in terms of a credible commitment to an interest rate rule that either targets inflation or the exchange rate.

\section{Model calibration}

\subsection{Initial considerations}

In what follows we suggest a plausible calibration of the many parameters introduced in the model and discuss in some detail the reasons underlying our choices. In general, we rely on previous work done with the IMF's Global Economy Model (GEM), as well as estimates from the literature and our own empirical work.

Given the importance of a multi-country setting, some thought has been given to the composition of the regional blocs. As mentioned in Section 2, to conserve on complexity we choose a four-region model - US (the United States), JE (Japan and the euro area countries), AS (Emerging Asia: China, India, Hong Kong, Malaysia, Philippines, Singapore, South Korea, Taiwan province of China and Thailand) and RC (the Remaining Countries not considered elsewhere).

\footnotetext{
${ }^{15}$ Recall that a productivity shock is defined as a deviation from the common world trend. Variants of the model allow for the possibility of shocks to labor productivity or capital productivity instead of total factor productivity.
} 
The decision to combine Japan and the euro area into one region reflects, from the vantage point of our project, their overlap in key structural characteristics - low productivity growth, very low inflation (or deflation), and structural rigidities, particularly in the labor market. Needless to say, Japan and the euro area have exhibited very different behaviors in the past regarding the accumulation of U.S. assets, foreign exchange intervention policy, and so on. However, our prior is that their role in the global rebalancing process will become comparatively less relevant in the years ahead and compared to Emerging Asia.

This latter bloc groups Asian countries with strong growth and whose currencies exhibit limited flexibility against the U.S. dollar. Moreover, their labor markets tend to be rapidly growing and fairly flexible. In addition, the ongoing process of market liberalization is expected to reduce entry barriers and enhance competition, including in the major constituents such as India and China. The Remaining Countries bloc is dominated by the other members of the European Union (particularly the United Kingdom) and the other major OECD countries such as Canada, Australia, New Zealand and Mexico.

Keeping the composition of the four regions in mind, in what follows we discuss the calibration of the domestic economies. We then focus on the international elements of the model and pursue a realistic description of the macroeconomic interdependencies between regions, particularly their trade linkages and fiscal spillovers.

\subsection{Parameterization of the regional blocs}

Tables 1 through 5 document the parameterization adopted for the four regional blocs. Unless otherwise stated, similar behavioral parameter values apply to all regions.

Table 1 presents the parameters that are key for the consumers' optimization problem. Although consumers may differ with respect to their access to financing, the preferences of the liquidity-constrained and forward-looking households are taken to be the same. We assume that in US, JE and RC the share of liquidity-constrained consumers $\left(s_{L C}\right)$ is 25 percent. The share is much higher in Emerging Asia at 50 percent, reflecting the nascent or underdeveloped financial markets for domestic consumers - particularly, in the cases of China, India, Indonesia and the Philippines.

The rate of time preference (the annualized inverse of $\beta$ in eq. 1) in combination with trend growth ( $g$ in eq. 1) of two percent per year is consistent with an annualized quarterly real world interest rate of three percent. US, the most impatient region, has the highest rate of time preference at 3.2 percent; AS, the most patient, has a rate of 2.6 percent. For all regions, we assume a high degree of intertemporal substitution in consumption $(1 / \sigma)$ of 5 . This combined with a high value for habit persistence $\left(b_{c}=0.91\right)$ generates sluggish consumption behavior in the short run and hump-shaped dynamics in response to changes in the real interest rate. Conversely for labor, we assume a low Frisch elasticity $(1 / \zeta)$ in the long run of 0.40 , coupled with lower habit persistence $\left(b_{\ell}\right)$ of 0.75 . These choices are similar to the assumptions found in Bayoumi, Laxton and Pesenti (2004), adjusted for our use of the GHH utility function.

For the firms' optimization problem, we also refer the reader to Table 1 . The elasticity of substitution between labor and capital $\left(\xi_{N}\right.$ and $\xi_{T}$ in 5$)$ is set at 0.75 in both the tradable and nontradable sectors. This is slightly lower than the conventional (Cobb-Douglas) unitary assumption, in order to help reduce the sensitivity of capital to changes in its relative price. The bias towards the use of capital $\left(\alpha_{T}\right.$ and $\left.\alpha_{N}\right)$ is calibrated to achieve a relatively high investment share of GDP in AS, and a low share in US, in line with their respective historical averages (see Table 2). In all regions, the nontradable sector (e.g., services) is assumed to 
be less capital intensive than the tradable sector (e.g., manufacturing). The depreciation rate is assumed to be two percent per quarter across all regions (eight percent per year).

The dynamics of the model are governed by the nominal rigidities and real adjustment costs described in Table 3. The standard parameter choice of 400 for quadratic adjustment costs in prices is roughly equivalent to a four-quarter contract length under Calvo-style pricing. Real rigidities in investment align with the parameterization in Juillard, Karam, Laxton and Pesenti (2005) for a Bayesian-estimated, closed economy DSGE model of the United States. For real rigidities in imports, a value of 0.95 approximates the typical sluggish reaction by volumes to movements in the real exchange rate.

There are separate markups on tradable and non-tradable goods (Table 4) since firms have some pricing power under monopolistic competition. We use estimates for the price markups from Martins, Scarpetta and Pilat (1996) in the case of US, JE and RC. The US bloc has the lowest price markups, indicating the greatest degree of competition, while Japan and the euro area have the highest. For AS the markups are indicative of some (very) preliminary estimates done in the Research Department of the IMF for certain member countries of the AS bloc.

Similarly, in the labor market agents have some pricing power, resulting in the wage markups of Table 4. For US and JE the markups (16 percent and 30 percent respectively) correspond to Bayoumi, Laxton and Pesenti (2004). ${ }^{16}$ We further assume that RC is somewhere in between US and JE, with a 20 percent wage markup, while we assume AS has a labor market as competitive as US.

Finally, to provide a nominal anchor for the domestic economy, monetary policy is parameterized as follows (Table 5). US, JE and RC are all committed to price stability, and we assume they follow an inflation-forecast-based (IFB) rule. ${ }^{17}$ A representative calibration of IFB rules is used, with a weight of 0.75 on the lagged short-term interest in order to impart a high degree of smoothing in the setting of policy rates, and a weight of 2.00 on the three-quarter ahead gap between inflation and its target. The year-on-year CPI inflation target is assumed to be fixed at two percent for JE and RC, and somewhat higher at 2.5 percent for US. Emerging Asia is assumed to pursue a fixed exchange rate regime against the U.S. dollar. ${ }^{18}$ In an alternative scenario presented below, Emerging Asia switches to an inflation-based rule, but starts with a high value for its implicit inflation objective and adopts a lower 2.5 percent target two years after the regime switch.

\footnotetext{
${ }^{16}$ Their determination of the wage markups is based, in turn, on Jean and Nicoletti (2002), who consider the wage differentials for a variety of industries in the United States and six member states of the Euro Area.

${ }^{17}$ IFB rules have been used extensively in central-bank models with Inflation-Targeting regimes in both advanced and emerging-market economies - see, for example, Laxton, Rose and Tetlow (1993), Batini and Haldane (1999), Hunt, Rose and Scott (2000), and Coats and others (2003). They have also been used in empirical work to characterize monetary policy in other countries that do not have explicit InflationTargeting regimes, but have flexible exchange rates - see Orphanides (2003) and Julllard and others (2004). It is important to note that IFB rules are ad hoc. Svensson (1999) and Svensson and Woodford (2005) have proposed Inflation-Forecast-Targeting (IFT) rules based on optimizing loss functions and it is only a question of time before IFT rules are used extensively on linearized versions of models whose type and size are similar to ours.

${ }^{18}$ This should be interpreted as a sensible approximation rather than in literal terms, given that China is the largest member of AS, and the limited flexibility of its currency against the U.S. dollar is at the center of the current policy debate. Similarly, other members such as Hong Kong, Malaysia, South Korea, Singapore, Thailand, Philippines and Indonesia attempt to manage the volatility of their currencies vis-a-vis the U.S. dollar.
} 


\subsection{The international dimensions}

The main results of the model rely heavily upon the calibration of each region's external sector in Table 6. For given steady-state net foreign asset positions for each region, it is straightforward to calculate the current account and trade balances consistent with longterm stock-flow equilibrium. Using the IMF's Direction of Trade Statistics on merchandise trade, the national accounts data on the imports of goods and services, and the United Nations' Commodity Trade Statistics (COMTRADE) data on each region's imports of consumer and capital goods, we derive a disaggregated steady-state matrix delineating the pattern and composition of trade for all regions' exports and imports. A more aggregated form is found in Figure 3. On the basis of this trade matrix, we derive all the weight coefficients in the demand function for imports $\left(\nu_{A}\right.$ and $\nu_{E}$ in eq. 3$)$ and the regional composition of imports $\left(b_{A}\right.$ and $b_{E}$ in eq. 4$)$.

For the corresponding trade elasticities, we assume that the elasticity of substitution between domestically-produced and imported tradable consumption goods $\left(\mu_{A}\right.$ in eq. 3 ) and investment goods $\left(\mu_{E}\right)$ is 2.5 as in Bayoumi, Laxton and Pesenti (2004). The elasticity of substitution between goods from different regions for imported consumption goods $\left(\rho_{A}\right.$ in 4) and imported investment goods $\left(\rho_{E}\right)$ is set at 1.5 , consistent with existing estimates of import elasticities.

Lastly, we need to calibrate the behavior of net foreign assets, also in Table $6 .{ }^{19}$ For the long-run behavior of net foreign assets our prior is that a permanent increase in government debt by one percentage point of GDP is roughly associated with an increase in the net foreign liability position of the region by 0.5 percentage points of GDP. ${ }^{20}$ As we discuss below, overlapping generations models (particularly those which follow the Blanchard-Weil-Yaari formulation) provide theoretical underpinnings to evaluate this non-Ricardian behavior. Quantitative simulations using models with such characteristics - specifically, the IMF's Global Fiscal Model (GFM) described in Botman, Laxton, Muir and Romanov (2005) and Multimod (Laxton et al (1998)) — are consistent with a value between roughly 0.40 and 0.80. Moreover, when the US expands its net foreign liabilities as a result of a permanent change in its public debt, the absorption of new issuance by each region is calibrated (on the basis of net foreign asset holdings in recent years) by assigning 24 percent of new issuance by US to AS, and 38 percent to each of JE and RC. This calibration implies that for a one percent NFL-to-GDP shock in US, the AS net-foreign-asset-to-GDP rises the most around 0.8 percent of GDP — while JE and RC see their ratios only rise by around 0.3 and 0.5 percent of GDP respectively.

\section{A baseline scenario}

\subsection{The six component shocks}

We now construct a baseline scenario for the global rebalancing of current accounts. This is of interest not only per se - as a model-based quantitative assessment of macroeconomic adjustment paths in the global economy — but also as a benchmark, against which one can analyze and discuss alternative scenarios. The baseline is an attempt to identify the sources of

\footnotetext{
${ }^{19} \mathrm{With}$ reference to the notation of the Appendix, the short-run speed of adjustment is governed by $\phi_{B 1}$ and $\phi_{B 2}$, set at 0.05 and 0.10 respectively. This is consistent with most previous work based on GEM see Laxton and Pesenti (2003), Hunt and Rebucci (2005), and Bayoumi, Laxton and Pesenti (2004).

${ }^{20}$ In terms of the notation adopted in the Appendix, this implies that $\phi_{F 1}$ is equal to $1 / 2$.
} 
the current global disequilibrium, accounting for both the shocks emanating from the United States and the respective role played by other regions. The purpose of the baseline is to coherently guide our thinking on the central questions surrounding external developments: What are the key macroeconomic factors underlying the recent dynamics of current account imbalances and real exchange rates in the world economy? What assumptions about the size and persistence of the key underlying shocks are needed to fit the facts? What is the range of possible future trajectories for the relevant macroeconomic variables?

We are less interested in explaining and rationalizing current account dynamics over the past decade than in providing elements for an analysis of the present global outlook. Correspondingly, the baseline scenario is formulated on the general premise that the prevailing imbalances have mainly reflected savings behavior as of late, by both private and public agents, rather than the investment dynamics fueled by the market exuberance observed in the second half of the 1990s. ${ }^{21}$

Specifically, our working hypotheses are that the central tendencies underlying the global macroeconomic imbalances in the early 2000s can be attributed to a combination of six related but distinct 'shocks'. The first three shocks center around the U.S. economy:

1. Higher U.S. government debt (with initial tax cuts followed by future tax hikes) centered around the announced plans of the U.S. federal government

2. A permanent decline in the private savings rate in the United States

3. An increase in the demand for U.S. assets abroad, particularly in Emerging Asia

The next two shocks reflect relative productivity trends in the rest of the world. In the model, worldwide convergence of productivity growth rates is taken as the anchoring feature of the economy in the long term. However, prolonged deviations from balanced growth can play a key role in the unfolding of medium-term rebalancing scenarios, in line with the asymmetric tendencies observed across regions in the past decade. The shocks are:

4. Very persistent and rapid productivity growth in Emerging Asia with a central tendency starting at 5.5 percent per year

5. Very persistent and lagging productivity growth in Japan and the euro area with a central tendency of 0.75 percent per year

The final shock attempts to capture policy choices in Emerging Asia, including strategies of export promotion in China. The specific way these competitiveness-friendly strategies are introduced is through:

6. A short-run and temporary positive shock to AS fiscal policy to subsidize exports in order to increase rest of the world demand for AS exports by 5 percentage points of their imports

We now consider each of these shocks in turn, by outlining their central tendencies and discussing their effects on the regional economies. The dynamics are reported for the first 80 quarters (i.e., a 20-year horizon) after each shock begins. ${ }^{22}$ Afterwards, we will discuss the baseline scenario, which is simply an integrated presentation of these shocks.

\footnotetext{
${ }^{21}$ See Hunt and Rebucci (2005) for a model-based analysis of current account imbalances over the 1990s.

${ }^{22}$ It is worth emphasizing that in several cases the variables reported in the charts keep increasing (or falling) after the 20 year horizon to approach their steady-state levels.
} 
It should be understood, however, that the behavior of the national economies in the baseline scenario is not a simple add-up of the six shocks. Each shock in fact can enhance, amplify, or dampen the outcomes of the other shocks. For example, a very persistent productivity shock in Emerging Asia results in AS increasing its share in the world economy from 9.4 percent to 12.2 percent in the long run. In the case of the public debt shock in the United States, there is a considerable reaction of the Asian current account to the increased availability in the portfolio of US assets. The change in the current-account-to-GDP ratio is smaller in the baseline scenario for the US public debt shock than in the presentation of the US public debt shock in isolation. This is simply because AS is much larger in the baseline (over 12.2 percent of the world instead of 9.4 percent) due to the productivity shock, and has to devote fewer resources (as a share of GDP) in order to absorb its share of new US government debt. To put it simply, the sum is greater (or, in this case, lesser) than its parts. Where appropriate, in the remainder of this section we will try to highlight the most important cross-effects that occur in the baseline scenario.

\subsubsection{Public debt in the US}

For the public savings shock in the US, we couple a sustained increase in the government deficit for the next five years with a steady-state government debt shock of 11.5 percent of GDP (Figures 4 and 5). ${ }^{23}$ The steady-state government deficit of the US rises from 2.2 to 2.7 percent. $^{24}$ We observe lower taxes today, but higher taxes in the future to meet the interest payment obligations on the debt. The increased borrowing by the fiscal authority crowds out the trade balance, thereby worsening the current account deficit relative to the initial steady state. We also observe a real exchange rate appreciation in the short run, but a depreciation in the long run.

In the long run the increase in government debt increases US net foreign liabilities by 5.75 percent of GDP, which is financed by the rest of the world. Relative to each region's GDP, Emerging Asia sees the largest effect, as its net foreign asset (NFA) position increases by 4.40 percent of GDP in the long run, which means it must be financed by an increase in the current account surplus of 0.5 percent of GDP in the medium term and 0.2 percent of GDP in the long run. There are similar effects in JE and RC, but they are smaller.

\subsubsection{Private savings in the US}

The reduction in US consumers' desire to save is represented by an increase in the rate of time preference in the US relative to the rest of the world of 50 basis points, as well as a risk premium shock of 30 basis points for 25 years (Figures 6 and 7 ). ${ }^{25}$ At the same time,

\footnotetext{
${ }^{23}$ We implement the government debt shock as follows. We increase the steady-state government-debtto-GDP ratio in the United States by 11.5 percentage points. We implement the shock in the short run by letting the deficit-to-GDP ratio for the US peak at 5 percent after two years, and then decline to the steady-state value of 2.7 percent of GDP. This demonstrates the effect of the US government deficit shock alone. In a framework with an endogenous link between government debt, net foreign assets and the world real interest rate (as found in overlapping generations models of the Blanchard-Weil-Yaari type such as the aforementioned GFM) there would also be a permanent increase in the US interest rate to account for the crowding out effects on investment.

${ }^{24}$ Figures 4 through 15 report variables as deviations from the initial steady state. For instance, for the US government deficit in Figure 4 the starting point corresponds to a deficit of 2.2 percent and the endpoint to a deficit 0.5 percentage points above the initial level.

${ }^{25}$ The private savings shock has both a temporary and permanent component. The permanent component is the rate of time preference shock. Relative to the initial world rate of time preference $\left(1 / \beta^{4}-1\right)$ of 2.7
} 
we assume AS is more patient than $\mathrm{JE}$ or $\mathrm{RC}$ - they have a lower rate of time preference at 2.6 percent. So a negative private savings shock in the United States eventually results in an increase in the real interest rate, and a reduction in domestic demand.

In the short run there is a deterioration of the current account balance of 0.5 percent of GDP in US. However, there is a long run depreciation, which means there is an improvement in the steady-state trade balance. The spillover effects are relatively minor, their magnitudes depending entirely upon the extent of US trade linkages with AS, JE and RC.

\subsubsection{Foreign demand for US assets}

The third major component of the baseline scenario is an increase in the demand for US assets in the rest of the world (Figures 8 and 9). ${ }^{26}$ The major foreign investor in US dollar assets in this shock is AS (and to a lesser extent, JE, as Japan behaves much like the rest of Asia in its demand for US assets). We see that AS saves more and increases its net foreign asset holdings by 20.5 percentage points of GDP permanently, with lesser increases in JE and $\mathrm{RC}$ (5.2 and 9.0 percentage points of GDP respectively). This results in an increase in the US net-foreign-liability-to-GDP ratio by 20 percentage points.

As a counterpart to its asset accumulation, AS runs a current account surplus that shows up as a US current account deficit of 3.7 percent in the short run and one percent in the long run. In the short run, households in US consume more but in AS consume less. The converse is true in the long run. Output growth in AS is also positive, once the sharp negative effects of the sudden real appreciation wears off. The short-run appreciation of the AS real effective exchange rate is the result of adjusted uncovered interest parity, since higher real interest rate differentials are necessary in the future to maintain its nominal exchange rate peg vis-à-vis the U.S.

\subsubsection{Productivity growth in JE (Japan and the euro area)}

Japan and the euro area face a persistent negative shock of 0.75 percentage points to its productivity growth rate that lasts for thirteen years (Figures 10 and 11). ${ }^{27}$ Relative to the initial steady state, we see a notable decrease in output. Paired with a decrease in the marginal product of capital, there is a sustained decrease in investment to achieve a new lower capital-output ratio. Since the productivity shock is generalized across the entire economy, we see a long-term real appreciation. The spillover effects in the rest of the world are mostly confined to RC and AS (which has strong links to Japan), but less in US, reflecting their trading patterns with the rest of the world.

In the baseline scenario this productivity shock serves to reduce the economic size of Japan and the euro area relative to the other regions, reducing the international effects of

percent, AS is more patient at 2.6 percent (a negative 10 basis point shock) while US is much more impatient at 3.2 percent (a positive 50 basis point shock). For the temporary component, we increase the risk premium $Z_{B}$ (see eq. A.42 in the Appendix) for all regional blocs by one percent for 25 years.

${ }^{26}$ For the technical implementation, we rely on the autonomous holdings $\left(b_{F N E U T}^{*}\right)$ in the desired net foreign asset position equation (A.43 in the Appendix). In order to finance the increase in US net foreign liabilities by 20 percentage points of GDP, AS increases its steady-state holdings of net foreign assets by 20.5 percentage points of GDP; JE increases its steady-state holdings of net foreign assets by 5.2 percentage points of GDP; and RC increases its steady-state holdings of net foreign assets by nine percentage points of GDP.

${ }^{27}$ To be more precise, we assume that productivity grows at 1.25 percent per year for 13 years in Japan and the euro area for both the tradable and nontradable sectors, instead of at the world trend growth rate of two percent. 
other shocks. One exception is that the current account balance effects of the US public debt shock is higher as a share of GDP, since JE still has the same portion of US debt to finance through accumulation of NFA as in the isolated presentation of the US public debt shock.

\subsubsection{Productivity growth in AS (Emerging Asia)}

This shock basically has the same effects as the shock in Japan and the Euro Area, but with all the signs of the responses reverted (Figures 12 and 13). AS has on average a higher growth rate of productivity, starting around 5.5 percent per year before returning close to the world trend growth rate of two percent after roughly 30 years. ${ }^{28}$ Relative to the initial steady state, we see a large increase in output. Because of the increase in the marginal product of capital, there is also a sustained increase in investment to achieve a new higher capital-output ratio. Since the productivity shock is generalized across the entire economy, we see a long-term real depreciation of around 4.5 percent.

In the first two years there is a small increase in inflation by about 0.2 percent, followed by a sustained 0.8 percent disinflation as the expansion of productive capacity continues. The disinflation continues almost until 12 years after the shock begins. Given the higher degree of flexibility in price setting for the labor and goods markets in AS, and the fact that monetary policy is conducted to defend an exchange rate peg rather than pursue an inflation target, the dynamics of the shock are less extreme than would occur in a regional bloc such as JE.

The spillover effects from the shock in AS are not much larger than those spillovers from the JE productivity shock, despite its much more sustained and larger extent. This results from the fact that AS is merely $9.4 \%$ of world GDP in the initial equilibrium (whereas $\mathrm{JE}$ is $34.6 \%$ ) and the fact that AS has stronger linkages with US than JE does (relatively speaking). Therefore, the productivity shock in AS also contributes to our formulation of the baseline scenario in US, where we see a current account deficit opening up in the mediumto long-term.

\subsubsection{Fiscal policy in AS}

The role of AS in the baseline scenario is enhanced by a positive fiscal policy shock in Emerging Asia that is used to finance exports to the rest of the world (Figures 14 and 15). ${ }^{29}$ By running a higher deficit than the initial steady state conditions imply, the government is able to subsidize the export of its goods and services abroad. In turn, this short-run subsidization is associated with a permanent shift in the rest of the world's preferences for AS goods. ${ }^{30}$

\footnotetext{
${ }^{28}$ Technically, the productivity growth rate shocks differ between the tradable and nontradable sectors. For the nontradable sector, productivity grows in AS at three percent per year for eight years. The shock in the tradable sector is much larger, and much longer. Overall, the productivity growth rate in Emerging Asia is close to 5.5 percent a year at the beginning of the shock, declining steadily to around 2.25 percent after 30 years and returning to the trend two percent growth rate two years later.

${ }^{29}$ Export subsidies are not modeled as direct subsidies because they usually take the form of tax rebates, accelerated depreciation allowances, and tax holidays.

${ }^{30}$ This shock is implemented as a positive increase in the AS fiscal deficit above 4 percent of GDP in the first year, which declines to 1.0 percent of GDP by the end of the ninth year. Afterwards it reverts to the deficit consistent with the original long-run debt target of 24 percent of GDP. At the same time, world preferences for Asian imports shift up by 5 percentage points of their total imports by moving the bias parameters for imported consumption goods $\left(b_{A}\right.$ in eq. 4$)$ and investment goods $\left(b_{E}\right)$ over roughly
} 
In the long run, demand for Emerging Asia's goods is permanently higher by five percent of imports in the three other regional blocs (JE, US and RC). However, since the increase in the government deficit is only temporary, there is no long run shift in the level of net foreign liabilities in AS. Therefore, the long run trade balance is unchanged in AS and the higher demand of AS goods abroad is offset by a permanent real appreciation of the exchange rate of 23 percent, leading to a higher level of AS imports from abroad.

This has implications for the other regions of the world. In the medium term the increase in exports in the rest of the world roughly offsets the increase in demand for imports from AS, meaning the US sees almost no change in its current account position, while JE and $\mathrm{RC}$ see slight improvements. There are some significant short-run increases in the currentaccount-to-GDP ratios in JE ( 0.3 percent of GDP) and RC ( 0.7 percent of GDP). The main effect of this shock is a long-run realignment of real effective exchange rates worldwide. Also, the shift in world preferences toward AS imports means there is now a higher degree of openness between AS and the rest of the world. So when all six shocks are combined to form the baseline scenario, responses of trade movements to the various shocks are higher vis-à-vis Asia (and they are, to varying degrees, less amongst the other regional blocs).

\subsection{The integrated scenario}

The six aforementioned shocks form the components for our integrated baseline scenario. As alluded to, the shocks should be viewed as the central tendencies of the scenario, while the latter is presented more broadly as a range of potential outcomes. Indeed, over time there has been considerable uncertainty about the evolution and correction of the U.S. current account imbalance, and there is no basis to assume that this will not be case in the future. Figure 16 demonstrates this point by showing the evolution of the IMF's forecasts in its World Economic Outlook, from 1999 to the present. In later forecasts we see the same basic story as the one we are proposing. Earlier forecasts put more weight on beliefs that the U.S. current account deficit was caused by high investment rates, rather than low private savings and large public dissaving. We can also observe that consumption continues to trend upwards over time, but in later forecasts there is a need for a notable correction toward the end of the forecast horizon.

In presenting the baseline scenario, we therefore consider a range of possibilities that accounts for the degree of uncertainty around the central tendency of the six component shocks already outlined. A high degree of uncertainty, in particular, surrounds the outcome of shocks related to private savings in the United States, rest of world preferences for holdings of US assets, and the positive productivity shock in Emerging Asia. For the outcome of shocks related to the U.S. fiscal policy and lagging productivity in Japan and the euro area, the uncertainty bounds are more narrow.

The baseline scenario begins in 2005q1. In order to achieve the state of disequilibrium we believe exists in that period, we do not start reporting from the initial steady state of the model, but rather from period 13 (i.e., the start of the fourth year) after the occurrence of each of the shocks presented above. We believe that using this time frame for the combination of the six shocks (with minor modifications to smooth demand and monetary policy)

three years. For example, the bias of American consumers for imported goods from Emerging Asia $\left(b_{A}^{U S, A S}\right)$ increases from 0.11 to 0.16 , with a corresponding decrease in demand for imported goods from $\mathrm{RC}\left(b_{A}^{U S, R C}\right)$ from 0.58 to 0.53 . This implies that in the long run, for every additional one hundred units of imports in JE, RW or US, five of those units now come from AS rather than from the other trading partners. 
is the best strategy to represent our baseline view of the world economy at the beginning of 2005.

Figure 17 presents the baseline scenario in the United States. The key features are a gradual build up in government debt and decline in net foreign assets for US. The exchange rate depreciates gradually to allow the net asset position to stabilize. This generates the trade surplus required to finance the interest obligations resulting from the increase in net foreign liabilities. Consumption as a share of GDP is higher in the short run but is eventually crowded out as US becomes more heavily indebted. In addition, investment is crowded out by persistent budgetary deficits. Overall, the dynamics in the United States are driven by the current account deficit moderating from more than 5 percent of GDP to a sustainable level in 10 years' time.

Emerging Asia's most important role in the baseline is through its absorption of the increased supply of US assets (Figure 18). Initially AS runs a large and growing current account surplus. Eventually, the trade balance turns negative to support the large increase in the net foreign asset position. To absorb the inflows from the interest payments on its net foreign asset position, the AS real effective exchange rate roughly appreciates between 10 and 20 percent over the next five years, achieved through higher inflation. Because of limited exchange rate flexibility, there is an increase in the real interest rate necessary to defend the stability of the currency. Overall, the economy cools in the short run, as higher interest rates dampen investment and real appreciation affects net exports. However, consumption increases as a share of GDP in the medium term in anticipation of higher wealth (and lower saving) in the long run.

Japan and the euro area are relatively stable in terms of adjustment, experiencing few effects as Emerging Asia absorbs most of the increased US demand for goods and the increased supply of US assets (Figure 19). The JE external account is broadly stable going forward, with only a temporary and small current account improvement until it stabilizes around 0.5 percent of GDP in about 10 years time.

The Remaining Countries bloc is not a key part of either the baseline scenario, or the alternative scenarios presented below. It behaves much like Emerging Asia since it has strong links with the United States (mainly Canada and Mexico). But RC absorbs less US debt as there is no large underlying positive shock to its preference for US assets. Furthermore, it experiences relatively little inflation and has a smaller movement in its real effective exchange rate than Emerging Asia because it conducts its monetary policy by targeting inflation rather than a nominal exchange rate peg.

\section{Elements for alternative scenarios}

This section has two objectives. First, we consider some scenarios that are designed to highlight the potential risks of large current account imbalances. Second, we discuss some possible solutions that may mitigate these risks. In summary, we argue that the short-run output costs for the U.S. economy associated with financial market turbulence and a sudden loss in appetite for U.S. assets are likely to be the same order of magnitude as a large, credible fiscal consolidation that would make a significant contribution to reducing these imbalances steadily over time and make both the U.S. and world economy less susceptible to shocks. We also consider the effects of competition-friendly structural policies aimed at reducing long-standing structural rigidities and distortions in the product markets in Europe and Japan. Our analysis suggests that such policies could play a meaningful role in reducing 
current account imbalances on a sustainable basis.

\subsection{Sudden loss in appetite for U.S. assets}

Among the major risks surrounding the large buildup of U.S. external liabilities, there has been considerable discussion that a sudden loss in appetite for these assets by the rest of the world could precipitate a large and abrupt depreciation in the U.S. dollar, adversely impact interest rates, and cause significant second-round negative effects on other countries. We attempt to evaluate these predictions.

Initially, we consider the effects of a sudden portfolio reshuffling in the rest of the world (Emerging Asia, Japan and the euro area, and the RC blocs) under the assumption that Emerging Asia maintains a peg relative to the US currency. The effects of this first scenario are reported as solid lines in Figure 20. Next, we consider the same scenario, but in this case central banks in Emerging Asia gradually adopt a flexible exchange rate regime (and inflation targeting). ${ }^{31}$ The effects of this second scenario are reported as dashed lines in Figure 20 and serve to illustrate how flexibility in the exchange rate can help reduce variability in both output and inflation in Emerging Asia.

If market sentiment soured on dollar assets, higher real interest rates in the United States and a significant depreciation in the US dollar in effective terms would result. Dollar depreciation would improve the US trade balance but have a contractionary effect on US GDP growth as higher real interest rates have a larger depressing effect on domestic demand than the effect of the real exchange rate depreciation. Interestingly, this analysis suggests a fairly benign scenario in partner countries where growth rises temporarily in response to lower real interest rates.

These scenarios seem consistent with a view that adjustment in relative prices and real interest rates may not have enormous implications for the world economy as a whole, insofar as the adjustment process was orderly and did not yield persistently higher real interest rates in the rest of the world. It is important to note that these simulations assume relatively high elasticities of substitution between domestically-produced tradables and importables. Reducing these elasticities to one approximately doubles the real depreciation in the U.S. dollar, but has much smaller effects on the other results reported in Figure 20 as the exchange rate simply has to do more work to re-equilibrate the economies to move U.S. dollar asset holdings toward their new desired levels. ${ }^{32}$

\subsubsection{Benefits of exchange rate flexibility in Emerging Asia}

While the effects appear somewhat benign for the world economy generally, they would be anything but benign for the regional economies in Emerging Asia that exhibit symptoms of overheating. In this scenario one can see the potential benefits of allowing greater exchange

\footnotetext{
${ }^{31}$ Technically, this is made operational by shifting the parameters in the reaction function for Emerging Asia gradually over time to be consistent with the parameters in the other country blocs of the model.

${ }^{32}$ Our baseline elasticities are in line with the parameters used in standard open-economy models, but they are significantly higher than the mid-point of the range of macroeconometric estimates, which falls closer to one. For example, Bergin (2004) finds evidence for a unitary elasticity. See Corsetti and Pesenti (2001) for a stylized model with a unit elasticity of substitution between home and foreign goods, complete pass-through, and home bias in government spending. More complex simulation models such as Erceg, Guerrieri and Gust (2005) and Bayoumi, Laxton and Pesenti (2004) employ estimates of 2.5 and 3.0, respectively, closer to estimates of long-run elasticities based on disaggregated data. It is important to note that estimates around 2.5 combined with adjustment costs on imports results in dynamic reponses for imports that are consistent with typical impulse response functions over 1-2 year horizons.
} 
rate flexibility in Emerging Asia as a way to reduce variability in both output and inflation. Indeed, a comparison of the solid lines and the dashed lines in Figure 20 shows intensifying pressure on domestic inflation and output, associated with a reduction in demand for US assets by AS central banks, if they (perhaps, paradoxically) kept trying to peg their exchange rates to the US dollar. ${ }^{33}$

In the first case, attempting to maintain the peg would generate significant overheating pressures and higher inflation, as accelerating prices would be the only method to appreciate their real exchange rates toward values in line with underlying fundamentals. In the second case, we allow the weight on the exchange rate in the Emerging Asia monetary policy reaction function to fall gradually over time and at the same time the weight on (expected) inflation to rise. Consequently, the real exchange rate depreciates by less in Emerging Asia, and this results in less variability in output and inflation. ${ }^{34}$

\subsubsection{Are these scenarios too benign?}

Possibly. The 'conundrum' of historically low interest rates, against the backdrop of historically strong global growth and U.S. monetary tightening, is far from being well understood. And uncertainty lingers about the sustainability and vulnerability of prevailing relaxed financial conditions. Correspondingly, there is a clear and present risk that real rates may rise universally if a sharp U.S. dollar depreciation were to precipitate a reassessment of global risks, including for inflation. This could also trigger adjustments in the prices of other assets (such as housing and equities) and bring into play confidence effects with further reverberations throughout the economy.

To elaborate on these risks, we consider a scenario (see Figure 21) where additional ramifications of a sharp decline in market sentiment toward abundant US dollar assets are considered. In this case, global inflation fears and pressures emerge and interest rates tend to rise significantly across markets. AS attempts to contain the overheating pressures from past low real exchange rates through revaluation and sharply higher interest rates. For other countries, inflationary pressures are exacerbated as the competitive forces from cheap AS exports recede. In this case, note that the adverse effects on global growth are significant.

\subsection{Reducing budget deficits in the United States}

In a recent model-based analysis of current account imbalances, Erceg, Guerrieri and Gust (2005) suggest that fiscal deficits do not have very significant effects on current account deficits. ${ }^{35}$ The implication is that a large reduction in the U.S. government deficits would not play a major role in correcting current account imbalances. But this analysis relies on

\footnotetext{
${ }^{33}$ Dooley, Folkerts-Landau and Garber (2004) argue that diversification of foreign reserves by Asian central banks, amounting to sterilized intervention to weaken the dollar, would be incompatible unless these central banks changed their (fixed) exchange rate policies.

${ }^{34}$ We acknowledge that the difference between the scenarios is not large. It would be much larger if we assumed there was an immediate move to a flexible exchange rate regime. We show some results below for a US fiscal experiment that better contrasts the differences between a pure exchange rate peg and a pure flexible exchange rate regime in the AS bloc.

${ }^{35}$ Erceg, Guerrieri, and Gust (2005) add rule-of-thumb consumers to a model based on the representative agent paradigm and then use the model to study the effects of recent U.S. fiscal deficits on the current account deficit. The effects they find are much smaller than in models allowing for the possibility that permanent increases in government debt can have permanent consequences on the stock of net foreign liabilities. Faruqee and Laxton (2000) show that liquidity-constrained consumers by themselves do not result in significant long-term crowding-out effects associated with permanent increases in government debt.
} 
a single, narrow mechanism (i.e., liquidity constraints) through which fiscal variables might operate (beyond tax distortions), while other theoretical frameworks - and other models - reach rather different conclusions. This is the case, for instance, with simulation results based on the aforementioned Global Fiscal Model, a multi-country choice-theoretic model - in the life-cycle, overlapping generations tradition - that has been developed specifically to study the medium- and long-term consequences of alternative fiscal policies that involve permanent changes in government debt. ${ }^{36}$

The theoretical framework adopted in this paper provides a synthesis between these disparate modeling strategies, by considering the link between government debt and net asset positions in relation to the technology of financial intermediation. ${ }^{37}$ When this link is switched off, and no allowance is made for the possibility that permanent changes in government debt can result in a permanent shift in the desired level of net foreign liabilities, our simulation results show that the effects of fiscal deficits on current account deficits can be very small. However, when the link is explicitly and realistically taken into account, our results predict a rather different path for current account rebalancing.

\subsubsection{Effects of a permanent reduction in government debt through tax hikes}

Figure 22 reports the results for a US fiscal consolidation scenario where the governmentdebt-to-GDP ratio is reduced by 60 percentage points in the long run by increasing taxes by three percent of GDP over fifteen years. The tax hike is assumed to fall entirely on labor income, but after the fifteenth year of the simulation, the tax rate is allowed to fall in order to stabilize the government debt ratio at a value that is 60 percentage points below baseline.

The solid line in Figure 22 reports the results when the Emerging Asian currencies are assumed to be pegged to the dollar, while the dashed lines refer to the case in which they have a flexible exchange rate regime. In both cases output growth falls in the United States and the current account balance improves significantly. The contractionary effects on real GDP are moderated by a real depreciation in the US dollar. These simulations show clearly that US fiscal consolidation would not be achieved without some short-run costs for output growth, but unlike the results by Erceg et al. (2005) they suggest that a large and credible fiscal consolidation could have large and durable benefits by reducing current account imbalances.

The dashed lines report the results when the AS countries no longer 'import' an inappropriate monetary stance by pegging their exchange rates to the US dollar. In the case of a peg their real exchange rate depreciates with the US dollar and real interest rates decline. This results in a significant expansion in demand in the short run and higher inflation. In the case where they are assumed to follow a flexible exchange rate regime there is substantially less variability in output and inflation as the real exchange rate is allowed to appreciate in line with fundamentals. Note that the rest of the world (Japan, Europe and RC) benefits from fiscal consolidation in the United States as the rise in world savings results in lower real interest rates and higher investment.

The fiscal scenarios reported above allow the desired level of net foreign liabilities to fall

\footnotetext{
${ }^{36}$ For an introduction to the structure and properties of the IMF's GFM see Botman and others (2005) and Kumhof, Laxton and Muir (2005). The model assumes that prices and wages are perfectly flexible, but has a well-defined steady state where private and public sector preferences determine if countries are net creditors or debtors.

${ }^{37}$ The section on the budget constraint for the Ricardian households in the Appendix explains more fully the implementation of these linkages.
} 
by $1 / 2$ of the decline in government debt while in Erceg et al. (2005) this mechanism does not exist. To see the importance of this assumption for our results we have constructed two alternative scenarios, one that employs a lower estimate of $1 / 4$ and another that employs an estimate of $3 / 4$ - see Figure 23. Not surprisingly, this parameter has a significant effect on the path of the current account balance. In the limiting case when it is assumed to be zero, the effects on the current account balance over the medium term become insignificant. Indeed, in the long run the effects would be absolutely zero as the relationship between current account deficit and fiscal deficit, measured as ratios of nominal GDP, will be exactly the same as the relationship between the stocks of net foreign liabilities and government debt.

\subsubsection{Alternative views about the link between government debt and net for- eign liabilities}

As a check of the reliability of our simulations, it is worthwhile to investigate what assumptions may point to larger or smaller estimates in models where the relationship between government debt and net foreign liabilities is modeled endogenously and falls directly out of assumptions about behavior. The aforementioned GFM is based on an overlapping generations framework with finite lives and potential myopia in consumer spending decisions because the planning horizon can be set to be shorter than the expected lifetime of an average consumer. An important consequence of these assumptions is that there will be a strong link in the long run between government debt and the stock of net foreign liabilities.

Figure 24 presents results for the same fiscal consolidation experiment considered above. We consider two cases. The first assumes a planning horizon of 10 years (solid lines) while the second assumes a planning horizon of 20 years (dashed lines). Note that in both cases there are significant effects on the current account balance from permanently reducing government debt. In the first case the current account balance improves by about 2.0 percentage points, while in the second case when the planning horizon is 20 years it improves by about 1.5 percentage points.

It is important to emphasize that the improvements in the current account balance are durable to the extent that there is a permanent reduction in net foreign liabilities of 40 and 30 percentage points, respectively. Kumhof, Laxton and Muir (2005) show that the long-run elasticity between the stock of government debt and net foreign liabilities in GFM ranges from a low of 0.50 to a high of 0.75 for plausible assumptions about structural parameters such as: the planning horizon of agents; the type of fiscal consolidation (labor taxes, corporate income taxes, or government absorption); key elasticities (especially intertemporal substitution).

\subsubsection{Does the effect on the current account depend on the type of fiscal con- solidation?}

Yes. The effects on the current account balance will generally be larger if the fiscal consolidation is a result of a cut in government absorption rather than an increase in taxes. Figure 25 compares the same tax-induced fiscal consolidation reported earlier (solid lines) with an alternative fiscal consolidation where government absorption is cut by three percentage points of GDP for 15 years (dashed lines). In the short run expenditure cuts are associated with much stronger contractionary effects on real GDP, as well as larger effects on the current account balance. 


\subsection{How much would structural reforms in Japan and the euro area contribute?}

Given the uneven pattern of global growth and demand and the sluggish economic performance in Japan and the euro area, it has been suggested that one component solution to help reduce global imbalances would be to raise the growth potential - hampered by deepseated structural rigidities - in these regions through further structural reforms. Namely, policies aimed at lowering barriers to competition, enhancing flexibility in employment and production practices, raising labor utilization, and reducing distortions in labor and product markets could substantially improve growth prospects, boost domestic demand, and attract foreign investors. Some have challenged the notion that structural reforms would do much at all and may even exacerbate global imbalances, given that they may weigh on consumer confidence (and spending) over drawn-out transitions typical of structural change episodes.

To evaluate these viewpoints, we study scenarios of reducing labor and product market distortions (i.e. markups) in JE following Bayoumi, Laxton and Pesenti (2004). Labor market reforms alone (not shown) can have minimal effects on reducing high domestic net saving, particularly if uncertainty over reforms further weighed on households. However, credible product market reforms can offer strong complementary effects enhancing the impact of labor market reforms on growth and employment (and thereby confidence). ${ }^{38}$ Moreover, the direct output effects from comparable product market reforms tend to be larger. Considering these reforms, Figure 26 shows the effects of reducing price markups in both the tradables and nontradables sectors in Japan and the euro area gradually to US levels over a 10 year period. Growth rises significantly in Japan and the euro area with some small spillovers to the rest of the world. Note that accommodative monetary policy in JE lends further support to domestic demand during the structural adjustment toward higher economic activity.

The simulations presented in Figure 26 include a permanent six percentage point reduction in the desired net foreign asset to GDP ratios - akin to the implications of higher productivity - in Japan and the euro area, as well as an increase in desired NFA positions in other countries. The solid lines are based on the shifts in the long-run desired NFA positions that obtain under the same simulation experiment in GFM, while the dashed lines assumes that the United States alone would finance the increase in investment in Japan and the euro area through an increase in its desired NFA holdings. Obviously, if the effects on growth were more sustained and trend productivity growth were to increase there could be even larger changes in the desired NFA positions.

\section{Conclusion}

Global imbalances are a complex, multi-faceted issue, with potentially far-reaching implications for the global economy that should not be ignored. Concern about potential scenarios where the adjustment process could be costly to both the United States and the world economy has motivated several policymakers and analysts to demand credible and swift action to help mitigate the risks by reducing the magnitude of these imbalances. While predicting their future evolution cannot be done with any certitude, a better understanding of the likely conditions, causes, and consequences surrounding these external developments can guide key policies needed to help navigate economies toward a desirable resolution. Examining the implications, risks, and attendant policies attached to global rebalancing through

\footnotetext{
${ }^{38}$ See, for example, IMF (2005) for evidence based on OECD countries.
} 
the lens of a dynamic, multi-region model of the global economy, this analysis has yielded some useful insights in this regard.

Our baseline view is that steady global rebalancing with an orderly unwinding of financial positions and currency realignments - notably a gradual depreciation in the U.S. dollar can be achieved. The challenge for policymakers at the national level is to help ensure this outcome that is in the collective interest. In this instance, the burden of adjustment will largely fall on the United States and Emerging Asia in terms of reversing their past (net) national saving trends. This may require a committed U.S. fiscal consolidation through a combination of higher taxes and reining in government absorption. Supportive fiscal policies in Emerging Asia, aimed at easing export competitiveness strains, could facilitate adjustment, aided by greater exchange rate flexibility that limited output and inflation variability. Although more uncertain, some 'normalization' of private consumption rates (in opposing directions) in the two regions would further facilitate external adjustment.

Europe and Japan, for their part, could meaningfully contribute to the multilateral adjustment process through stronger pursuit of growth-enhancing structural reforms that align with their own national interests. Namely, policies aimed at addressing long-standing structural rigidities and distortions could substantially improve growth prospects, strengthen consumption and investment spending, and increase the attractiveness to foreign investors. Labor market reforms alone might not significantly contribute to rebalancing, especially if uncertainty about policy direction and resolve weighed on confidence. However, committed product market initiatives could complement these reforms to enhance confidence and further raise growth and domestic demand. Led by these competition-friendly reforms and with structural adjustment supported by monetary policy, credible growth-enhancing measures tackling deep-seated structural impediments and distortions would boost domestic consumption and investment prospects, attract foreign capital, and thereby contribute to external rebalancing.

Far less benign adjustment scenarios are also quite conceivable. A more dangerous route, in the absence of underlying, broad-based adjustment in macroeconomic and structural policies, would rely on global financial markets to take a lead role. If mounting concerns over imbalances triggered sizeable international portfolio shifts, a sudden loss of appetite for U.S. dollar assets could effect more drastic changes in interest and exchange rates, including a significantly weaker U.S. dollar. This is particularly the case if relaxed financial conditions were to give way, with harmful knock-on effects for global growth.

\section{References}

[1] Batini, N. and A. Haldane, 1999, "Forward-Looking Rules for Monetary Policy," in J. B. Taylor (ed.), Monetary Policy Rules, Chicago: The University of Chicago Press.

[2] Botman, D., D. Muir, D. Laxton and A. Romanov, 2005, "A New-Open-EconomyMacro Model for Fiscal Policy Evaluation," unpublished manuscript, International Monetary Fund.

[3] Bayoumi, T., D. Laxton and P. Pesenti, 2004, "Benefits and Spillovers of Greater Competition in Europe: A Macroeconomic Assessment," NBER Working Paper No. 10416, National Bureau of Economic Research, Inc. 
[4] Bergin, P., 2004, "How Well Can the New Open Economy Macroeconomics Explain the Exchange Rate and Current Account?" NBER Working Paper No. 10356, National Bureau of Economic Research, Inc.

[5] Choudhri, E., H. Faruqee, and D. Hakura, 2005, "Explaining the Exchange Rate PassThrough in Different Prices," Journal of International Economics, Vol. 65, pp. 349-374.

[6] Coats, W., D. Laxton and D. Rose, 2003, The Czech National Bank's Forecasting and Policy Analysis System, Prague: Czech National Bank.

[7] Corden, M., 1994, Economic Policy, Exchange Rates, and the International System, Oxford: Oxford University Press, and Chicago: The University of Chicago Press.

[8] Corsetti, G. and L. Dedola, 2002, "Macroeconomics of International Price Discrimination," ECB Working Paper No. 176, Frankfurt: European Central Bank.

[9] Corsetti, G. and P. Pesenti, 2001, "Welfare and Macroeconomic Interdependence," The Quarterly Journal of Economics, 1, Vol. 116, no. 2, pp. 421-445(25), MIT Press.

[10] Corsetti, G. and P. Pesenti, 2005a, "International Dimensions of Optimal Monetary Policy," Journal of Monetary Economics 52 (2), March, pp. 281-305.

[11] Corsetti, G. and P. Pesenti, 2005b, "The Simple Geometry of Transmission and Stabilization in Closed and Open Economy," NBER Working Paper No. 11341, May, National Bureau of Economic Research, Inc.

[12] De Rato, R., 2005, "Correcting Global Imbalances - Avoiding the Blame Game," Remarks by Managing Director, IMF at the Foreign Policy Association of Financial Services, March.

[13] Devereux, M., and C. Engel, 2002, "Exchange Rate Pass-Through, Exchange Rate Volatility, and Exchange Rate Disconnect," Journal of Monetary Economics, Vol. 49, pp. 913-940.

[14] Dooley, M., D. Folkerts-Landau, and P. Garber, 2004, "Asian Reserve Diversification: Does it Threaten the Pegs," Global Market Research, Deutsche Bank.

[15] Dooley, M., D. Folkerts-Landau, and P. Garber, 2005, "Direct Investment, Rising Real Wages and the Absorption of Excess Labor in the Periphery," Paper prepared for an NBER Conference on G7 Current Account Imbalances: Sustainability and Adjustment, June 1-2, 2005, Newport, Rhode Island.

[16] Edwards, S., 2004, "Thirty Years of Current Account Imbalances, Current Account Reversals and Sudden Stops," NBER Working Paper No. 10276, National Bureau of Economic Research, Inc.

[17] Eichengreen, B., 2004, "Global Imbalances and the Lessons of Bretton Woods," NBER Working Papers 10497, National Bureau of Economic Research, Inc.

[18] Eichengreen, B. and M. Adalet, 2005, "Current Account Reversals: Always a Problem?" Paper prepared for an NBER Conference on G7 Current Account Imbalances: Sustainability and Adjustment, June 1-2, 2005, Newport, Rhode Island. 
[19] Engel, C., 1993, "Real exchange rates and relative prices : An empirical investigation," Journal of Monetary Economics, Vol. 32, pp. 35-50.

[20] Engel, C., 2002, "Expenditure Switching and Exchange Rate Policy," NBER Macroeconomics Annual Report.

[21] Engel, C., and J. Rogers, 1996, "How Wide is the Border?" American Economic Review 86, pp. 1112-1125.

[22] Erceg, C. J., L. Guerrieri, and C. Gust, 2005, "Expansionary Fiscal Shocks and the Trade Deficit," FRB International Finance Discussion Paper No. 825.

[23] Faruqee, H. and J. Lee, 2005, "Global Dispersion of Current Accounts: Is the Universe Expanding?", unpublished manuscript, International Monetary Fund.

[24] Faruqee, H. and D. Laxton, 2000, "Life-Cycles, Dynasties, Savings: Implications for Closed and Small, Open Economies," IMF Working Paper No. 00/126.

[25] Freund, C., 2000, "Current Account Adjustment in Industrial Countries," FRB International Finance Discussion Paper No. 692.

[26] Ghironi, F., İ. Talan, and A. Rebucci, 2005, "Net Foreign Asset Position and Consumption Dynamics in the International Economy" IMF Working Paper No. 05/82.

[27] Gourinchas, P. and H. Rey, 2005, "From World Banker to World Venture Capitalist: The U.S. External Adjustment and the Exorbitant Privilege," Paper prepared for an NBER Conference on G7 Current Account Imbalances: Sustainability and Adjustment, June 1-2, 2005, Newport, Rhode Island.

[28] Hunt, B. and A. Rebucci, 2005, "The U.S. Dollar and the Trade Deficit: What accounts for the Late 1990s?" forthcoming in International Finance.

[29] Hunt, B., D. Rose and A. Scott, 2000, "The core model of the Reserve Bank of New Zealand's Forecasting and Policy System," Economic Modelling, Volume 17, Issue2, pp. 247-274.

[30] International Monetary Fund, 2005, "The World Economic Outlook (WEO) Database," IMF, Washington D.C.

[31] Juillard, M., P. Karam, D. Laxton, and P. Pesenti, 2004, "A Simple Welfare-Based Monetary Policy Rule in an Estimated DSGE Model of the U.S. Economy," Paper prepared for the IMF Workshop on DSGE Modeling, April, 26-30, 2004, Washington D.C.

[32] Kumhof, M., D. Laxton and D. Muir, 2005, "The Consequences of U.S. Fiscal Consolidation for the Current Account," unpublished manuscript, International Monetary Fund.

[33] Lane, P. and G. Milesi-Ferretti, 2001, "Long-Term Capital Movements," in B. Bernanke and K. Rogoff (eds.) NBER Macroeconomics Annual 2001, Cambridge: MIT Press.

[34] Lane, P. and G. Milesi-Ferretti, 2003, "International Financial Integration," IMF Staff Papers. 
[35] Lane, P. and G. Milesi-Ferretti, 2004, "Financial Globalization and Exchange Rates," CEPR Discussion Papers 4745.

[36] Laxton, D., and P. Pesenti, 2003, "Monetary Policy Rules for Small, Open, Emerging Economies," Journal of Monetary Economics 50, July, pp. 1109-1146.

[37] Laxton, D., D. Rose and R. Tetlow, 1993, "Monetary Policy, Uncertainty, and the Presumption of Linearity," Bank of Canada Technical Report No. 63.

[38] Milesi-Ferretti G. and A. Razin, 2000, "Current Account Reversals and Currency Crises: Empirical Regularities," in P. Krugman (ed.), Currency Crises, Chicago: University of Chicago Press.

[39] Obstfeld, M. and K. Rogoff, 2000a, "Perspectives on OECD Economic Integration: Implications for U.S. Current Account Adjustment," presented at Federal Reserve Bank of Kansas City Symposium, Jackson Hole, 2000.

[40] Obstfeld, M. and K. Rogoff, 2000b, "The Six Major Puzzles in International Macroeconomics: Is there a Common Cause?" in B. Bernanke and K. Rogoff (eds.), NBER Macroeconomics Annual 2000, Cambridge: MIT Press.

[41] Obstfeld, M., 2002, "Exchange Rates and Adjustment: Perspectives from the New Open Economy Macroeconomics," NBER Working Paper No. 9118, National Bureau of Economic Research, Inc.

[42] Orphanides, A., 2003, "Historical Monetary Policy Analysis and the Taylor Rule." Journal of Monetary Economics, Vol. 50, pp. 983-1022.

[43] Rogoff, K., 1996, "The Purchasing Power Parity Puzzle," Journal of Economic Literature 34, June 1996, 647-68.

[44] Jean, S. and G. Nicoletti, 2002, "Product market Regulation and Wage Premia in Europe and North America," OECD Economics Department Working Paper 318, OECD Economics Department.

[45] Svensson, L., 1999, "Inflation Targeting as a Monetary Policy Rule," Journal of Monetary Economics, 43, pp. 607-654.

[46] Svensson, L. and M. Woodford, 2005, "Implementing Optimal Policy through InflationForecast Targeting" in B. Bernanke and M. Woodford (eds.), The Inflation Targeting Debate, Chicago: The University of Chicago Press.

[47] Tille, C., 2003, "The Impact of Exchange Rate Movements on U.S. Foreign Debt," Federal Reserve Bank of New York, Current Issues in Economics and Finance, Vol. 9 pp. 1-7. 


\section{Appendix: Theoretical framework}

\section{Introduction}

The structure of the model is introduced in Section 2 and illustrated in Figure 2. Needless to say, the model is fairly complex even though it abstracts from a number of issues (such as trade in oil, commodities and other 'upstream' intermediate inputs, distribution costs, ${ }^{39}$ as well as balance-sheet and 'revaluation' effects stemming from asymmetries in the currency denomination of assets and liabilities across countries) of obvious relevance for the analysis of the international transmission mechanism. In what follows we provide a brief but comprehensive overview of the model. In some sections we focus on country-specific equations that are independent of foreign variables, thus qualitatively similar across countries. We therefore drop country indexes for notational simplicity, with the understanding that all four countries are analogously characterized. In the sections involving international transactions, instead, we explicitly incorporate country indexes in our notation. As a general convention throughout the model, when we state that variable $X$ follows an autoregressive process, we mean that:

$$
X_{t}=\left(1-\lambda_{X}\right) X+\lambda_{X} X_{t-1}+e_{X, t}
$$

where $0<\lambda_{X}<1, X$ is the steady-state value of $X_{t}$, and $e_{X, t}$ is a noise term.

\section{Final goods}

In each country there is a continuum of symmetric firms producing the two final goods, $A$ (the consumption good) and $E$ (the investment good) under perfect competition.

Consider first the consumption sector. Each firm is indexed by $x \in[0, s]$, where $0<$ $s<1$ is the country size. Firm $x$ 's output at time (quarter) $t$ is denoted $A_{t}(x)$. The consumption good is produced with the following nested constant elasticity of substitution (CES) technology:

$$
\begin{aligned}
& A_{t}(x)^{1-\frac{1}{\varepsilon_{A}}}=\left(1-\gamma_{A, t}\right)^{\frac{1}{\varepsilon_{A}}} N_{A, t}(x)^{1-\frac{1}{\varepsilon_{A}}} \\
& +\gamma_{A, t}^{\frac{1}{\varepsilon_{A}}}\left[\nu_{A}^{\frac{1}{\mu_{A}}} Q_{A, t}(x)^{1-\frac{1}{\mu_{A}}}+\left(1-\nu_{A}\right)^{\frac{1}{\mu_{A}}} M_{A, t}(x)^{1-\frac{1}{\mu_{A}}}\right]^{\frac{\mu_{A}}{\mu_{A}-1}}\left(1-\frac{1}{\varepsilon_{A}}\right)
\end{aligned}
$$

Three intermediate inputs are used in the production of the consumption good $A$ : a basket $N_{A}$ of nontradable goods, a basket $Q_{A}$ of domestic tradable goods, and a basket $M_{A}$ of imported goods. The elasticity of substitution between tradables and nontradables is $\varepsilon_{A}>0$, and the elasticity of substitution between domestic and imported tradables is $\mu_{A}>0$. The weights of the three inputs are, respectively, $1-\gamma_{A}, \gamma_{A} \nu_{A}$ and $\gamma_{A}\left(1-\nu_{A}\right)$ with $0<\gamma_{A}, \nu_{A}<$ 1.

Firm $x$ takes as given the prices of the three inputs and minimizes its costs subject to the technological constraint (A.2). As a convention throughout the model, $A$ is the numeraire of the economy and all national prices are expressed in terms of domestic consumption units, that is relative to the Consumer Price Index (CPI) ${ }^{40}$ Cost minimization implies that firm

\footnotetext{
${ }^{39}$ The reader interested in these two features is referred to the variant of the model considered in Laxton and Pesenti (2003).

${ }^{40}$ The transformation of all prices in relative terms and all quantities in detrended terms is motivated by the desire to avoid dealing with unit roots, either nominal or real, in quantitative simulations of the model with stochastic inflation and growth rates.
} 
$x$ 's demands for intermediate inputs are:

$$
\begin{aligned}
N_{A, t}(x) & =\left(1-\gamma_{A, t}\right) p_{N, t}^{-\varepsilon_{A}} A_{t}(x) \\
Q_{A, t}(x) & =\gamma_{A, t} \nu_{A} p_{Q, t}^{-\mu_{A}} p_{X A, t}^{\mu_{A}-\varepsilon_{A}} A_{t}(x) \\
M_{A, t}(x) & =\gamma_{A, t}\left(1-\nu_{A}\right) p_{M A, t}^{-\mu_{A}} p_{X A, t}^{\mu_{A}-\varepsilon_{A}} A_{t}(x)
\end{aligned}
$$

where $p_{N}, p_{Q}$ and $p_{M A}$ are the relative prices of the inputs in terms of consumption baskets and $p_{X A}$ is the price of the composite basket of domestic and foreign tradables, or:

$$
p_{X A, t} \equiv\left[\nu_{A} p_{Q, t}^{1-\mu_{A}}+\left(1-\nu_{A}\right) p_{M A, t}^{-\mu_{A}}\right]^{\frac{1}{1-\mu_{A}}}
$$

The technologies of production of consumption and investment goods can be quantitatively different but their formal characterizations are similar, with self-explanatory changes in notation. For instance, a firm $e \in[0, s]$, that produces the investment good, demands nontradable goods according to:

$$
N_{E, t}(e)=\left(1-\gamma_{E, t}\right)\left(p_{N, t} / p_{E, t}\right)^{-\varepsilon_{E}} E_{t}
$$

Note that $p_{M A}$ and $p_{M E}$ are sector-specific as they reflect the different composition of imports in the two sectors, while $p_{N}$ and $p_{Q}$ are identical across sectors.

\section{Demand for domestic intermediate goods}

Consider now the composition of the baskets of intermediate goods. Intermediate inputs come in different varieties (brands) and are produced under conditions of monopolistic competition. In each country there are two kinds of intermediate goods, tradables and nontradables. Each kind is defined over a continuum of mass $s$. Without loss of generality, we assume that each nontradable good is produced by a single domestic firm indexed by $n \in[0, s]$, and each tradable good is produced by a firm $h \in[0, s]$.

Focusing first on the basket $N_{A}$, this is a CES index of all domestic varieties of nontradables. Denoting as $N_{A}(n, x)$ the demand by firm $x$ of an intermediate good produced by firm $n$, the basket $N_{A}(x)$ is:

$$
N_{A, t}(x)=\left[\left(\frac{1}{s}\right)^{\frac{1}{\theta_{N, t}}} \int_{0}^{s} N_{A, t}(n, x)^{1-\frac{1}{\theta_{N, t}}} d n\right]^{\frac{\theta_{N, t}}{\theta_{N, t}-1}}
$$

where $\theta_{N, t}>1$ denotes the elasticity of substitution among intermediate non-tradables.

Firm $x$ takes as given the prices of the nontradable goods $p(n)$. Cost minimization implies:

$$
N_{A, t}(n, x)=\frac{1}{s}\left(\frac{p_{t}(n)}{p_{N, t}}\right)^{-\theta_{N, t}} N_{A, t}(x)
$$

where $p_{N}$ is the price of one unit of the non-tradable basket, or:

$$
p_{N, t}=\left[\left(\frac{1}{s}\right) \int_{0}^{s} p_{t}(n)^{1-\theta_{N, t}} d n\right]^{\frac{1}{1-\theta_{N, t}}}
$$

The basket $N_{E}$ is similarly characterized. Aggregating across firms, ${ }^{41}$ and accounting for public demand of nontradables — here assumed to have the same composition as private

\footnotetext{
${ }^{41}$ The convention throughout the model is that variables which are not explicitly indexed (to firms or households) are expressed in per-capita (average) terms. For instance, $A_{t} \equiv(1 / s) \int_{0}^{s} A_{t}(x) d x$.
} 
demand — we obtain the total demand for good $n$ as:

$$
\int_{0}^{s} N_{A, t}(n, x) d x+\int_{0}^{s} N_{E, t}(n, e) d e+G_{N, t}(n)=\left(\frac{p_{t}(n)}{p_{N, t}}\right)^{-\theta_{N, t}}\left(N_{A, t}+N_{E, t}+G_{N, t}\right)
$$

Following the same steps we can derive the domestic demand schedules for the intermediate goods $h$ :

$$
\int_{0}^{s} Q_{A, t}(h, x) d x+\int_{0}^{s} Q_{E, t}(h, e) d e=\left(\frac{p_{t}(h)}{p_{Q, t}}\right)^{-\theta_{T, t}}\left(Q_{A, t}+Q_{E, t}\right) .
$$

\section{Demand for imports}

The derivation of the foreign demand schedule for good $h$ is analytically more complex but, as we show in (A.19) at the end of this section, it shares the same functional form as (A.11) and (A.12) above and can be written as a function of the relative price of good $h$ (with elasticity $\left.\theta_{T, t}\right)$ and total foreign demand for imports.

Let's focus first on import demand in the consumption good sector. Since we deal with goods produced in different countries, we need to introduce explicit country indexes in our notation. Thus, we will refer to a generic country as $C O$, to the importing country as $H$, and to the representative firm in the consumption sector as $x^{H} \in\left[0, s^{H}\right]$. Its imports $M_{A}^{H}\left(x^{H}\right)$ are a CES function of baskets of goods imported from the other countries, or:

$$
M_{A, t}^{H}\left(x^{H}\right)^{1-\frac{1}{\rho_{A}^{H}}}=\sum_{C O \neq H}\left(b_{A}^{H, C O}\right)^{\frac{1}{\rho_{A}^{H}}}\left(M_{A, t}^{H, C O}\left(x^{H}\right)\left(1-\Gamma_{M A, t}^{H, C O}\left(x^{H}\right)\right)^{1-\frac{1}{\rho_{A}^{H}}}\right.
$$

where:

$$
0 \leq b^{H, C O} \leq 0, \quad \sum_{C O \neq H} b^{H, C O}=1
$$

In (A.13) above $\rho_{A}^{H}$ is the elasticity of import substitution across countries: the higher is $\rho_{A}^{H}$, the easier it is for firm $x^{H}$ to substitute imports from one country with imports from another. The parameters $b_{A}^{H, C O}$ determine the composition of the import basket across countries. $M_{A}^{H, C O}\left(x^{H}\right)$ denotes imports of country $H$ 's firm $x^{H}$ from country $C O$.

The response of imports to changes in fundamentals and their price elasticities are typically observed to be smaller in the short term than in the long run. To model realistic dynamics of imports volumes (such as delayed and sluggish adjustment to changes in relative prices) we assume that imports are subject to adjustment costs $\Gamma_{M A}^{H, C O}$. These costs are specified in terms of import shares relative to firm $x^{H}$ 's output and can be different across exporters. They are zero in steady state. Specifically, we adopt the parameterization:

$\Gamma_{M A, t}^{H, C O}\left[\frac{M_{A, t}^{H, C O}\left(x^{H}\right)}{A_{t}^{H}(x)} / \frac{M_{A, t-1}^{H, C O}}{A_{t-1}^{H}}\right]=\frac{\phi_{M A}^{H, C O}}{2} \frac{\left[\left(M_{A, t}^{H, C O}\left(x^{H}\right) / A_{t}^{H}(x)\right) /\left(M_{A, t-1}^{H, C O} / A_{t-1}^{H}\right)-1\right]^{2}}{\left(1+\left[\left(M_{A, t}^{H, C O}\left(x^{H}\right) / A_{t}^{H}(x)\right) /\left(M_{A, t-1}^{H, C O} / A_{t-1}^{H}\right)-1\right]^{2}\right)}$

such that $\Gamma_{M A}^{H, C O}[1]=0, \Gamma_{M A}^{H, C O}[\infty]=\phi_{M A}^{H, C O} / 2$, and $\Gamma_{M A}^{H, C O}[0]=\Gamma_{M A}^{H, C O}[2]=\phi_{M A}^{H, C O} / 4{ }^{42}$

\footnotetext{
${ }^{42}$ Relative to the quadratic specification adopted e.g. in Laxton and Pesenti (2003), this parameterization of import adjustment costs allows the non-linear model to deal with potentially large shocks.
} 
Denoting $p_{M}^{H, C O}$ the price in country $H$ of a basket of intermediate inputs imported from $C O$, cost minimization implies:

$$
\frac{M_{A, t}^{H, C O}\left(x^{H}\right)\left(1-\Gamma_{M A, t}^{H, C O}\left(x^{H}\right)\right)}{\left(1-\Gamma_{M A, t}^{H, C O}\left(x^{H}\right)-M^{H, C O}\left(x^{H}\right) \Gamma_{M A, t}^{\prime H, C O}\left(x^{H}\right)\right)^{\rho_{A}^{H}}}=b_{A}^{H, C O}\left(\frac{p_{M, t}^{H . C O}}{p_{M A, t}^{H}\left(x^{H}\right)}\right)^{-\rho_{A}^{H}} M_{A, t}^{H}\left(x^{H}\right)
$$

where $\Gamma_{M A}^{\prime H, C O}\left(x^{H}\right)$ is the first derivative of $\Gamma_{M A}^{H, C O}\left(x^{H}\right)$ with respect to $M_{A}^{H, C O}\left(x^{H}\right)$. The import price in the consumption sector, $p_{M A}^{H}$, is defined as:

$$
p_{M A, t}^{H}\left(x^{H}\right)=\left[\sum_{C O \neq H} b^{H, C O}\left(\frac{p_{M, t}^{H, C O}}{1-\Gamma_{M A, t}^{H, C O}\left(x^{H}\right)-M^{H, C O}\left(x^{H}\right) \Gamma_{M A, t}^{\prime H, C O}\left(x^{H}\right)}\right)^{1-\rho_{A}^{H}}\right]^{\frac{1}{1-\rho_{A}^{H}}}
$$

In principle, the cost-minimizing import price $p_{M A}^{H}\left(x^{H}\right)$ is firm-specific, as it depends on firm $x^{H}$ 's import share. To the extent that all firms $x^{H}$ are symmetric within the consumption sector, however, there will be a unique import price $p_{M A}^{H} \cdot{ }^{43}$

Let's now consider the basket $M_{A}^{H, C O}\left(x^{H}\right)$ in some detail. In analogy with (A.8) above, it is a CES index of all varieties of tradable intermediate goods produced by firms $h^{C O}$ operating in country $C O$ and exported to country $H$. Denoting as $M_{A}^{H, C O}\left(h^{C O}, x^{H}\right)$ the demand by firm $x^{H}$ of an intermediate good produced by firm $h^{C O}$, the basket $M_{A}^{H, C O}\left(x^{H}\right)$ is:

$$
M_{A, t}^{H, C O}\left(x^{H}\right)=\left[\left(\frac{1}{s^{C O}}\right)^{\frac{1}{\theta_{T, t}^{C O}}} \int_{0}^{s^{C O}} M_{A, t}^{H, C O}\left(h^{C O}, x^{H}\right)^{1-\frac{1}{\theta_{T, t}^{C O}}} d h^{C O}\right]^{\frac{\theta_{T, t}^{C O}}{\theta_{T, t}^{C,}-1}}
$$

where $\theta_{T}^{C O}>1$ is the elasticity of substitution among intermediate tradables, the same elasticity entering (A.12) in country $C O$.

The cost-minimizing firm $x^{H}$ takes as given the prices of the imported goods $p^{H}\left(h^{C O}\right)$ and determines its demand of good $h^{C O}$ according to:

$$
M_{A, t}^{H, C O}\left(h^{C O}, x^{H}\right)=\frac{1}{s^{C O}}\left(\frac{p_{t}^{H}\left(h^{C O}\right)}{p_{M, t}^{H, C O}}\right)^{-\theta_{T, t}^{C O}} M_{A, t}^{H, C O}\left(x^{H}\right)
$$

where $M_{A, t}^{H, C O}\left(x^{H}\right)$ has been defined in (A.16) and $p_{M}^{H, C O}$ is:

$$
p_{M, t}^{H, C O}=\left[\left(\frac{1}{s^{C O}}\right) \int_{0}^{s^{C O}} p_{t}^{H}\left(h^{C O}\right)^{1-\theta_{T, t}^{C O}} d h^{C O}\right]^{\frac{1}{1-\theta_{T, t}^{C O}}}
$$

The import demand schedules in the investment good sector can be derived in perfect analogy with the analysis above. As a last step, we can derive country $C O$ 's demand schedule for country $H$ 's intermediate good $h^{H}$, that is, the analog of (A.12). Aggregating across firms (and paying attention to the order of the country indexes) we obtain:

$$
\begin{aligned}
& \int_{0}^{s^{C O}} M_{A, t}^{C O, H}\left(h^{H}, x^{C O}\right) d x^{C O}+\int_{0}^{s^{C O}} M_{E, t}^{C O, H}\left(h^{H}, e^{C O}\right) d e^{C O} \\
& =\frac{s^{C O}}{s^{H}}\left(\frac{p_{t}^{C O}\left(h^{H}\right)}{p_{M, t}^{C O, H}}\right)^{-\theta_{T, t}^{H}}\left(M_{A, t}^{C O, H}+M_{E, t}^{C O, H}\right)
\end{aligned}
$$

\footnotetext{
${ }^{43}$ It follows that $p_{M A}^{H} M_{A}^{H}=\sum_{C O \neq H} p_{M}^{H, C O} M^{H, C O}\left(1-\Gamma_{M A}^{H, C O}\right) /\left(1-\Gamma_{M A}^{H, C O}-M_{M A}^{H, C O} \Gamma_{M A}^{\prime H, C O}\right)$
} 


\section{Supply of intermediate goods}

The nontradable $n$ is produced with the following CES technology:

$$
N_{t}(n)=Z_{N, t}\left[\left(1-\alpha_{N}\right)^{\frac{1}{\xi_{N}}} \ell_{t}(n)^{1-\frac{1}{\xi_{N}}}+\alpha_{N}^{\frac{1}{\xi_{N}}} K_{t}(n)^{1-\frac{1}{\xi_{N}}}\right]^{\frac{\xi_{N}}{\xi_{N}-1}}
$$

Firm $n$ uses labor $\ell(n)$ and capital $K(n)$ to produce $N(n)$ units of its variety. $\xi_{N}>0$ is the elasticity of input substitution, and $Z_{N}$ is a productivity shock common to all producers of nontradables. ${ }^{44}$

Defining as $w_{t}$ and $r_{t}$ the prices of labor and capital, the marginal cost in nontradables production is: ${ }^{45}$

$$
m c_{t}(n)=\frac{\left\{\left(1-\alpha_{N}\right) w_{t}^{1-\xi_{N}}+\alpha_{N} r_{t}^{1-\xi_{N}}\right\}^{\frac{1}{1-\xi_{N}}}}{Z_{N, t}}
$$

and the capital-labor ratio is:

$$
\frac{K_{t}(n)}{\ell_{t}(n)}=\frac{\alpha_{N}}{1-\alpha_{N}}\left(\frac{r_{t}}{w_{t}}\right)^{-\xi_{N}}
$$

Labor inputs are differentiated and come in different varieties (skills). They are defined over a continuum of mass equal to the country size and indexed by $j \in[0, s]$. Each firm $n$ uses a CES combination of labor inputs:

$$
\ell_{t}(n)=\left[\left(\frac{1}{s}\right)^{\frac{1}{\psi_{t}}} \int_{0}^{s} \ell(n, j)^{1-\frac{1}{\psi_{t}}} d j\right]^{\frac{\psi_{t}}{\psi_{t}-1}}
$$

where $\ell(n, j)$ is the demand of labor input of type $j$ by the producer of good $n$ and $\psi>1$ is the elasticity of substitution among labor inputs. Cost minimization implies that $\ell(n, j)$ is a function of the relative wage:

$$
\ell_{t}(n, j)=\left(\frac{1}{s}\right)\left(\frac{w_{t}(j)}{w_{t}}\right)^{-\psi_{t}} \ell_{t}(n)
$$

where $w(j)$ is the wage paid to Home labor input $j$ and the wage index $w$ is defined as:

$$
w_{t}=\left[\left(\frac{1}{s}\right) \int_{0}^{s} w_{t}(j)^{1-\psi_{t}} d j\right]^{\frac{1}{1-\psi_{t}}}
$$

Similar considerations hold for the production of tradables. We denote by $T(h)$ the supply of each intermediate tradable $h$. Using self-explanatory notation, we have:

$$
T_{t}(h)=Z_{T, t}\left[\left(1-\alpha_{T}\right)^{\frac{1}{\xi_{T}}} \ell_{t}(h)^{1-\frac{1}{\xi_{T}}}+\alpha_{T}^{\frac{1}{\xi_{T}}} K_{t}(h)^{1-\frac{1}{\xi_{T}}}\right]^{\frac{\xi_{T}}{\xi_{T}-1}}
$$

\footnotetext{
${ }^{44}$ Recall that a productivity shock is defined as a deviation from the common world trend. Variants of the model allow for the possibility of shocks to labor productivity or capital productivity instead of total factor productivity.

${ }^{45}$ Following the notational convention regarding prices, $m c_{t}, w_{t}$ and $r_{t}$ denote marginal costs, wages and rental rates in consumption units.
} 
where $Z_{T}$ is an autoregressive process (in logarithm). Aggregating across firms, we obtain the total demand for labor input $j$ as:

$$
\begin{aligned}
& \int_{0}^{s} \ell_{t}(n, j) d n+\int_{0}^{s} \ell_{t}(h, j) d h \\
& =\left(\frac{w_{t}(j)}{w_{t}}\right)^{-\psi_{t}}\left(\frac{1}{s}\right)\left(\int_{0}^{s} \ell_{t}(n) d n+\int_{0}^{s} \ell_{t}(h) d h\right) \equiv\left(\frac{w_{t}(j)}{w_{t}}\right)^{-\psi_{t}} \ell_{t}
\end{aligned}
$$

where $\ell$ is per-capita total labor in the economy.

\section{Price setting in the nontradables sector}

Consider now profit maximization in the intermediate nontradables sector. Each firm $n$ takes into account the demand (A.11) for its product and sets its nominal price by maximizing the present discounted value of real profits. There are costs of nominal price adjustment measured in terms of total profits foregone. The adjustment cost is denoted $\Gamma_{P N, t}$ $\left[p_{t}(n), p_{t-1}(n)\right]^{46}$

The price-setting problem is then characterized as:

$\max _{\left\{p_{\tau}(n)\right\}_{\tau=t}^{\infty}} \mathrm{E}_{t} \sum_{\tau=t}^{\infty} D_{t, \tau} \pi_{t, \tau} g_{t, \tau}\left[p_{\tau}(n)-m c_{\tau}(n)\right]\left(\frac{p_{\tau}(n)}{p_{N, \tau}}\right)^{-\theta_{N, t}}\left(N_{A, \tau}+N_{E, \tau}+G_{N, \tau}\right)\left(1-\Gamma_{P N, \tau}(n)\right)$

where $D_{t, \tau}$ (with $D_{t, t}=1$ ) is the appropriate discount rate, to be defined below in eq. (A.48). As real variables are detrended and prices are deflated by the CPI, eq. (A.30) includes $\pi_{t, \tau}$, the CPI inflation rate between time $t$ and time $\tau$, and $g_{t, \tau}$, the rate of growth of the global trend between $t$ and $\tau$.

As firms $n$ are symmetric and charge the same equilibrium price $p(n)=p_{N}$, the first order condition can be written as:

$$
\begin{aligned}
& 0=\left(1-\Gamma_{P N, t}(n)\right)\left[p_{t}(n)\left(1-\theta_{N, t}\right)+\theta_{N, t} m c_{t}(n)\right]-\left[p_{t}(n)-m c_{t}(n)\right] \frac{\partial \Gamma_{P N, t}}{\partial p_{t}(n)} p_{t}(n) \\
& -\mathrm{E}_{t} D_{t, t+1} \pi_{t, t+1} g_{t, t+1}\left[p_{t+1}(n)-m c_{t+1}(n)\right] \frac{N_{A, t+1}+N_{E, t+1}+G_{N, t+1}}{N_{A, t}+N_{E, t}+G_{N, t}} \frac{\partial \Gamma_{P N, t+1}}{\partial p_{t}(n)} p_{t}(n)
\end{aligned}
$$

Interpreting the previous equation, when prices are fully flexible $\left(\Gamma_{P N}=0\right)$, the optimization problem collapses to the standard markup rule:

$$
p_{t}(n)=\frac{\theta_{N, t}}{\theta_{N, t}-1} m c_{t}(n)
$$

where the gross markup is a negative function of the elasticity of input substitution. Deviations from markup pricing occur if firms are penalized for modifying their prices in the short term. The speed of adjustment in response to shocks depends on the trade-off between current and future expected costs, making the price-setting process forward-looking.

\footnotetext{
${ }^{46}$ It is worth emphasizing that the adjustment costs are related to changes in nominal prices. However, the maximization problem can be carried out in terms of relative prices. In fact, denote with $G_{P N, t}\left[P_{t}(n), P_{t-1}(n)\right]$ the adjustment cost as a function of nominal (i.e. non deflated by the CPI) prices $P_{t}(n)$ and $P_{t-1}(n)$, with $G_{P N, t}\left[P_{t}(n), P_{t-1}(n)\right]=\Gamma_{P N, t}\left[p_{t}(n), p_{t-1}(n)\right]$, and express the pricesetting problem in nominal terms. It is easy to verify that the first order condition of the new problem coincides with (A.31) since $P_{t}(n) \partial G_{P N, t} / \partial P_{t}(n)=p_{t}(n) \partial \Gamma_{P N, t} / \partial p_{t}(n)$ and $P_{t}(n) \partial G_{P N, t+1} / \partial P_{t}(n)=$ $p_{t}(n) \partial \Gamma_{P N, t+1} / \partial p_{t}(n)$.
} 
The specific parameterization we adopt allows the model to reproduce realistic nominal dynamics:

$$
\Gamma_{P N, t}(n) \equiv \frac{\phi_{P N}}{2}\left(\pi_{t-1, t} \frac{p_{t}(n) / p_{t-1}(n)}{\Pi_{t-4, t}^{0.25}}-1\right)^{2}
$$

The adjustment cost is related to changes of the nominal price of nontradable $n$ relative to the inflation target for the CPI, $\Pi_{t-4, t}$. The inflation target is specified in annualized terms (hence indexed by $t-4, t$ ), while changes in $p(n)$ occur at a quarterly frequency. ${ }^{47}$ Underlying this specification is the notion that firms should not be penalized when their price hikes are indexed to some (publicly observable) benchmark such as the inflation target for the economy as a whole.

\section{Price setting in the tradables sector and exchange rate pass-through}

Consider now the price-setting problem in the tradables sector. To the extent that the four country blocs represent segmented markets in the global economy, each firm $h$ has to set four prices, one in the domestic market and the other three in the export markets. Exports are invoiced (and prices are set) in the currency of the destination market. As we re-introduce export markets, once again our notation needs to make explicit the country indexes. In what follows we use the index $C O$ for a generic country, and denote as $H$ the country where the exporting firm $h^{H}$ is located.

Accounting for (A.21), the four price-setting problems of firm $h$ in country $H$ can then be characterized as follows:

$$
\begin{aligned}
& \max _{\sum_{C O}\left\{p_{\tau}^{C O}\left(h^{H}\right)\right\}_{\tau=t}^{\infty}} \sum_{C O} \mathrm{E}_{t} \sum_{\tau=t}^{\infty} D_{t, \tau}^{H} \pi_{t, \tau}^{H} g_{t, \tau}\left[\varepsilon_{\tau}^{H, C O} p_{\tau}^{C O}\left(h^{H}\right)-m c_{\tau}^{H}\left(h^{H}\right)\right] \\
& * \frac{s^{C O}}{s^{H}}\left(\frac{p_{\tau}^{C O}\left(h^{H}\right)}{p_{M, \tau}^{C O, H}}\right)^{-\theta_{T, t}^{H}}\left(M_{A, \tau}^{C O, H}+M_{E, \tau}^{C O, H}\right)\left(1-\Gamma_{P M, \tau}^{C O, H}(h)\right)
\end{aligned}
$$

When $H \neq C O$, recall that $p^{C O}\left(h^{H}\right)$ is the price of good $h^{H}$ in country $C O, p_{M}^{C O, H}$ is the price of country $C O$ 's imports from country $H$, and $M_{A}^{C O, H}+M_{E}^{C O, H}$ are country $C O$ 's imports from country $H$. The term $\varepsilon^{H, C O}$ is the bilateral exchange rate between country $H$ and country $C O$ (an increase in $\varepsilon^{H, C O}$ represents a depreciation of country $H$ 's currency against country $C O)^{48}$ and $\Gamma_{P M}^{H, C O}\left(h^{H}\right)$ are adjustment costs related to changes of the price of good $h^{H}$ in country $C O$. These costs are the analogs of (A.33):

$$
\Gamma_{P M, t}^{C O, H}\left(h^{H}\right) \equiv \frac{\phi_{P M}^{C O, H}}{2}\left(\pi_{t-1, t}^{C O} \frac{p_{t}^{C O}\left(h^{H}\right) / p_{t-1}^{C O}\left(h^{H}\right)}{\left(\Pi_{t-4, t}^{C O}\right)^{0.25}}-1\right)^{2}
$$

For the domestic prices of tradables $p^{H}\left(h^{H}\right)$ we still use (A.34) with $C O=H$, adopting the notational conventions $p_{M}^{H, H}=p_{Q}^{H}, M_{A}^{H, H}=Q_{A}^{H}$ and $M_{E}^{H, H}=Q_{E}^{H}$ as described in (A.12), and $\Gamma_{P M}^{H, H}=\Gamma_{P Q}^{H}$.

\footnotetext{
${ }^{47}$ This specification implies that the inflation target is known at any point in time. More generally, the adjustment cost could be specified relative to any variable that converges asymptotically to the steady-state inflation rate.

${ }^{48}$ All exchange rates are quoted in real terms, that is, in relative consumption units. Of course, $\varepsilon^{H, C O}=$ $1 / \varepsilon^{C O, H}$ and $\varepsilon^{H, H}=1$.
} 
Despite its fastidiousness, the notation above is straightforward and the equations are self-explanatory. Profit maximization yields:

$$
\begin{aligned}
& 0=\left(1-\Gamma_{P M, t}^{C O, H}\left(h^{H}\right)\right)\left[\varepsilon_{t}^{H, C O} p_{t}^{C O}\left(h^{H}\right)\left(1-\theta_{T, t}^{H}\right)+\theta_{T, t}^{H} m c_{t}^{H}\left(h^{H}\right)\right] \\
& -\left[\varepsilon_{t}^{H, C O} p_{t}^{C O}\left(h^{H}\right)-m c_{t}^{H}\left(h^{H}\right)\right] \frac{\partial \Gamma_{P M, t}^{C O, H}}{\partial p_{t}^{C O}\left(h^{H}\right)} p_{t}^{C O}\left(h^{H}\right)-\mathrm{E}_{t}\left\{D_{t, t+1}^{H} \pi_{t, t+1}^{H} g_{t, t+1}\right. \\
& \left.*\left[\varepsilon_{t+1}^{H, C O} p_{t+1}^{C O}\left(h^{H}\right)-m c_{t+1}^{H}\left(h^{H}\right)\right]\left(\frac{M_{A, t+1}^{C O, H}+M_{E, t+1}^{C O, H}}{M_{A, t}^{C O, H}+M_{E, t}^{C O, H}}\right) \frac{\partial \Gamma_{P M, t+1}^{C O, H}}{\partial p_{t}^{C O}\left(h^{H}\right)} p_{t}^{C O}\left(h^{H}\right)\right\}
\end{aligned}
$$

If adjustment costs in the export market are highly relevant (that is, if the $\phi_{P M}^{C O, H}$ coefficient is relatively large), the prices of country $H$ 's goods in the foreign markets are characterized by significant stickiness in local currency. In this case, the degree to which exchange rate (and other shocks to marginal costs in country $H$ ) pass-through onto import prices in country $C O$ is rather low. If instead the $\phi_{P M}^{C O, H}$ coefficients are zero worldwide, expression (A.36) collapses to a markup rule under the law of one price, and exchange rate pass-through is full:

$$
p_{t}^{H, H}\left(h^{H}\right)=p_{Q, t}^{H}=\varepsilon_{t}^{H, C O} p_{t}^{C O}\left(h^{H}\right)=\varepsilon_{t}^{H, C O} p_{M, t}^{C O, H}=\frac{\theta_{T, t}}{\theta_{T, t}-1} m c_{t}
$$

\section{Consumer preferences}

In each country there is a continuum of households indexed by $j \in[0, s]$, the same index of labor inputs. Some households have access to capital markets, some do not. The latter finance their consumption by relying exclusively on their labor incomes. We refer to the first type as 'Ricardian' or 'forward-looking'; they represent a share $\left(1-s_{L C}\right)$ of domestic households and are indexed by $j \in\left[0, s\left(1-s_{L C}\right)\right]$. We refer to the second type as 'nonRicardian' or 'liquidity-constrained'; they represent a share $s_{L C}$ of domestic households and are indexed by $j \in\left(s\left(1-s_{L C}\right), s\right]$.

The specification of households' preferences adopts the Greenwood, Hercowitz and Huffman (1988) (GHH) utility function, adjusted for habit formation and preference shocks. Denoting with $\mathcal{W}_{t}(j)$ the lifetime expected utility of household $j$, we have:

$$
\mathcal{W}_{t}(j) \equiv \mathrm{E}_{t} \sum_{\tau=t}^{\infty} \beta_{t, \tau} g_{t, \tau}^{1-\sigma} u_{\tau}\left(C_{\tau}(j), \ell_{\tau}(j)\right)
$$

where the instantaneous felicity is a function of detrended consumption $C$ and labor effort $\ell$ :

$$
\begin{aligned}
& u_{t}\left(C_{t}(j), \ell_{t}(j)\right)=Z_{U}\left(1-\frac{b_{c}}{g_{t-1, t}}\right)\left(\frac{1-b_{\ell}}{1-\sigma}\right) \\
& *\left[\frac{C_{t}(j)-b_{c} C_{j, t-1} / g_{t-1, t}}{1-b_{c} / g_{t-1, t}}-\frac{Z_{V}}{1+\zeta}\left(\frac{\ell_{t}(j)-b_{\ell} \ell_{j, \tau-1}}{1-b_{\ell}}\right)^{1+\zeta}\right]^{1-\sigma}
\end{aligned}
$$

In the expressions above $\beta_{t, \tau}$ is the discount rate between time $t$ and time $\tau$, possibly different across countries. As mentioned in Section 2, because of technological progress associated with home production activities (here related to the global trend), the term $g_{t, \tau}^{1-\sigma}$ in (A.38) implies that the disutility of labor effort increases with the common trend. ${ }^{49}$ The parameter $\sigma$ in (A.38) and (A.39) is the reciprocal of the elasticity of intertemporal

\footnotetext{
${ }^{49}$ The restriction $\beta_{t, \tau} g_{t, \tau}^{1-\sigma}<1$ is imposed to ensure that utility is bounded.
} 
substitution. The parameter $\zeta$ which affects the curvature of labor disutility is the reciprocal of the Frisch elasticity.

There is habit persistence in consumption with coefficient $0<b_{c}<1$. The term $C_{j, t-1}$ in (A.39) is past per-capita consumption of household $j$ 's peers, (i.e., either forward-looking or liquidity-constrained agents). Similarly, there is habit persistence in leisure with coefficient $0<b_{\ell}<1 .{ }^{50}$ The terms $Z_{U}$ and $Z_{V}$ are constants. Households' preferences are therefore symmetric within their respective categories but, because of different reference groups in habit formation, they are not symmetric across categories.

\section{Budget constraint (Ricardian households)}

The individual flow budget constraint for Ricardian agent $j \in\left[0,\left(1-s_{L C}\right) s\right]$ is:

$$
\begin{aligned}
& B_{t}(j)+\varepsilon_{t} B_{t}^{*}(j) \leq\left(1+i_{t-1}\right) \frac{B_{t-1}(j)}{\pi_{t-1, t} g_{t-1, t}}+\left(1+i_{t-1}^{*}\right)\left[1-\Gamma_{B, t-1}\right] \frac{\varepsilon_{t} B_{t-1}^{*}(j)}{\pi_{t-1, t}^{U S} g_{t-1, t}} \\
& +\left(1-\tau_{K, t}\right) r_{t} K_{t}(j)+\left(1-\tau_{L, t}\right) w_{t}(j) \ell_{t}(j)\left(1-\Gamma_{W, t}(j)\right) \\
& -C_{t}(j)-p_{E, t} I_{t}(j)+\Phi_{t}(j)-T T_{t}(j)
\end{aligned}
$$

Households hold two nominal bonds, denominated in domestic and US currency, respectively. ${ }^{51}$ In terms of our notation, $B_{t}(j)$ is (detrended) holdings of domestic bond by household $j$, expressed in terms of domestic consumption units, $B_{t}^{*}(j)$ is (detrended) holdings of the international bond, expressed in terms of US consumption units, and $\varepsilon_{t}$ is the CPI-based real exchange rate, expressed as the price of one US consumption basket in terms of domestic consumption. ${ }^{52}$

The short-term nominal rates $i_{t}$ and $i_{t}^{*}$ are paid at the beginning of period $t+1$ and are known at time $t$. The two rates are directly controlled by their respective national governments. Only the US-currency bond is traded internationally: the US bond is in zero net supply worldwide, while the domestic bond is issued by the local government. ${ }^{53}$ It follows that the net financial wealth of Ricardian household $j$ at time $t$ is:

$$
F_{t}(j) \equiv\left(1+i_{t-1}^{*}\right)\left[1-\Gamma_{B, t-1}\right] \frac{\varepsilon_{t} B_{t-1}^{*}(j)}{\pi_{t-1, t}^{U S} g_{t-1, t}}
$$

A financial friction $\Gamma_{B}$ is introduced to guarantee that international net asset positions follow a stationary process and the economies converge asymptotically to a well-defined steady state. ${ }^{54}$ Agents who take a position in the international bond market must deal with financial intermediaries who charge a transaction fee $\Gamma_{B}$ on sales/purchases of the

\footnotetext{
${ }^{50}$ The instantaneous felicity is normalized such that in a steady state $U, U_{C}$ and $U_{\ell}$ can all be written as constant $* f(C, \ell)$, where $f$ is some function of steady-state consumption and labor effort, independent of the habit persistence coefficients.

${ }^{51}$ The choice of currency denomination of the international bond is arbitrary. With a simple re-definition of the relevant variables one could think of $B^{*}$ in terms of any available currency, or basket of currencies.

${ }^{52}$ It is understood that $\varepsilon$ is shorthand for $\varepsilon^{H, U S}$, where $H$ denotes the country under consideration.

${ }^{53}$ If the country under consideration is the US, $\varepsilon=1$ and $i=i^{*}$.

${ }^{54}$ See Ghironi, İşcan, and Rebucci (2005) for an analysis of the steady-state distribution of net foreign assets with heterogeneous discounting.
} 
international bond. ${ }^{55}$ This transaction cost is a function of the average net asset position of the whole economy. Specifically, we adopt the following functional form:

$$
1-\Gamma_{B, t}=\left(1-\phi_{B 1} \frac{\exp \left(\phi_{B 2}\left[\varepsilon_{t} B_{t}^{*}-b_{F D E S, t}^{*} G D P_{t}\right]\right)-1}{\exp \left(\phi_{B 2}\left[\varepsilon_{t} B_{t}^{*}-b_{F D E S, t}^{*} G D P_{t}\right]\right)+1}-Z_{B, t}\right) \frac{\beta_{t}^{U S}}{\beta_{t}}
$$

where $0 \leq \phi_{B 1} \leq 1, \phi_{B 2}>0$, and $\varepsilon_{t} B^{*} \equiv(1 / s) \varepsilon_{t} \int_{0}^{s\left(1-s_{L C}\right)} B^{*}(j) d j$ represents the percapita net asset position of the country in consumption units. The term $b_{F D E S}^{*}$ is the 'desired' net asset position of the country expressed as a ratio of GDP. ${ }^{56}$ This variable measures the degree of international exposure that financial intermediaries consider appropriate for the economy, based on their assessment of the economic outlook.

To understand the role played by $\Gamma_{B}$, suppose first that $b_{F D E S}^{*}=Z_{B}=0$ and $\beta^{U S}=\beta$. In this case, when the net asset position of the country is equal to its 'desired' level of zero, it must be the case that $\Gamma_{B}=0$ and the return on the international bond is equal to $1+i^{*}$. If the country is a net creditor worldwide $\Gamma_{B}$ rises above zero, implying that the country's households lose an increasing fraction of their international bond returns to financial intermediaries. When holdings of the international bond go to infinity, the return on the international bond approaches $\left(1+i^{*}\right)\left(1-\phi_{B 1}\right)$. By the same token, if the country is a net debtor worldwide $\Gamma_{B}$ falls from zero to $-\phi_{B 1}$, implying that households pay an increasing intermediation premium on their international debt. When net borrowing goes to infinity, the cost of borrowing approaches $\left(1+i^{*}\right)\left(1+\phi_{B 1}\right)$. The parameter $\phi_{B 2}$ controls the flatness of the $\Gamma_{B}$ function: if $\phi_{B 2}=0$ then $\Gamma_{B}=0$ regardless of the net asset position; if $\phi_{B 2}$ tends to infinity then $1-\Gamma_{B}=\left(1-\phi_{B 1}\right)$ for any arbitrarily small net lending position, and $1-\Gamma_{B}=\left(1+\phi_{B 1}\right)$ for any arbitrarily small net borrowing position. An appropriate parameterization allows the model to generate realistic dynamics for net asset positions and current account.

Consider now the other components of (A.42). The variable $Z_{B, t}$ is a stochastic autoregressive process: ${ }^{57}$ in our framework uncertainty in international financial intermediation plays the same role that 'uncovered interest parity shocks' or risk-premium fluctuations play in other open-economy models. Finally, when rates of time preference diverge across countries and $\beta^{*} \neq \beta$, the transaction cost is appropriately modified to account for asymmetries in real interest rates across countries.

The term $b_{F D E S}^{*}$ can be positive or negative. The above considerations are still valid after reinterpreting the concepts of 'net creditor' or 'net borrower' in terms of deviations from the desired levels. The desired net asset position in country $H$ is characterized as follows:

$$
b_{F D E S, t}^{* H}=b_{F N E U T}^{* H}-\phi_{F 1}^{H} \frac{B_{t}^{H}}{G D P_{t}^{H}}+\sum_{C O \neq H} \phi_{F 2}^{C O, H} \frac{B_{t}^{C O}}{G D P_{t}^{C O}}
$$

According to the previous expression, $b_{F D E S}^{* H}$ is a country-specific constant, $b_{F N E U T}^{* H}$, adjusted to account for changes in the debt-to-GDP ratios in either the domestic economy

\footnotetext{
${ }^{55}$ In our model it is assumed that all intermediation firms are owned by the country's residents, and that their revenue is rebated to domestic households in a lump-sum fashion. A simple variant of the model in which intermediation firms are owned by foreign residents leaves the basic results virtually unchanged. There are no intermediation costs for US residents entering the international bond market, that is, there is no difference between onshore and offshore US interest rates.

${ }^{56}$ The concept of GDP in our model will be discussed below with reference to (A.83).

${ }^{57}$ Fluctuations in $Z_{B}$ cannot be large enough to push $\Gamma_{B}$ above 1.
} 
$\left(B^{H} / G D P^{H}\right)$ or the rest of the world $\left(B^{C O} / G D P^{C O}\right)$.

This specification provides a plausible link between debt imbalances and net asset positions. If the targeted debt-to-GDP ratio increased in the US, investors in the rest of the world would require a higher return on US securities, leading to a higher share of US assets in their portfolios or a reduction of net borrowing from the US. If however the target debt increased in the home country as well, the US premium would fall somewhat. Of course, our approach should be viewed only as a crude approximation to the actual determinants of cross-country spreads and interest rate premia in response to macroeconomic imbalances, whose endogenization should be eventually incorporated in a self-contained model. It remains unclear, however, whether a framework that incorporates a large amount of complications from which we abstract here would add much to our qualitative conclusions. Quantitatively, one could take $b_{F D E S}^{*}$ as a free variable and estimate the $\phi_{F 1}$ and $\phi_{F 2}$ parameters on the basis of empirical evidence on the link between net asset positions and debt levels. Alternatively, one could rely on cross-fertilization with respect to alternative theoretical models able to shed light on the structural determinants of these parameters, as mentioned in Section 5.2.2.

Households accumulate physical capital which they rent to domestic firms at the after-tax rate $r\left(1-\tau_{K}\right)$. The law of motion of capital is:

$$
K_{t+1}(j) g_{t, t+1}=(1-\delta) K_{t}(j)+\Gamma_{I, t} K_{t}(j) \quad 0<\delta \leq 1
$$

where $\delta$ is the country-specific depreciation rate of capital. To simulate realistic investment flows, capital accumulation is subject to adjustment costs. Capital accumulation is denoted $\Gamma_{I, t} K_{t}(j)$, where $\Gamma_{I}($.$) is an increasing, concave, and twice-continuously differentiable func-$ tion of the investment/capital ratio $I_{t}(j) / K_{t}(j)$ with two properties entailing no adjustment costs in steady state: $\Gamma_{I}(\delta+g-1)=\delta+g-1$ and $\Gamma_{I}^{\prime}(\delta+g-1)=1$. The specific functional form we adopt is quadratic and encompasses inertia in investment:

$$
\Gamma_{I, t}(j) \equiv \frac{I_{t}(j)}{K_{t}(j)}-\frac{\phi_{I 1}}{2}\left(\frac{I_{t}(j)}{K_{t}(j)}-(\delta+g-1)\right)^{2}-\frac{\phi_{I 2}}{2}\left(\frac{I_{t}(j)}{K_{t}(j)}-\frac{I_{t-1}}{K_{t-1}}\right)^{2}
$$

where $\phi_{I 1}, \phi_{I 2} \geq 0$, and $g$ is the steady-state growth rate.

Each household $j$ is the monopolistic supplier of a specific labor input and sets the nominal wage for its labor variety $j$ accounting for (A.29). Labor incomes are taxed at the rate $\tau_{L}$. There is sluggish wage adjustment due to resource costs that are measured in terms of the total wage bill. The adjustment cost is denoted $\Gamma_{W F L, t}$ (for Wage Forward-Looking) and its specification is the analog of (A.33) above, recalling that the real wage is expressed in detrended terms:

$$
\Gamma_{W F L, t}(j) \equiv \frac{\phi_{W F L}}{2}\left(\pi_{t-1, t} g_{t-1, t} \frac{w_{t}(j) / w_{t-1}(j)}{\Pi_{t-4, t}^{0.25} g_{t-1, t}}-1\right)^{2}
$$

Ricardian households own all domestic firms and there is no international trade in claims on firms' profits. The variable $\Phi$ includes all dividends accruing to shareholders, plus all revenue from nominal and real adjustment rebated in a lump-sum way to all Ricardian households, plus revenue from financial intermediation which is assumed to be provided by domestic firms exclusively.

Finally, agents pay lump-sum (non-distortionary) net taxes $T T_{t}(j)$ denominated in consumption units. 


\section{Consumer optimization (Ricardian households)}

The representative Ricardian household chooses bond holdings, capital and consumption paths, and sets wages to maximize its expected lifetime utility (A.38) subject to (A.40) and (A.44), taking into account (A.29).

For expositional convenience, it is worthwhile to write explicitly the maximization problem of agent $j \in\left[0,\left(1-s_{L C}\right) s\right]$ in terms of the following Lagrangian:

$$
\begin{aligned}
& \max _{\left\{C_{\tau}(j), I_{\tau}(j), B_{\tau}(j), B_{\tau}^{*}(j), K_{\tau+1}(j), w_{\tau}(j)\right\}_{\tau=t}^{\infty}} \mathrm{E}_{t} \beta_{t, \tau} g_{t, \tau}^{1-\sigma}\left\{u\left(C_{\tau}(j), w_{\tau}^{-\psi_{\tau}}(j) w_{\tau}^{\psi_{\tau}} \ell_{\tau}, \quad\right)\right. \\
& +\mu_{\tau}(j)\left(-B_{\tau}(j)-\varepsilon_{\tau} B_{\tau}^{*}(j)+\frac{\left(1+i_{\tau-1}\right) B_{\tau-1}(j)}{\pi_{\tau-1, \tau} g_{\tau-1, \tau}}+\frac{\left(1+i_{\tau-1}^{*}\right)\left(1-\Gamma_{B, \tau-1}\right) \varepsilon_{\tau} B_{\tau-1}^{*}(j)}{\pi_{\tau-1, \tau}^{U S} g_{\tau-1, t}}\right. \\
& +\left(1-\tau_{K, \tau}\right) r_{\tau} K_{\tau}(j)+\left(1-\tau_{L, \tau}\right) w_{\tau}(j)^{1-\psi_{\tau}} w_{\tau}^{\psi_{\tau}} \ell_{\tau}\left(1-\Gamma_{W, \tau}\left[w_{\tau}(j), w_{\tau-1}(j)\right]\right) \\
& \left.-C_{\tau}(j)-p_{E, \tau} I_{\tau}(j)+\Phi_{\tau}(j)-T T_{\tau}(j)\right) \\
& \left.+\lambda_{\tau}(j)\left(-K_{\tau+1}(j) g_{\tau, \tau+1}+(1-\delta) K_{\tau}(j)+\Gamma_{I, \tau}\left[I_{\tau}(j) / K_{\tau}(j)\right] K_{\tau}(j)\right)\right\}
\end{aligned}
$$

where $\mu$ and $\lambda$ are the multipliers associated with, respectively, the budget constraint and capital accumulation.

The first order conditions with respect to $C_{t}(j)$ and $I_{t}(j)$ yield:

$$
\mu_{t}(j)=\partial u_{t}(j) / \partial C_{t}(j)=\lambda_{t}(j) \Gamma_{I, t}^{\prime}(j) / p_{E, t}
$$

In a symmetric setup, $\partial u_{t}(j) / \partial C_{t}(j)$ is the same across Ricardian agents $j$. Their stochastic discount rate and pricing kernel is therefore the variable $D_{t, \tau}$, which is defined as:

$$
D_{t, \tau} \equiv \beta_{t, \tau} g_{t, \tau}^{1-\sigma} \frac{\mu_{\tau}}{\mu_{t}} \frac{1}{\pi_{t, \tau}} \frac{1}{g_{t, \tau}}
$$

Accounting for the above expressions, the first order conditions with respect to $B_{t}(j)$ and $B_{t}^{*}(j)$ are, respectively:

$$
\begin{aligned}
& 1=\left(1+i_{t}\right) \mathrm{E}_{t} D_{t, t+1} \\
& 1=\left(1+i_{t}^{*}\right)\left(1-\Gamma_{B, t}\right) \mathrm{E}_{t}\left(D_{t, t+1} \Delta_{t, t+1}\right)
\end{aligned}
$$

where $\Delta$ denotes the rate of nominal exchange rate depreciation against the US, or:

$$
\Delta_{t, \tau}=\frac{\varepsilon_{\tau}}{\varepsilon_{t}} \frac{\pi_{t, \tau}}{\pi_{t, t}^{*}}
$$

In a non-stochastic steady state (A.49) implies $(1+i) / \pi=g^{\sigma} / \beta$, where $\pi$ is the (gross steady-state quarterly) inflation rate, $(1+i) / \pi$ is the real interest rate, $g$ is the (gross steady-state quarterly) rate of growth of the world economy, $1 / \beta$ is the rate of time preference, and $g^{\sigma} / \beta$ is the 'natural' rate of the economy. ${ }^{58}$ Expressions (A.49) and (A.50) yield the risk-adjusted uncovered interest parity, recalling that the return on international bond holdings is modified to account for the costs of intermediation $\Gamma_{B}$. In a non-stochastic steady state the interest differential $(1+i) /\left[\left(1+i^{*}\right)\left(1-\Gamma_{B}\right)\right]$ is equal to the steady-state nominal depreciation rate of the currency vis-a-vis the US, and relative purchasing power parity holds.

\footnotetext{
${ }^{58}$ International differences in natural rates can arise from asymmetric rates of time preference. They are accounted for in the definition of $\Gamma_{B}$ in (A.42)
} 
The first order condition with respect to $K_{t+1}(j)$ is:

$$
\begin{aligned}
& \frac{p_{E, t}}{\Gamma_{I, t}^{\prime}(j)} \mathrm{E}_{t} g_{t, t+1}=\mathrm{E}_{t}\left\{D _ { t , t + 1 } \pi _ { t , t + 1 } g _ { t , t + 1 } \left(\left(1-\tau_{K, t+1}\right) r_{t+1}\right.\right. \\
& \left.\left.+\frac{p_{E, t+1}}{\Gamma_{I, t+1}^{\prime}(j)}\left[1-\delta+\Gamma_{I, t+1}(j)-\Gamma_{I, t+1}^{\prime}(j) \frac{I_{t+1}(j)}{K_{t+1}(j)}\right]\right)\right\}
\end{aligned}
$$

Expression (A.52) links capital accumulation to the behavior of the after-tax price of capital $\left(1-\tau_{K}\right) r$. In a non-stochastic steady state $1+\left(1-\tau_{K}\right) r / p_{E}$ is equal to the sum of the natural real rate $g^{\sigma} / \beta$ and the rate of capital depreciation $\delta .{ }^{59}$

Finally, the first order condition with respect to $w(j)$ determines wage dynamics for the wages of the Ricardian households:

$$
\begin{aligned}
& -\psi_{t} \frac{u_{\ell, t}(j)}{u_{C, t}(j)} \frac{1}{w_{t}(j)}=\left(\psi_{t}-1\right)\left[1-\Gamma_{W F L, t}(j)\right]\left(1-\tau_{L, t}\right)+\frac{\partial \Gamma_{W F L, t}(j)}{\partial w_{t}(j)} w_{t}(j)\left(1-\tau_{L, t}\right) \\
& +\mathrm{E}_{t} D_{t, t+1} \pi_{t, t+1} g_{t, t+1} \frac{\left(w_{t+1}(j) / w_{t+1}\right)^{-\psi_{t+1}}}{\left(w_{t}(j) / w_{t}\right)^{-\psi_{t}}} \frac{w_{t+1}(j)}{w_{t}(j)} \frac{\ell_{t+1}}{\ell_{t}} \frac{\partial \Gamma_{W F L, t+1}(j)}{\partial w_{t}(j)} w_{t}(j)\left(1-\tau_{L, t+1}\right)
\end{aligned}
$$

Different from (A.31) above, in expression (A.53) it is no longer true that the wage rate of the Ricardian household $w(j)$ is equal to the average wage rate in the economy $w$. In a non-stochastic steady state the real wage $w(j)$ is equal to the marginal rate of substitution between consumption and leisure, $-u_{\ell} / u_{c}$, augmented by the markup $\psi /(\psi-1)$ which reflects monopoly power in the labor market.

\section{Consumer optimization (liquidity-constrained households)}

Liquidity-constrained households have no access to capital markets. Their optimal choices are confined to labor supply. Similar to Ricardian households, they can optimally set their wages to exploit their market power. The maximization problem of agent $j \in\left(\left(1-s_{L C}\right) s, s\right]$ can be written in terms of the following static Lagrangian:

$$
\begin{aligned}
& \max _{C_{t}(j), w_{t}(j)} u_{t}\left(C_{t}(j), \ell_{t}(j)\right)+\mu_{t}(j)\left(-C_{t}(j)-T T_{t}(j)\right. \\
& \left.\quad+\left(1-\tau_{L, t}\right) w_{t}(j)^{1-\psi_{t}} w_{t}^{\psi_{t}} \ell_{t}\left(1-\Gamma_{W L C, t}\left[w_{t}(j), w_{t-1}(j)\right]\right)\right)
\end{aligned}
$$

It is assumed that redistributive policies rebate to these households the income losses associated with wage adjustment, so that their consumption level is:

$$
C_{t}(j)=\left(1-\tau_{L, t}\right) w_{t}(j) \ell_{t}(j)
$$

The first order conditions with respect to $C(j)$ and $w(j)$ determines partial adjustment of wages:

$$
-\psi_{t} \frac{u_{\ell, t}(j)}{u_{C, t}(j)} \frac{1}{w_{t}(j)}=\left(1-\tau_{L, t}\right)\left[\left(\psi_{t}-1\right)\left(1-\Gamma_{W L C, t}(j)\right)+\frac{\partial \Gamma_{W L C, t}(j)}{\partial w_{t}(j)} w_{t}(j)\right]
$$

Denoting $w_{F L}$ the wage rate $w(j)$ that solves (A.53), and $w_{L C}$ the wage rate $w(j)$ that solves (A.56), equation (A.27) determines the wage rate for the whole economy as:

$$
w_{t}^{1-\psi_{t}}=s_{L C} w_{L C, t}^{1-\psi_{t}}+\left(1-s_{L C}\right) w_{F L, t}^{1-\psi_{t}}
$$

\footnotetext{
${ }^{59}$ The expectation operator on the left hand side of (A.52) is needed as shocks to the trend $g_{t, t+1}$ are not part of the information set at time $t$. This is because variables are expressed as deviations from the current trend. An alternative specification which expresses variables as deviations from the lagged trend would make little difference.
} 


\section{Government}

Public spending falls on nontradable goods, both final and intermediate. In per-capita terms, $G_{C}$ is government consumption, $G_{I}$ is government investment, and $G_{N}$ denotes public purchases of intermediate nontradables. There are three sources of (net) tax revenue: taxes on capital income $\tau_{K}$, taxes on labor income $\tau_{L}$, and lump-sum taxes $T T$ net of transfers to households. The government finances the excess of public expenditure over net taxes by issuing debt denominated in nominal currency, denoted $B$ in per-capita terms. All national debt is held exclusively by domestic (Ricardian) agents. The budget constraint of the government is:

$$
B_{t} \geq\left(1+i_{t-1}\right) \frac{B_{t-1}}{\pi_{t-1, t} g_{t-1, t}}+G_{t}-G_{R E V, t}
$$

where:

$$
G_{t}=G_{C, t}+p_{E, t} G_{I, t}+p_{N, t} G_{N, t}
$$

and:

$$
G_{R E V, t}=\frac{1}{s}\left(\int_{0}^{s} T T_{t}(j) d j+\tau_{K, t} r_{t} \int_{0}^{s\left(1-s_{L C}\right)} K_{t}(j) d j+\tau_{L, t} \int_{0}^{s} w_{t}(j) \ell_{t}(j) d j\right)
$$

Define now the average tax rate for the economy $\tau$ as:

$$
\tau_{t} \equiv G_{R E V, t} / G D P_{t}
$$

Similarly, define the deficit-to-GDP ratio as:

$$
\frac{D E F_{t}}{G D P_{t}}=\left(B_{t}-\frac{B_{t-1}}{\pi_{t-1, t} g_{t-1, t}}\right) / G D P_{t}
$$

From (A.58), in steady state we have:

$$
\frac{B}{G D P}=\frac{\pi g}{\pi g-(1+i)}\left(\frac{G}{G D P}-\tau\right)=\frac{\pi g}{\pi g-1} \frac{D E F}{G D P}
$$

The previous equations define the relations between debt-to-GDP, average tax rate, and deficit-to-GDP ratio which are sustainable in the long term. In what follows we treat the long-run debt-to-GDP ratio as a policy parameter set by the government, and let $\tau$ and $D E F / G D P$ be determined by (A.63).

The government is assumed to control lump-sum taxes, $\tau$ and $\tau_{K}$ directly, while $\tau_{L}$ is endogenously determined. The fiscal rule for $\tau$ is specified as:

$$
\begin{aligned}
& \tau_{t}=\left(\tau_{t-1}+\tau_{t}+\mathrm{E}_{t} \tau_{t+1}\right) / 3+\phi_{T A X 1}\left(\frac{B_{t}}{G D P_{t}}-\phi_{T A X 2} B_{T A R, t}-\left(1-\phi_{T A X 2}\right) \frac{B_{t-1}}{G D P_{t-1}}\right) \\
& +\phi_{T A X 3}\left(\frac{D E F_{t}}{G D P_{t}}-\frac{D E F}{G D P}\right)+\phi_{T A X 4}\left(\frac{G_{t}}{G D P_{t}}-\frac{G}{G D P}\right)
\end{aligned}
$$

where $B_{T A R}$ is an autoregressive process for the targeted debt-to-GDP ratio. The tax rate is a smoothed function of past and expected future rates, adjusted upward when the current debt-to-GDP ratio is above the average of its current target and its past observed level, when the current deficit-to-GDP ratio is above its sustainable steady-state level, and when current government spending as a share of GDP is above its long-run level.

The government controls the short-term rate $i_{t}$. Monetary policy is specified in terms of annualized interest rate rules of the form:

$$
\left(1+i_{t}\right)^{4}=\omega_{i}\left(1+i_{t-1}\right)^{4}+\left(1-\omega_{i}\right)\left(1+i_{t}^{\text {neut }}\right)^{4}+\omega_{1} \mathrm{E}_{t}\left(\pi_{t-1, t+3}-\Pi_{t-1, t+3}\right)
$$


The current interest rate $i_{t}$ is an average of the lagged rate $i_{t-1}$ and the current 'neutral' rate $i_{t}^{\text {neut }}$, defined as: ${ }^{60}$

$$
1+i_{t}^{\text {neut }} \equiv \frac{\Pi_{t-4, t}^{0.25}\left(g_{t-1, t}\right)^{\sigma}}{\beta_{t-1, t}}
$$

This average is adjusted to account for the expected inflation gap three quarters in the future. ${ }^{61}$ The rule (A.65) could be modified to include policy responses to a set of other variables (such as exchange rate or current account ) expressed as deviations from their targets. In a steady state when all constant targets are reached it must be the case that:

$$
1+i=1+i^{\text {neut }}=\frac{\Pi^{0.25} g^{\sigma}}{\beta}=\frac{\pi g^{\sigma}}{\beta} .
$$

\section{Market clearing}

The model is closed by imposing the following resource constraints and market clearing conditions, adopting explicit country indexes.

For each country $H$, the domestic resource constraints for capital and labor are, respectively:

$$
\int_{0}^{s^{H}\left(1-s_{L C}^{H}\right)} K_{t}^{H}\left(j^{H}\right) d j^{H} \geq \int_{0}^{s^{H}} K_{t}^{H}\left(n^{H}\right) d n^{H}+\int_{0}^{s^{H}} K_{t}^{H}\left(h^{H}\right) d h^{H}
$$

and:

$$
\ell_{t}^{H}\left(j^{H}\right) \geq \int_{0}^{s^{H}} \ell_{t}^{H}\left(n^{H}, j^{H}\right) d n^{H}+\int_{0}^{s^{H}} \ell_{t}^{H}\left(h^{H}, j^{H}\right) d h^{H}
$$

The resource constraint for the nontradable $\operatorname{good} n^{H}$ is:

$$
N_{t}^{H}\left(n^{H}\right) \geq \int_{0}^{s^{H}} N_{A, t}^{H}\left(n^{H}, x^{H}\right) d x^{H}+\int_{0}^{s^{H}} N_{E, t}^{H}\left(n^{H}, e^{H}\right) d e^{H}+G_{N, t}^{H}\left(n^{H}\right)
$$

while the tradable $h^{H}$ can be used by domestic firms or imported by foreign firms:

$$
\begin{aligned}
& T_{t}\left(h^{H}\right) \geq \int_{0}^{s^{H}} Q_{A, t}\left(h^{H}, x^{H}\right) d x^{H}+\int_{0}^{s^{H}} Q_{E, t}\left(h^{H}, e^{H}\right) d e^{H} \\
& +\sum_{C O \neq H}\left(\int_{0}^{s^{C O}} M_{A, t}^{C O, H}\left(h^{H}, x^{C O}\right) d x^{C O}+\int_{0}^{s^{C O}} M_{E, t}^{C O, H}\left(h^{H}, e^{C O}\right) d e^{C O}\right)
\end{aligned}
$$

The final good $A$ can be used for private (by both liquidity-constrained and forwardlooking households) or public consumption:

$$
\int_{0}^{s^{H}} A_{t}^{H}\left(x^{H}\right) d x^{H} \geq \int_{0}^{s^{H}\left(1-s_{L C}^{H}\right)} C^{H}\left(j^{H}\right) d j^{H}+\int_{s^{H}\left(1-s_{L C}^{H}\right)}^{s^{H}} C^{H}\left(j^{H}\right) d j^{H}+s G_{C, t}
$$

and similarly for the investment good $E$ :

$$
\int_{0}^{s^{H}} E_{t}^{H}\left(e^{H}\right) d e^{H} \geq \int_{0}^{\left(1-s_{L C}^{H}\right) s^{H}} I_{t}^{H}\left(j^{H}\right) d j^{H}+s^{H} G_{I, t}^{H}
$$

\footnotetext{
${ }^{60}$ Recall that $\Pi_{t-\tau, t-\tau+4}$ is the year-on-year gross CPI inflation target prevailing at time $t$ for the fourquarter period between $t-\tau$ and $t-\tau+4$.

${ }^{61}$ In the case of AS, we model an exchange rate targeting regime by introducing the component $\omega_{2}^{A S} \Delta_{t}^{A S}$ in (A.65), where $\Delta^{A S}$ is defined in (A.51) and we choose a very high value of $\omega_{2}^{A S}$ to peg the nominal bilateral exchange rate against the US.
} 
All profits and intermediation revenue accrue to Ricardian households:

$$
\begin{aligned}
& \int_{0}^{s^{H}\left(1-s_{L C}^{H}\right)} \Phi_{t}^{H}\left(j^{H}\right) d j^{H}=\int_{0}^{s^{H}\left(1-s_{L C}^{H}\right)}\left(1+i_{t-1}^{*}\right) \Gamma_{B, t-1}^{H} \frac{\varepsilon_{t}^{H, U S} B_{t-1}^{* H}\left(j^{H}\right)}{\pi_{t-1, t}^{U S} g_{t-1, t}} d j^{H} \\
& +\int_{0}^{s^{H}\left(1-s_{L C}^{H}\right)} \Gamma_{W F L, t}^{H}\left(j^{H}\right)\left(1-\tau_{L, t}^{H}\right) w_{t}^{H}\left(j^{H}\right) d j^{H}+\int_{s^{H}\left(1-s_{L C}^{H}\right)}^{s^{H}} \Gamma_{W L C, t}^{H}\left(j^{H}\right)\left(1-\tau_{L, t}^{H}\right) w_{t}^{H}\left(j^{H}\right) d j^{H} \\
& +\int_{0}^{s^{H}}\left[p_{t}^{H}\left(n^{H}\right)-m c_{t}^{H}\left(n^{H}\right)\right]\left(\int_{0}^{s^{H}} N_{A, t}^{H}\left(n^{H}, x^{H}\right) d x^{H}+\int_{0}^{s^{H}} N_{E, t}^{H}\left(n^{H}, e^{H}\right) d e^{H}+G_{N, t}^{H}\left(n^{H}\right)\right) d n^{H} \\
& +\int_{0}^{s^{H}}\left[p_{t}^{H}\left(h^{H}\right)-m c_{t}^{H}\left(h^{H}\right)\right]\left(\int_{0}^{s^{H}} Q_{A, t}^{H}\left(h^{H}, x^{H}\right) d x^{H}+\int_{0}^{s^{H}} Q_{E, t}^{H}\left(h^{H}, e^{H}\right) d e^{H}\right) d h^{H} \\
& +\sum_{C O \neq H} \int_{0}^{s^{H}}\left[\varepsilon_{\tau}^{H, C O} p_{\tau}^{C O}\left(h^{H}\right)-m c_{\tau}^{H}\left(h^{H}\right)\right] \\
& *\left(\int_{0}^{s^{C O}} M_{A, t}^{C O, H}\left(h^{H}, x^{C O}\right) d x^{C O}+\int_{0}^{s^{C O}} M_{E, t}^{C O, H}\left(h^{H}, e^{C O}\right) d e^{C O}\right) d h^{H}
\end{aligned}
$$

Market clearing in the asset market requires:

$$
\int_{0}^{s^{H}\left(1-s_{L C}^{H}\right)} B_{t}^{H}\left(j^{H}\right) d j^{H}=s^{H} B_{t}^{H}
$$

for the four government bond markets, and:

$$
\sum_{C O} \int_{0}^{s^{C O}\left(1-s_{L C}^{C O}\right)} B_{t}^{* C O}\left(j^{C O}\right) d j^{C O}=0
$$

for the international bond market. Finally, aggregating the budget constraints across private and public agents after imposing the appropriate transversality conditions we obtain the law of motion for financial wealth:

$$
\begin{aligned}
& \mathrm{E}_{t} D_{t, t+1}^{H} \pi_{t, t+1}^{H} g_{t, t+1} F_{t+1}^{H}=F_{t}^{H}+\Gamma_{B, t-1}^{H} \frac{\left(1+i_{t-1}^{*}\right) \varepsilon_{t}^{H, U S} B_{t-1}^{* H}}{\pi_{t-1, t}^{U S} g_{t-1, t}} \\
& +p_{N, t}^{H} N_{t}^{H}+p_{T, t}^{H} T_{t}^{H}-C_{t}^{H}-p_{E, t}^{H} I_{t}^{H}-G_{t}^{H}
\end{aligned}
$$

where the total value of tradables is defined as:

$$
p_{T, t}^{H} T_{t}^{H} \equiv p_{Q, t}^{H}\left(Q_{A, t}^{H}+Q_{E, t}^{H}\right)+\sum_{C O \neq H} \frac{s^{C O}}{s^{H}} \varepsilon^{H, C O} p_{M, t}^{C O, H}\left(M_{A, t}^{C O, H}+M_{E, t}^{C O, H}\right)
$$

\section{Measuring output and current account}

Expression (A.78) can be written as:

$$
C U R B A L_{t}^{H}=\varepsilon_{t}^{H, U S}\left(B_{t}^{* H}-\frac{B_{t-1}^{* H}}{\pi_{t-1, t}^{U S} g_{t-1, t}}\right)=\frac{i_{t-1}^{*} \varepsilon_{t}^{H, U S} B_{t-1}^{* H}}{\pi_{t-1, t}^{U S} g_{t-1, t}}+T B A L_{t}
$$

The left hand side of (A.79) is country $H$ 's current account, the first term on the right hand side are net factor payments from the rest of the world to country $H$ and $T B A L$ is the trade balance. The latter can be thought of as:

$$
T B A L_{t}^{H}=E X_{t}^{H}-I M_{t}^{H}
$$


where total exports $E X$ are:

$$
E X_{t}^{H}=p_{T, t}^{H} T_{t}^{H}-p_{Q, t}^{H}\left(Q_{A, t}^{H}+Q_{E, t}^{H}\right)
$$

and total imports $I M$ are:

$$
\begin{aligned}
& I M_{t}^{H}=p_{M A, t} M_{A, t}^{H}+p_{M E, t} M_{E, t}^{H} \\
& =\sum_{C O \neq H} p_{M, t}^{H, C O}\left(M_{A, t}^{H, C O} \frac{1-\Gamma_{M A, t}^{H, C O}}{1-\Gamma_{M A, t}^{H, C O}-M_{A, t}^{H, C O} \Gamma_{M A, t}^{H, C O}}+M_{E, t}^{H, C O} \frac{1-\Gamma_{M E, t}^{H, C O}}{1-\Gamma_{M E, t}^{H, C O}-M_{E, t}^{H, C O} \Gamma_{M E, t}^{H, C O}}\right)
\end{aligned}
$$

The adjustment terms in the previous equation reflects the fact that it takes time for imports to be fully productive in production, so that their effective costs are higher from the viewpoint of national producers and consumers of final goods than at the border level.

Finally, we define the model-based Gross Domestic Product (in consumption units) as:

$$
G D P_{t}^{H}=A_{t}^{H}+p_{E, t}^{H} E_{t}^{H}+p_{N, t}^{H} G_{N, t}^{H}+E X_{t}^{H}-I M_{t}^{H}=p_{N, t}^{H} N_{t}^{H}+p_{T, t}^{H} T_{t}^{H}
$$

so that:

$C U R B A L_{t}^{H}=T B A L_{t}^{H}+\frac{i_{t-1}^{*} \varepsilon_{t}^{H, U S} B_{t-1}^{* H}}{\pi_{t-1, t}^{U S} g_{t-1, t}}=G D P_{t}^{H}-\left(C_{t}^{H}+p_{E, t}^{H} I_{t}^{H}+G_{t}^{H}\right)+\frac{i_{t-1}^{*} \varepsilon_{t}^{H, U S} B_{t-1}^{* H}}{\pi_{t-1, t}^{U S} g_{t-1, t}}$

While theoretically sound, this measure of output would bear little similarity with standard fixed-weight, constant-dollar measures of real GDP provided by national accounts. The problem is particularly severe for relatively open economies facing large swings in real exchange rates and relative prices. In our simulations, we therefore adopt 'national accounts' concepts for $G D P, T B A L$ and their components, evaluating constant-dollar expenditures at any time $t$ by using fixed steady-state prices instead of the corresponding relative prices at time $t$. 
Table 1: Baseline Parameterization of the Regional Blocs

\begin{tabular}{lllll}
\hline Parameter & US & AS & JE & RC \\
\hline \hline Rate of time preference $\left(1 / \beta^{4}-1\right) * 100$ & 3.2 & 2.6 & 2.7 & 2.7 \\
Depreciation rate $\delta$ & 0.020 & 0.020 & 0.020 & 0.020 \\
Intertemporal elasticity of substitution $1 / \sigma$ & 5.00 & 5.00 & 5.00 & 5.00 \\
Habit persistence in consumption $b_{c}$ & 0.91 & 0.91 & 0.91 & 0.91 \\
Inverse of the Frisch elasticity of labor $\varsigma$ & 2.50 & 2.50 & 2.50 & 2.50 \\
Habit persistence in labor $b_{\ell}$ & 0.75 & 0.75 & 0.75 & 0.75 \\
\hline Tradable Intermediate Goods & & & & \\
Substitution between factors of production $\xi_{T}$ & 0.75 & 0.75 & 0.75 & 0.75 \\
Bias towards capital $\alpha_{T}$ & 0.67 & 0.72 & 0.76 & 0.67 \\
\hline Nontradable Intermediate Goods & & & & \\
Substitution between factors of production $\xi_{N}$ & 0.75 & 0.75 & 0.75 & 0.75 \\
Bias towards capital $\alpha_{N}$ & 0.62 & 0.66 & 0.71 & 0.62 \\
\hline Final Consumption Goods & & & & \\
Substitution between domestic and imported goods $\mu_{A}$ & 2.5 & 2.5 & 2.5 & 2.5 \\
Bias towards domestic goods $\nu_{A}$ & 0.96 & 0.07 & 0.39 & 0.15 \\
Substitution between domestic tradables and nontradables $\varepsilon_{A}$ & 0.5 & 0.5 & 0.5 & 0.5 \\
Bias towards tradable goods $\gamma_{A}$ & 0.35 & 0.37 & 0.37 & 0.32 \\
\hline Final Investment Goods & & & & \\
Substitution between domestic and imported goods $\mu_{E}$ & 2.5 & 2.5 & 2.5 & 2.5 \\
Bias towards domestic goods $\nu_{E}$ & 0.98 & 0.05 & 0.78 & 0.17 \\
Substitution between domestic tradables and nontradables $\varepsilon_{E}$ & 0.5 & 0.5 & 0.5 & 0.5 \\
Bias towards tradable goods $\gamma_{E}$ & 0.77 & 0.82 & 0.80 & 0.76 \\
\hline
\end{tabular}

Table 2: Steady-State National Accounts Decomposition in the Baseline Scenario

\begin{tabular}{lllll}
\hline Ratio of GDP & US & AS & JE & RC \\
\hline \hline Total Consumption & 79.6 & 69.7 & 76.8 & 77.5 \\
Private $C$ & 67.1 & 58.7 & 56.5 & 63.5 \\
Liquidity-constrained consumers $C_{L C}$ & 5.1 & 9.9 & 3.0 & 4.4 \\
Forward-looking consumers $C_{F L}$ & 62.1 & 48.8 & 53.5 & 59.1 \\
Public $G_{C}+P_{N} G_{N}$ & 12.5 & 11.0 & 20.5 & 14.3 \\
Total Investment $P_{E} E$ & 19.7 & 29.6 & 23.3 & 22.9 \\
Private $P_{E} I$ & 17.2 & 27.6 & 20.2 & 20.4 \\
Public $P_{E} G_{I}$ & 2.5 & 2.0 & 3.0 & 2.5 \\
Trade balance $T B A L$ & 0.7 & -0.3 & -0.2 & -0.3 \\
Imports $I M$ & 12.1 & 26.2 & 15.8 & 24.3 \\
Consumption Goods $P_{M A} M A$ & 7.9 & 12.7 & 13.1 & 13.1 \\
Investment Goods $P_{M E} M E$ & 4.2 & 13.5 & 2.7 & 11.2 \\
\hline Government Debt $B$ & 61.5 & 24.0 & 67.0 & 30.0 \\
Net Foreign Assets $B^{*}$ & -54.2 & 31.3 & 17.4 & 23.5 \\
\hline \hline Share of World GDP (percent) & 27.9 & 15.5 & 32.2 & 24.4 \\
\hline
\end{tabular}


Table 3: Real Adjustment Costs and Nominal Rigidities

\begin{tabular}{lllll}
\hline Parameter & US & AS & JE & RC \\
\hline \hline Real Adjustment Costs & & & & \\
Capital accumulation $\phi_{I 1}$ & 1.00 & 1.00 & 1.00 & 1.00 \\
Investment changes $\phi_{I 2}$ & 78 & 78 & 78 & 78 \\
Imports of consumption goods $\phi_{M A}$ & 0.95 & 0.95 & 0.95 & 0.95 \\
Imports of investment goods $\phi_{M E}$ & 0.95 & 0.95 & 0.95 & 0.95 \\
\hline Nominal Rigidities & & & & \\
Wages for liquidity-constrained consumers $\phi_{W L C}$ & 400 & 400 & 400 & 400 \\
Wages for forward-looking consumers $\phi_{W F L}$ & 400 & 400 & 400 & 400 \\
Price of domestically-produced tradables $\phi_{P Q}$ & 400 & 400 & 400 & 400 \\
Price of nontradables $\phi_{P N}$ & 400 & 400 & 400 & 400 \\
Price of imported intermediate goods $\phi_{P M}$ & 400 & 400 & 400 & 400 \\
\hline
\end{tabular}

Table 4: Price and Wage Markups

\begin{tabular}{lcccc}
\hline Parameter & US & AS & JE & RC \\
\hline \hline Tradables & & & & \\
Markup $\theta_{T} /\left(\theta_{T}-1\right)$ & 1.15 & 1.14 & 1.21 & 1.17 \\
$\theta_{T}$ & 7.67 & 8.00 & 5.70 & 6.73 \\
\hline Nontradables & & & & \\
Markup $\theta_{N} /\left(\theta_{N}-1\right)$ & 1.28 & 1.27 & 1.40 & 1.33 \\
$\theta_{N}$ & 4.58 & 4.75 & 3.50 & 4.04 \\
\hline Wages & & & & \\
Markup $\psi /(\psi-1)$ & 1.16 & 1.16 & 1.30 & 1.20 \\
$\psi$ & 7.30 & 7.30 & 4.30 & 6.00 \\
\hline
\end{tabular}

Table 5: Monetary Policy

\begin{tabular}{lll}
\hline Parameter & IFB Rule & Fixed Exchange Rate Regime \\
\hline \hline Lagged interest rate at $\mathrm{t}-1 \omega_{i}$ & 0.75 & 1.00 \\
Inflation gap at $\mathrm{t}+3 \omega_{1}$ & 2.00 & 0.00 \\
Change in the nominal exch. rate at $\mathrm{t} \omega_{2}$ & 0.00 & 1000000 (proxy for $\infty)$ \\
\hline
\end{tabular}


Table 6: Calibrating the International Linkages

\begin{tabular}{lllll}
\hline Parameter & US & AS & JE & RC \\
\hline \hline Substitution between imports from different regions $\rho_{A}$ & 1.5 & 1.5 & 1.5 & 1.5 \\
\hline Bias towards imported consumption goods $b_{A}$ from & & & & \\
United States (US) & $\ldots$ & 0.33 & 0.22 & 0.52 \\
Emerging Asia (AS) & 0.15 & $\ldots$ & 0.16 & 0.06 \\
Japan / Euro Area (JE) & 0.32 & 0.42 & $\ldots$ & 0.42 \\
Remaining Countries (RC) & 0.53 & 0.25 & 0.62 & $\ldots$ \\
\hline Substitution between imports from different regions $\rho_{E}$ & 1.5 & 1.5 & 1.5 & 1.5 \\
\hline Bias towards imported investment goods $b_{E}$ from & & & & \\
United States (US) & $\ldots$ & 0.45 & 0.78 & 0.51 \\
Emerging Asia (AS) & 0.25 & $\ldots$ & 0.17 & 0.11 \\
Japan / Euro Area (JE) & 0.30 & 0.27 & $\ldots$ & 0.38 \\
Remaining Countries (RC) & 0.45 & 0.28 & 0.05 & $\ldots$ \\
\hline \hline Net Foreign Liabilities & & & & \\
Short-run dynamics $\phi_{B 1}$ & 0.05 & 0.05 & 0.05 & 0.05 \\
Short-run dynamics $\phi_{B 2}$ & 0.10 & 0.10 & 0.10 & 0.10 \\
$\%$ related to domestic government debt $\phi_{F 1}$ & 0.50 & 0.50 & 0.50 & 0.50 \\
$\%$ related to US government debt $\phi_{F 2}$ & $\ldots$ & 0.24 & 0.38 & 0.38 \\
\hline
\end{tabular}


Figure 1: Distribution of U.S. Current Accounts, 1960-2004

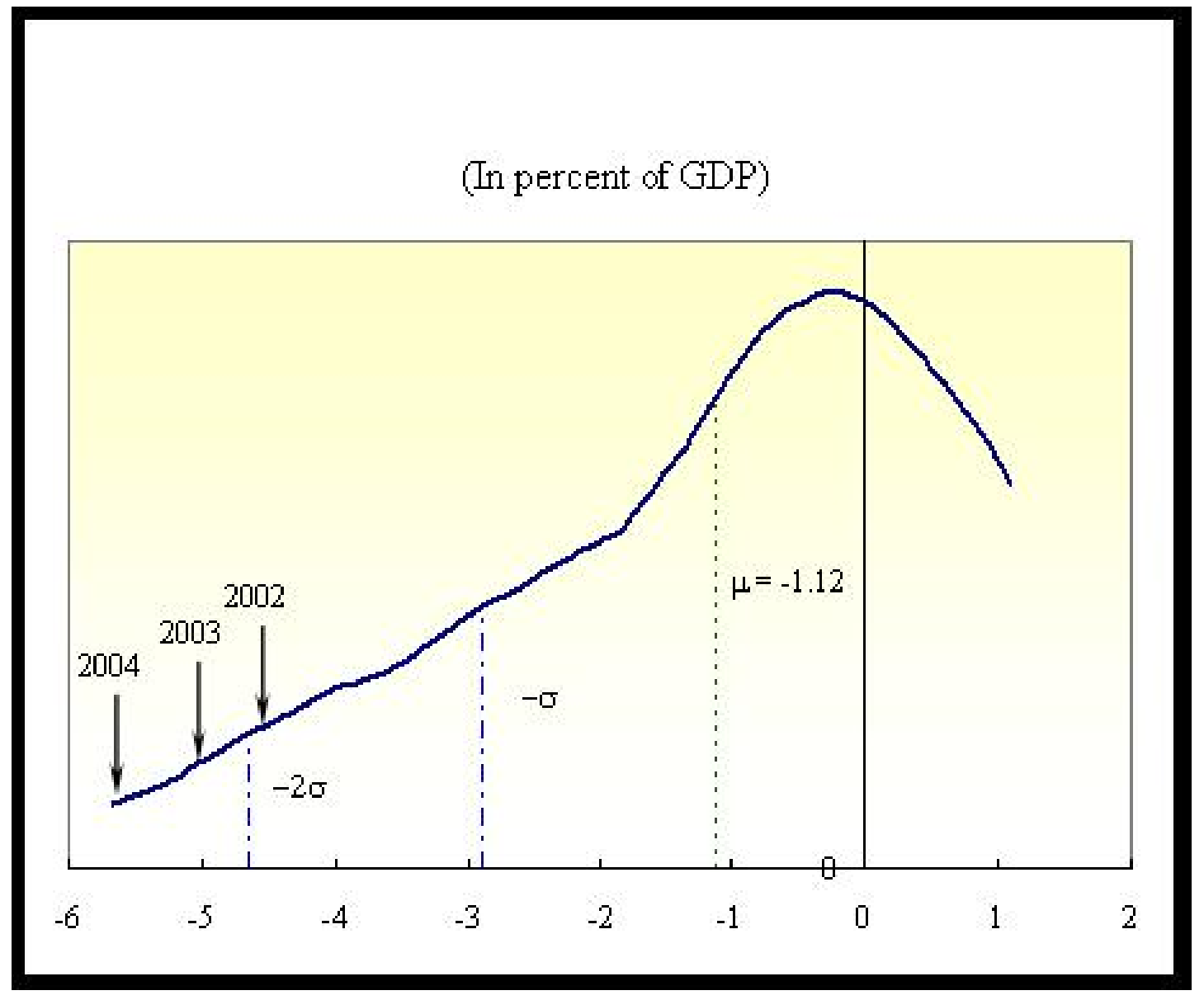


Figure 2: The Structure of the Model

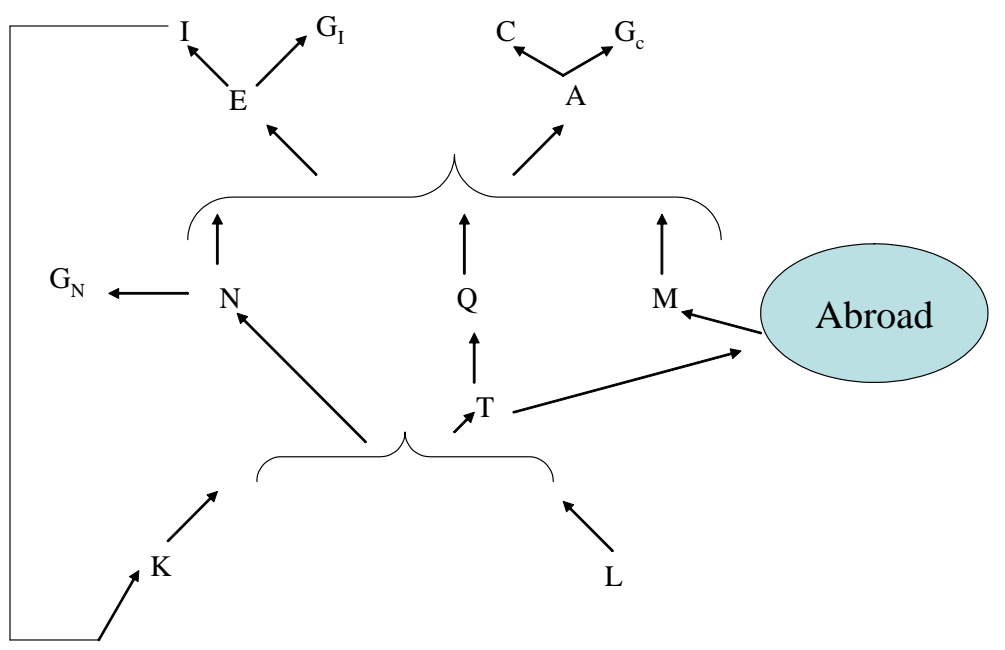


Figure 3: International Trade Linkages (steady-state calibration; percent of world GDP)

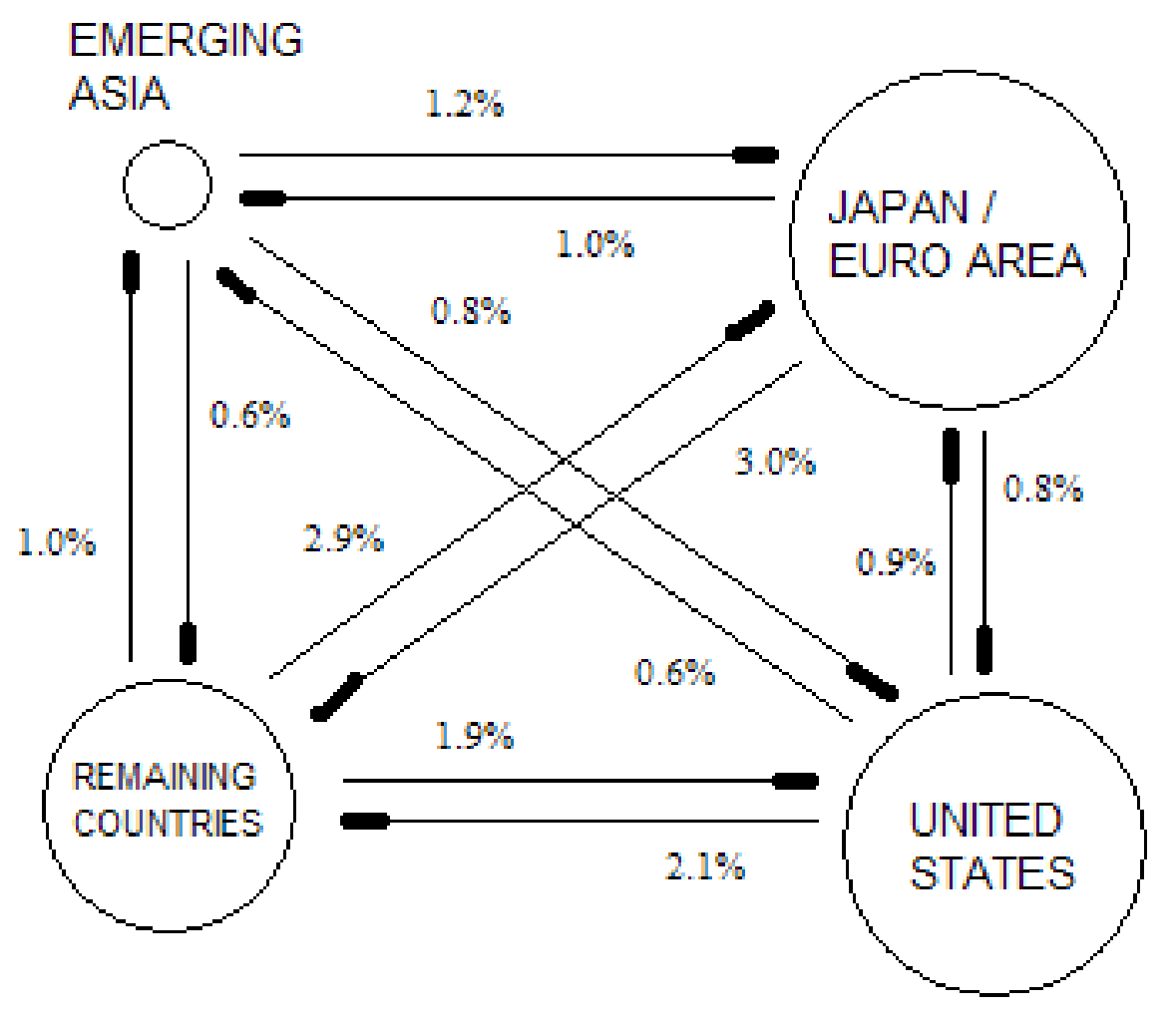


Figure 4: United States

Government Debt Shock in the United States
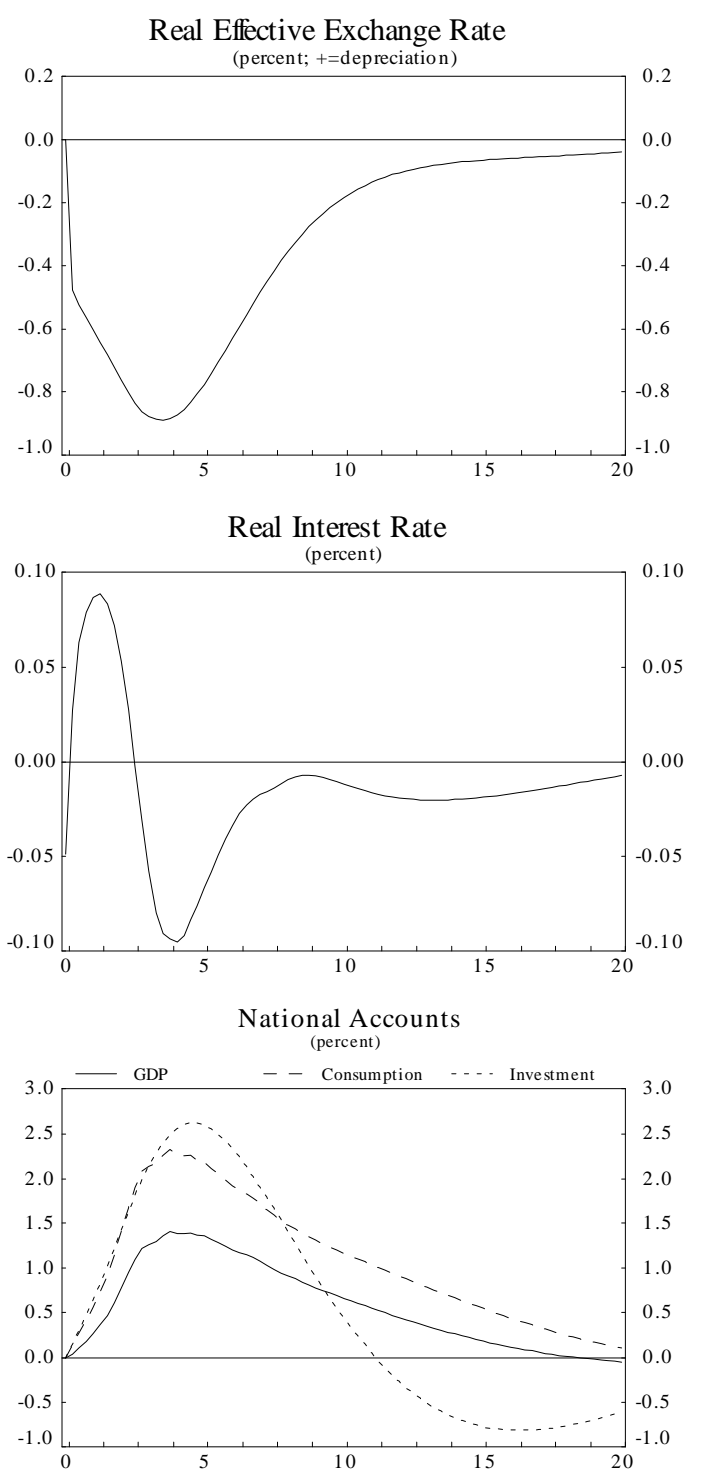

Net Foreign Liabilities

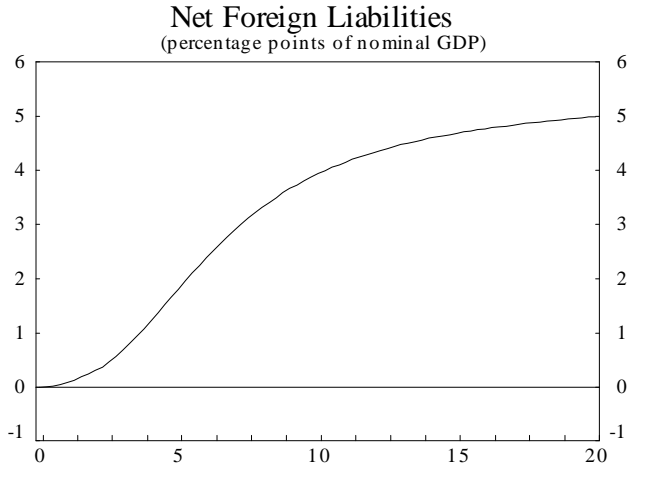

Trade Balance and the Current Account (percentage points of nominal GDP)

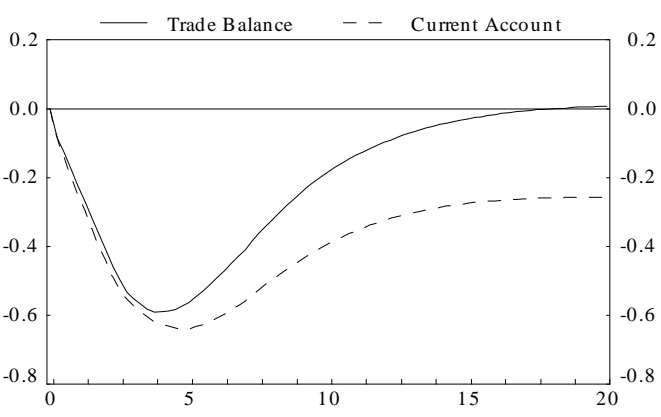

Year-on-Year Inflation
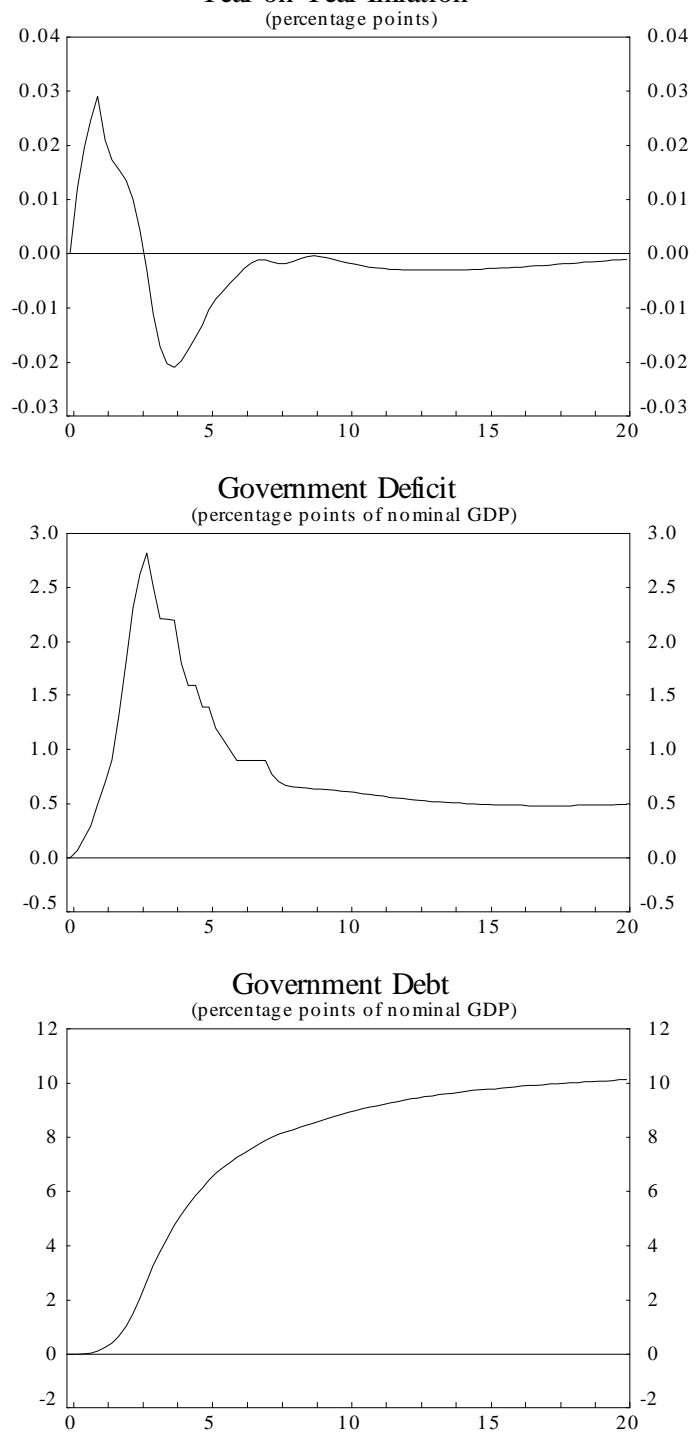
Figure 5: Rest of the World

Government Debt Shock in the United States

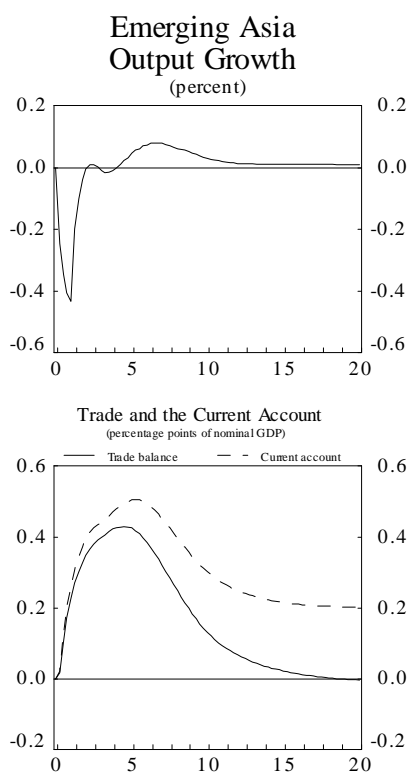

Real Effective Exchange Rate

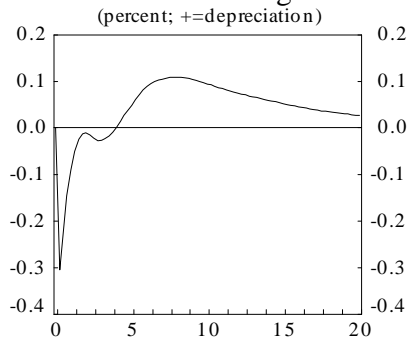

Real Interest Rates

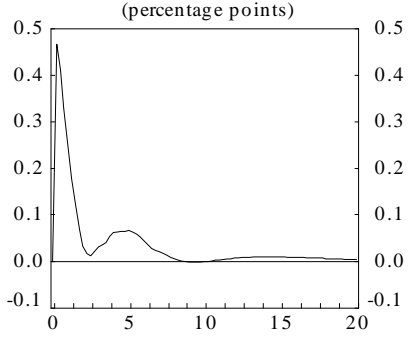

Year-on-Year Inflation

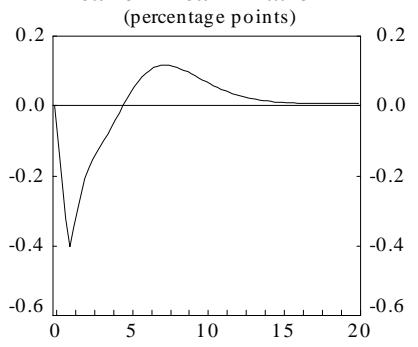

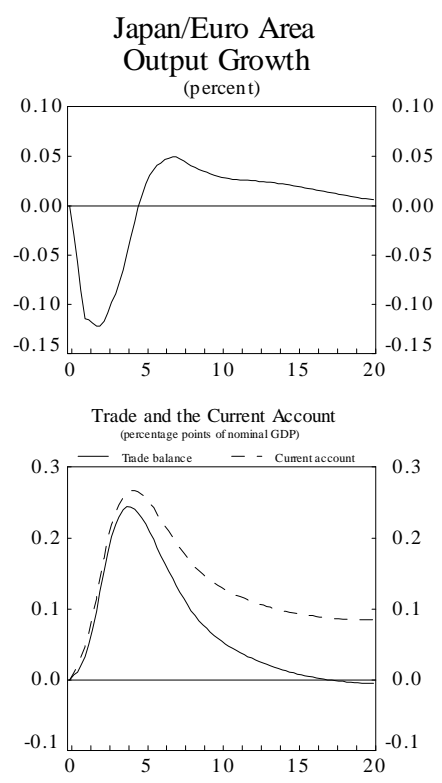

Real Effective Exchange Rate

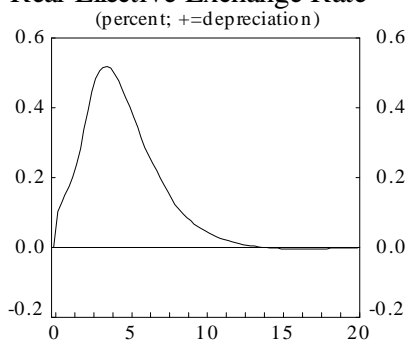

Real Interest Rates

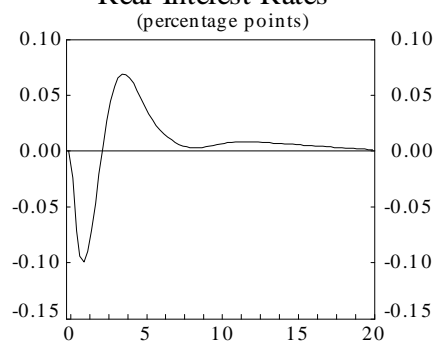

Year-on-Year Inflation

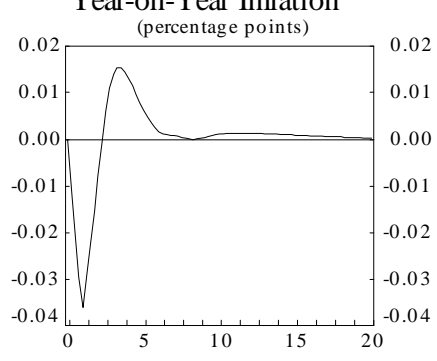

Remaining Countries

Output Growth

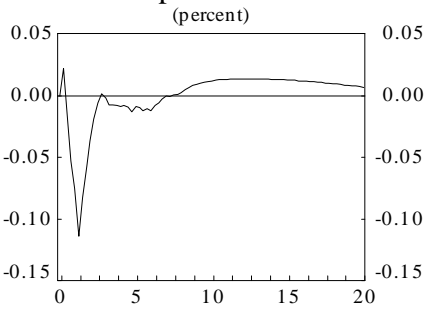

Trade and the Current Account
(percentage points of nominal GDP)

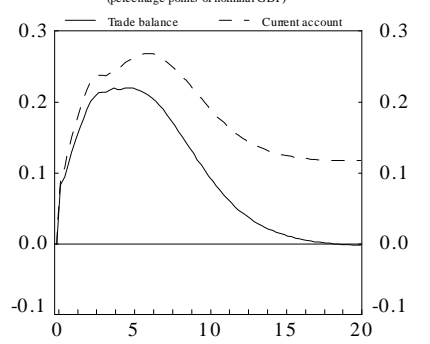

Real Effective Exchange Rate

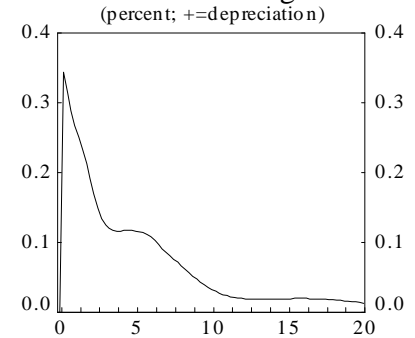

Real Interest Rates

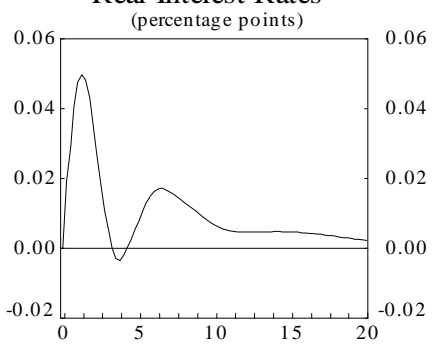

Year-on-Year Inflation

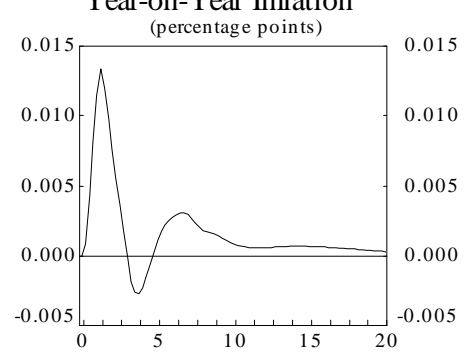


Figure 6: United States

Private Savings Shock in the United States
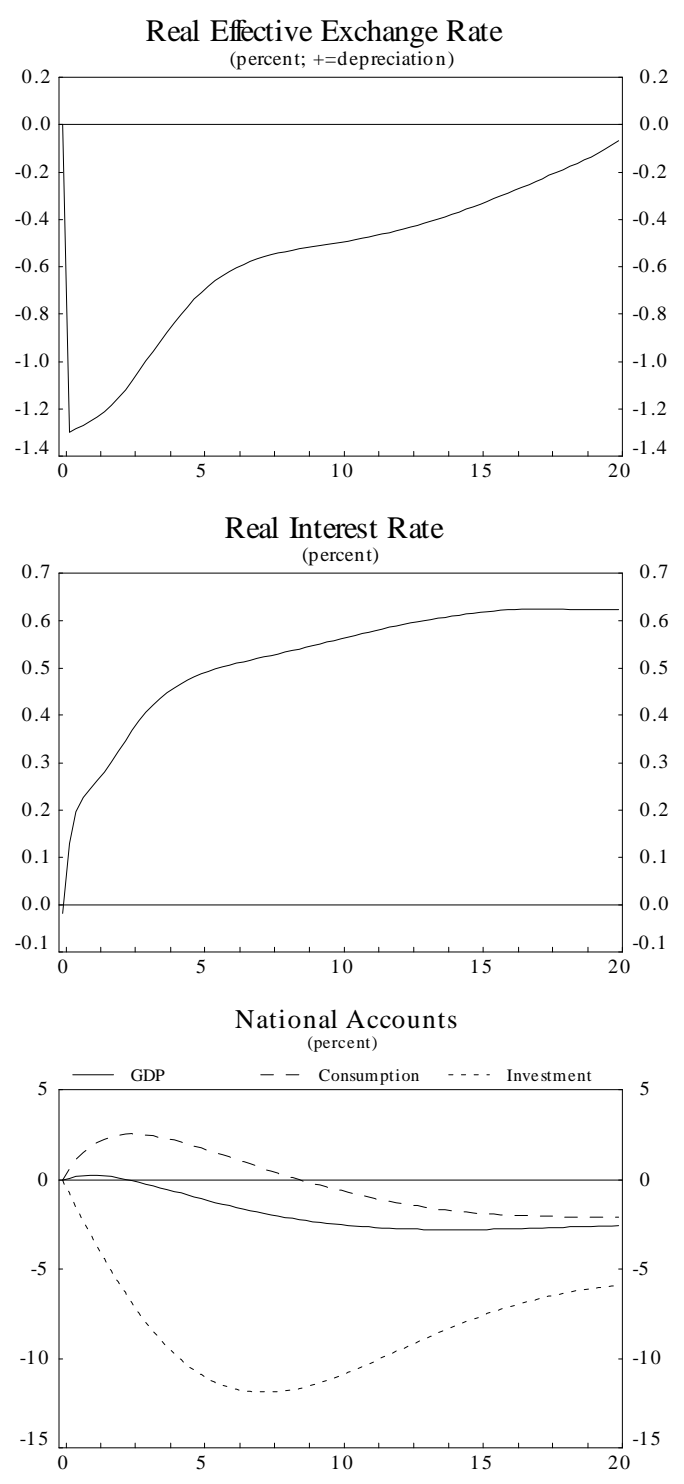

Net Foreign Liabilities

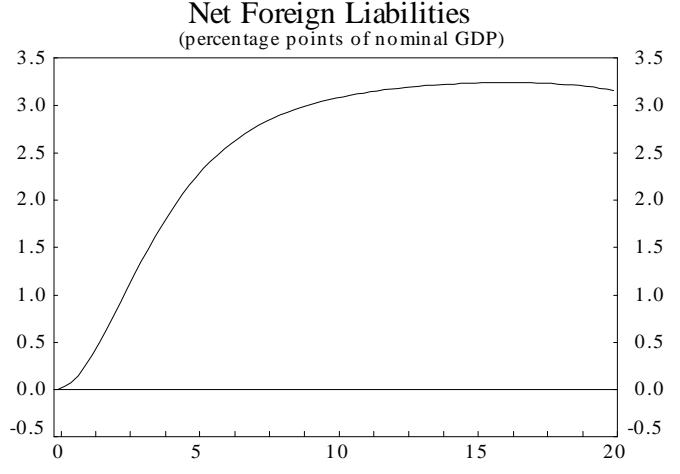

Trade Balance and the Current Account (percentage points of nominal GDP)

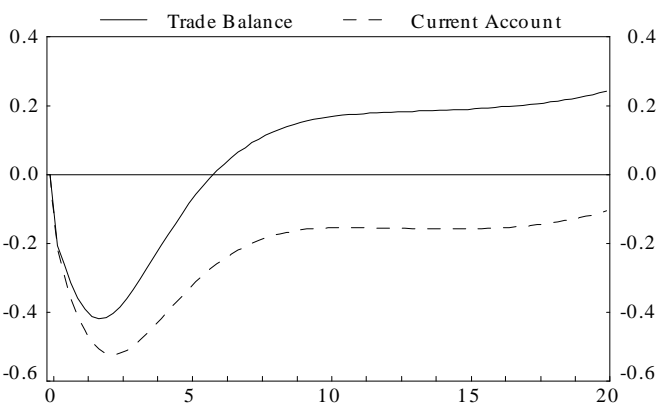

Year-on-Year Inflation
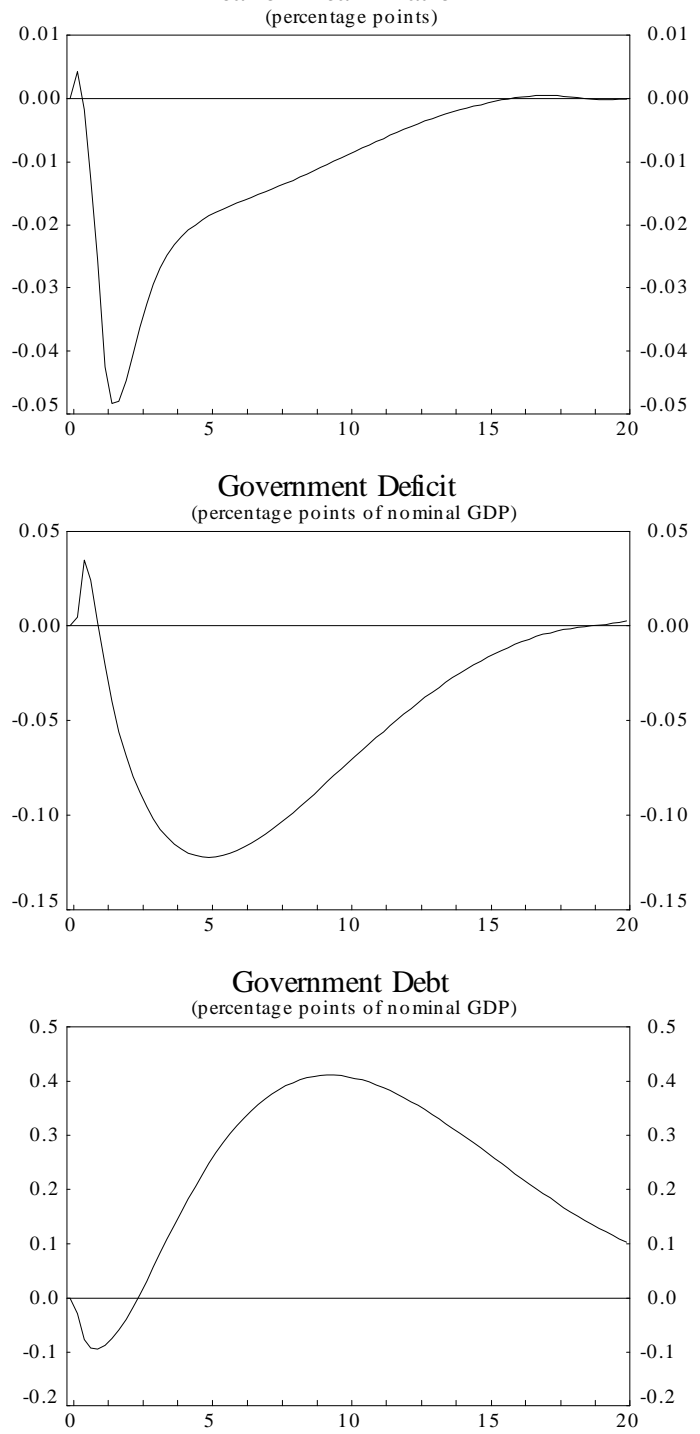
Figure 7: Rest of the World

Private Savings Shock in the United States

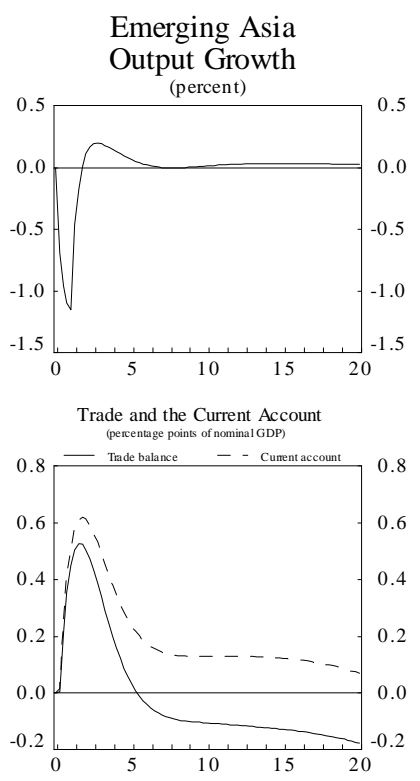

Real Effective Exchange Rate

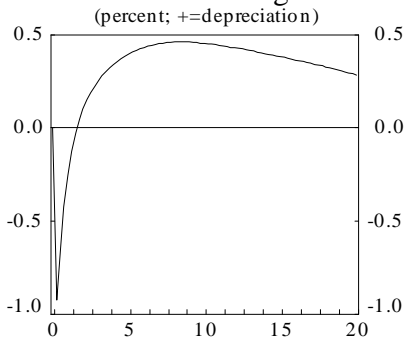

Real Interest Rates

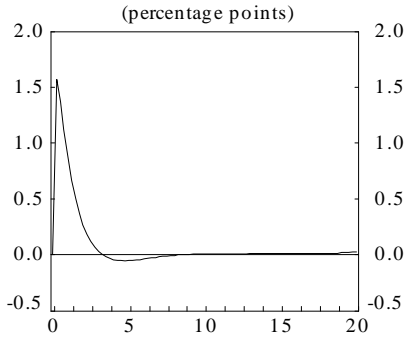

Year-on-Year Inflation

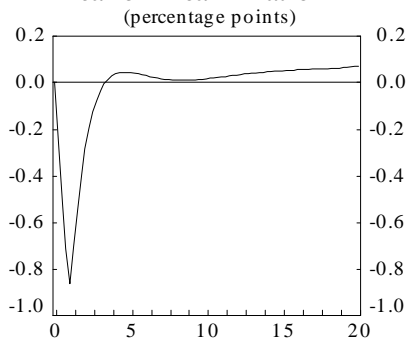

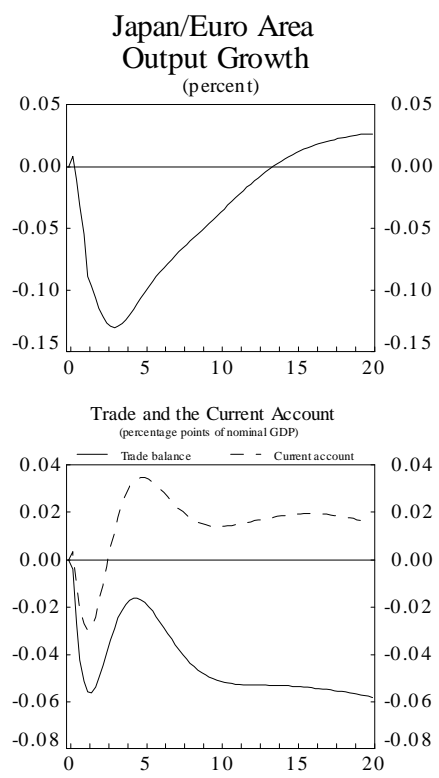

Real Effective Exchange Rate

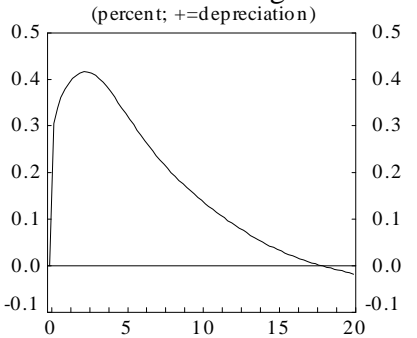

Real Interest Rates

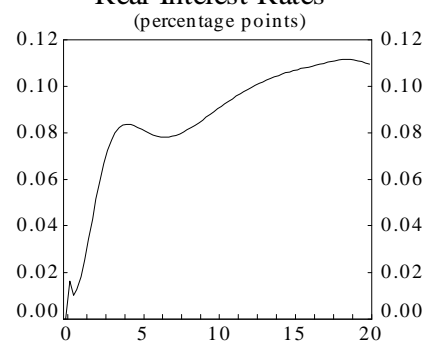

Year-on-Year Inflation

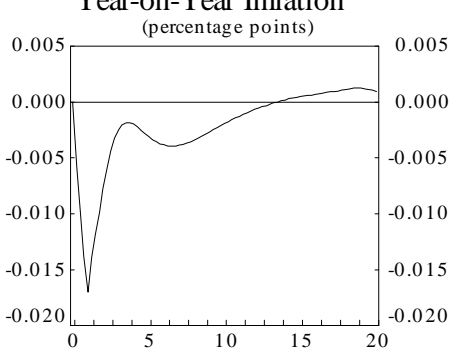

Remaining Countries

Output Growth (percent)

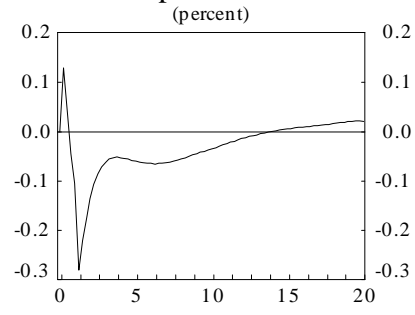

Trade and the Current Account
(percentage points of nominal GDP)

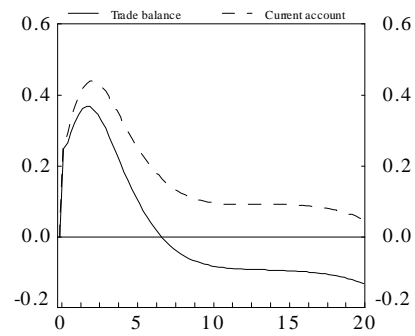

Real Effective Exchange Rate

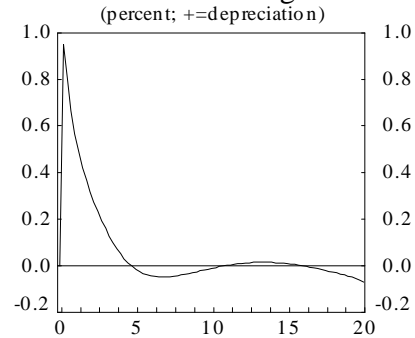

Real Interest Rates

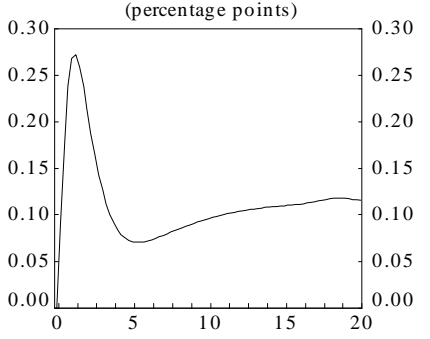

Year-on-Year Inflation

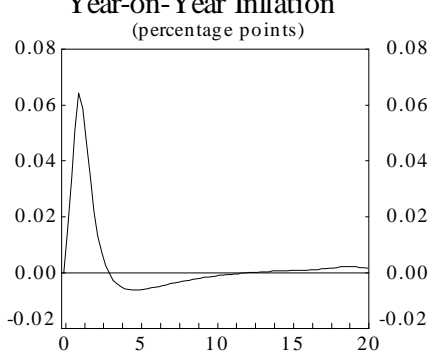


Figure 8: United States

Preference for US Assets Shock in the Rest of the World
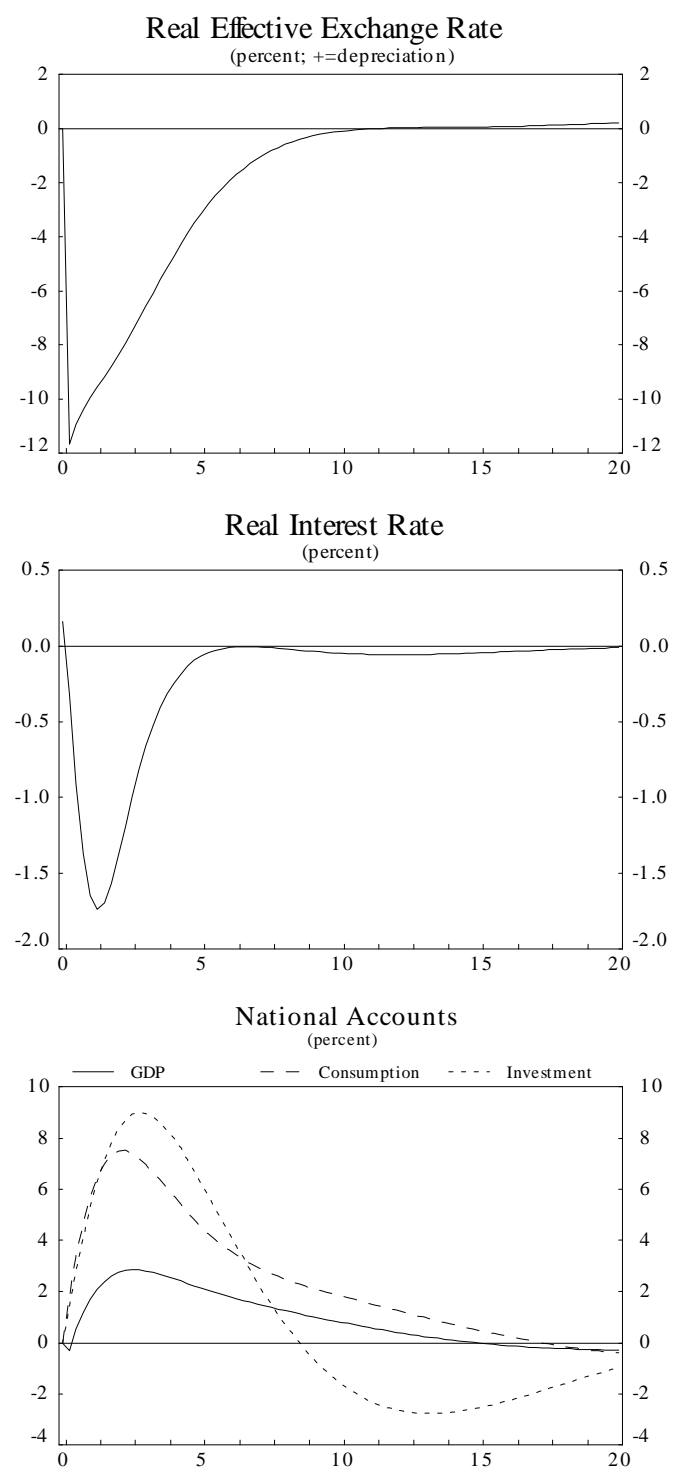

Net Foreign Liabilities

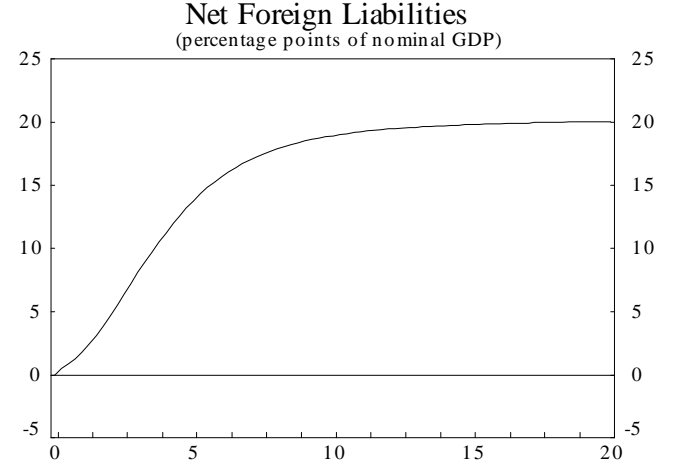

Trade Balance and the Current Account (percentage points of nominal GDP)

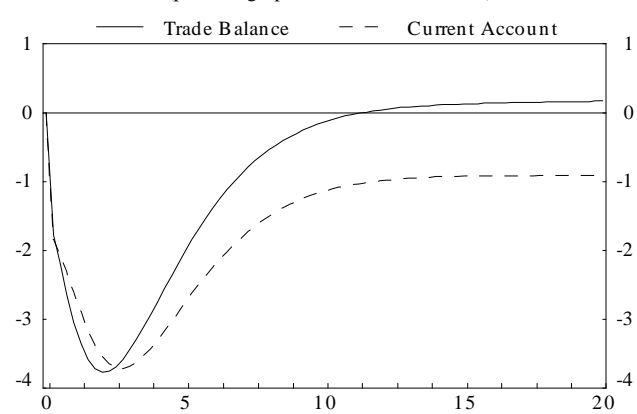

Year-on-Year Inflation
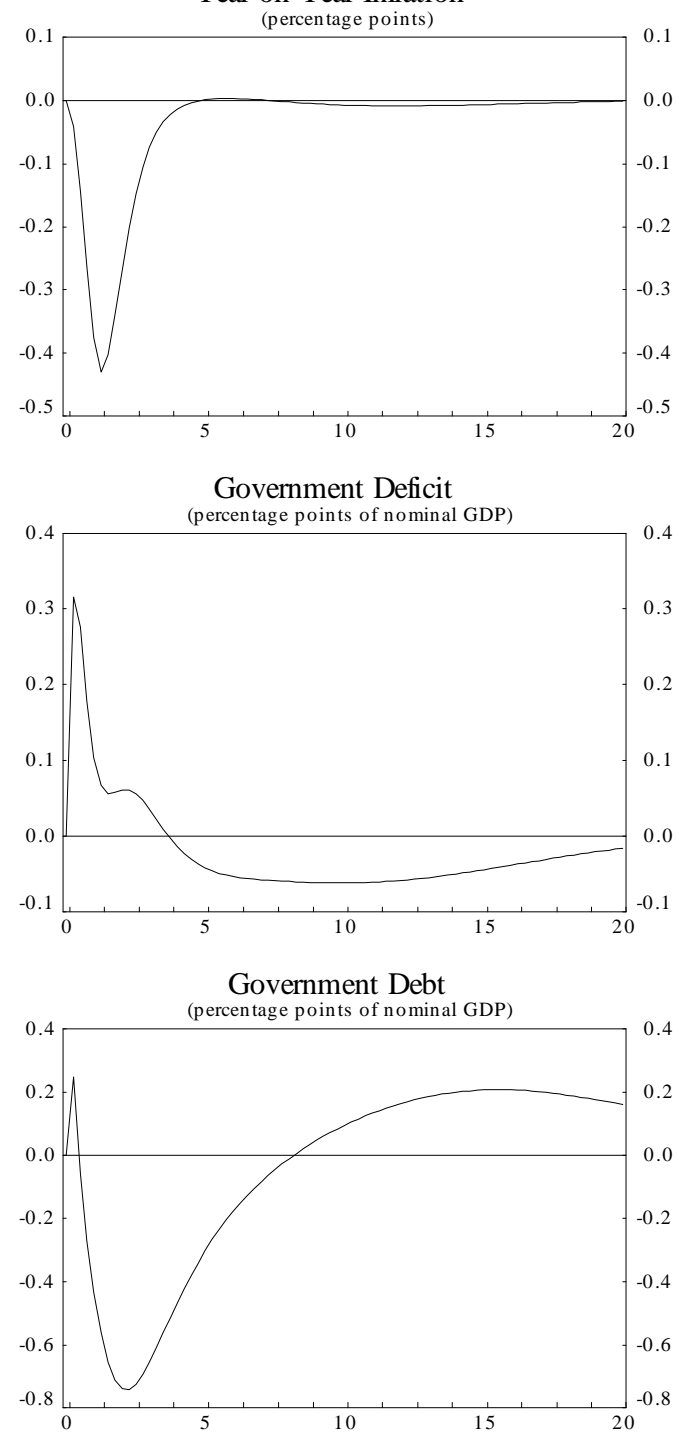
Figure 9: Rest of the World

Preference for US Assets Shock in the Rest of the World

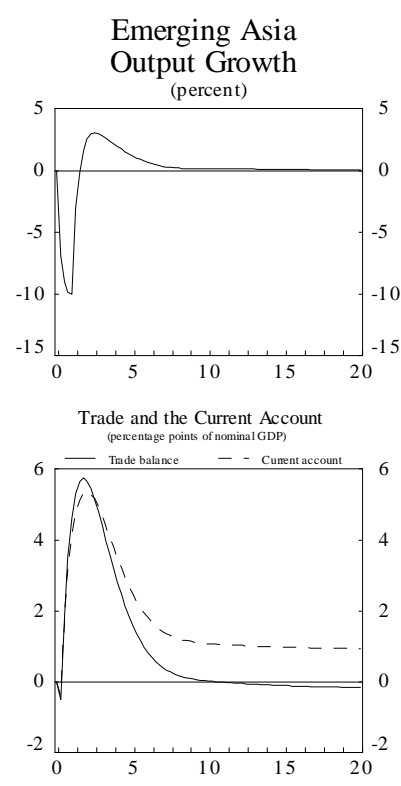

Real Effective Exchange Rate

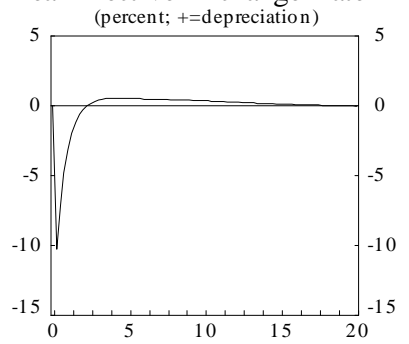

Real Interest Rates

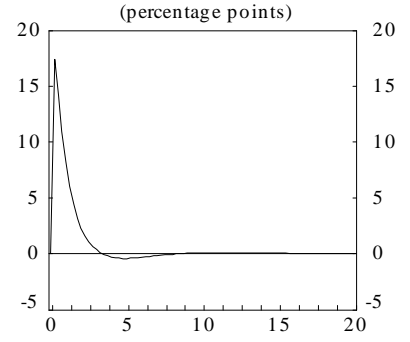

Year-on-Year Inflation

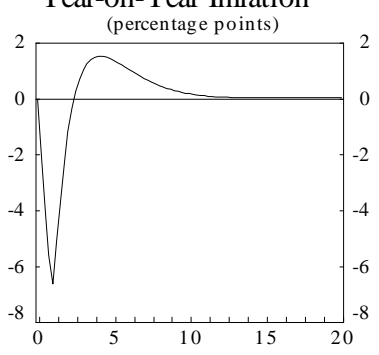

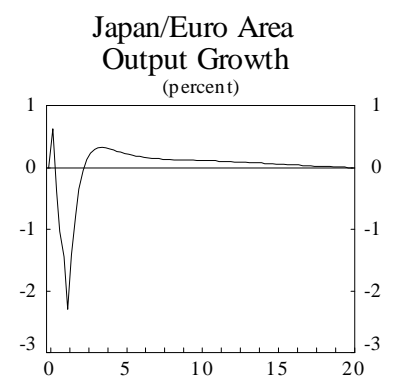

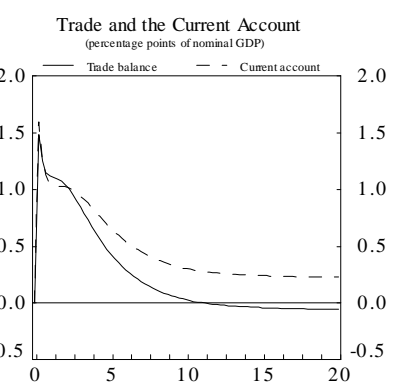

Real Effective Exchange Rate

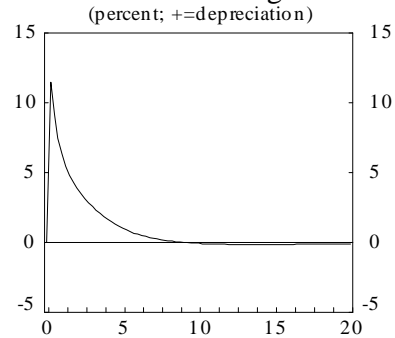

Real Interest Rates

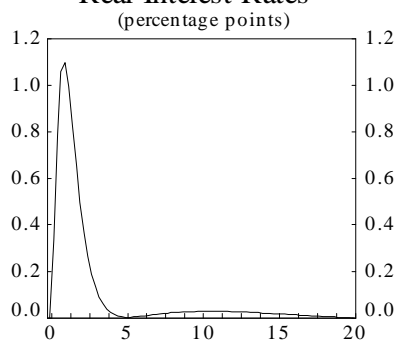

Year-on-Year Inflation

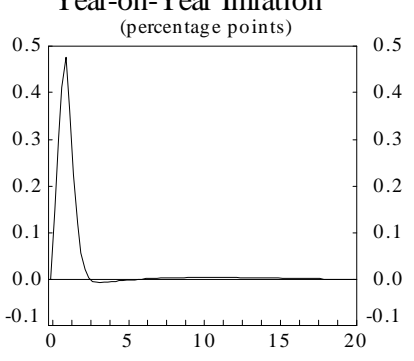

Remaining Countries

Output Growth

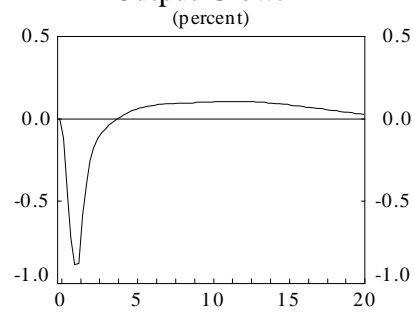

Trade and the Current Account
(ererenatge poins of nominal (liD)

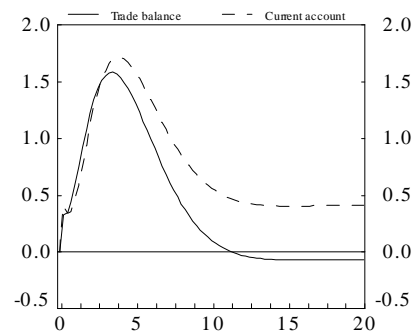

Real Effective Exchange Rate

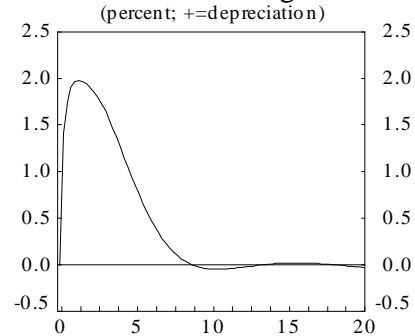

Real Interest Rates

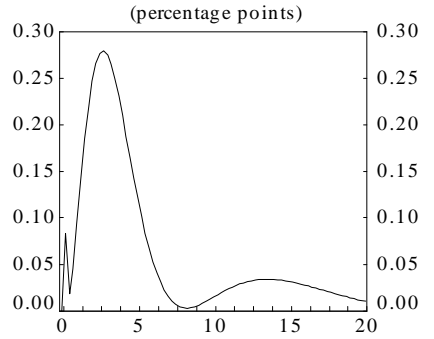

\section{Year-on-Year Inflation}

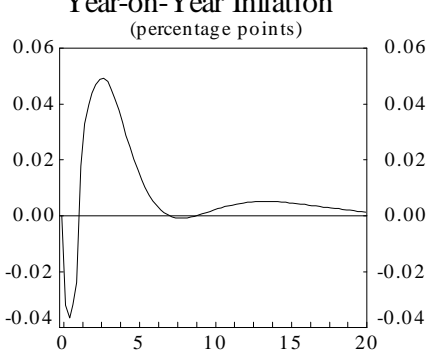


Figure 10: Japan and the Euro Area

Negative Productivity Shock in Japan and the Euro Area
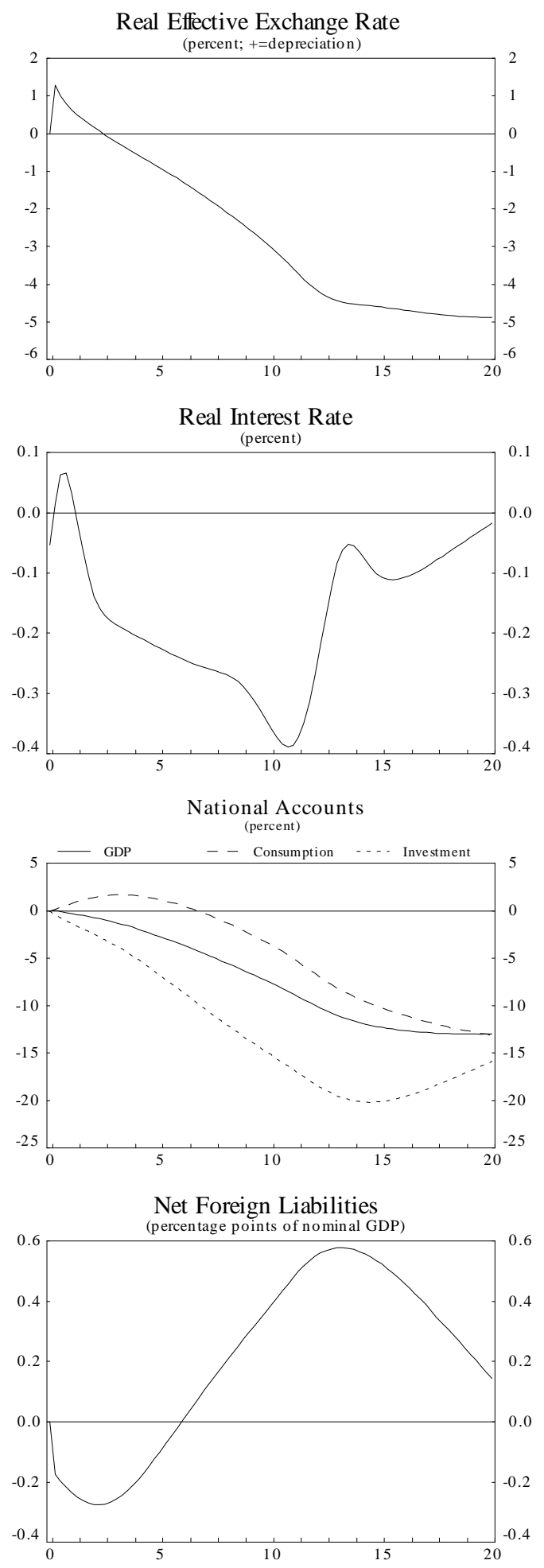

Trade Balance and the Current Account (percentage points of nominal GDP)

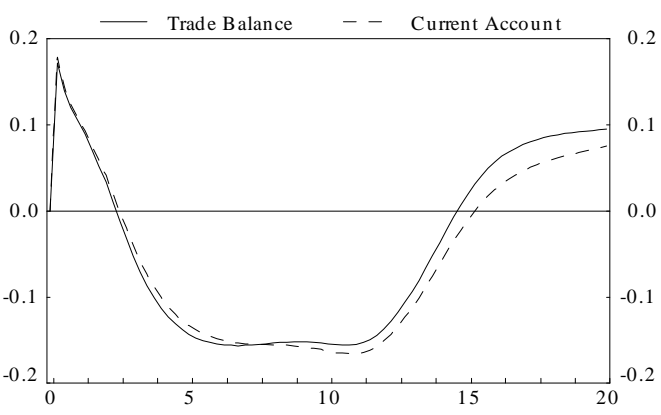

Year-on-Year Inflation
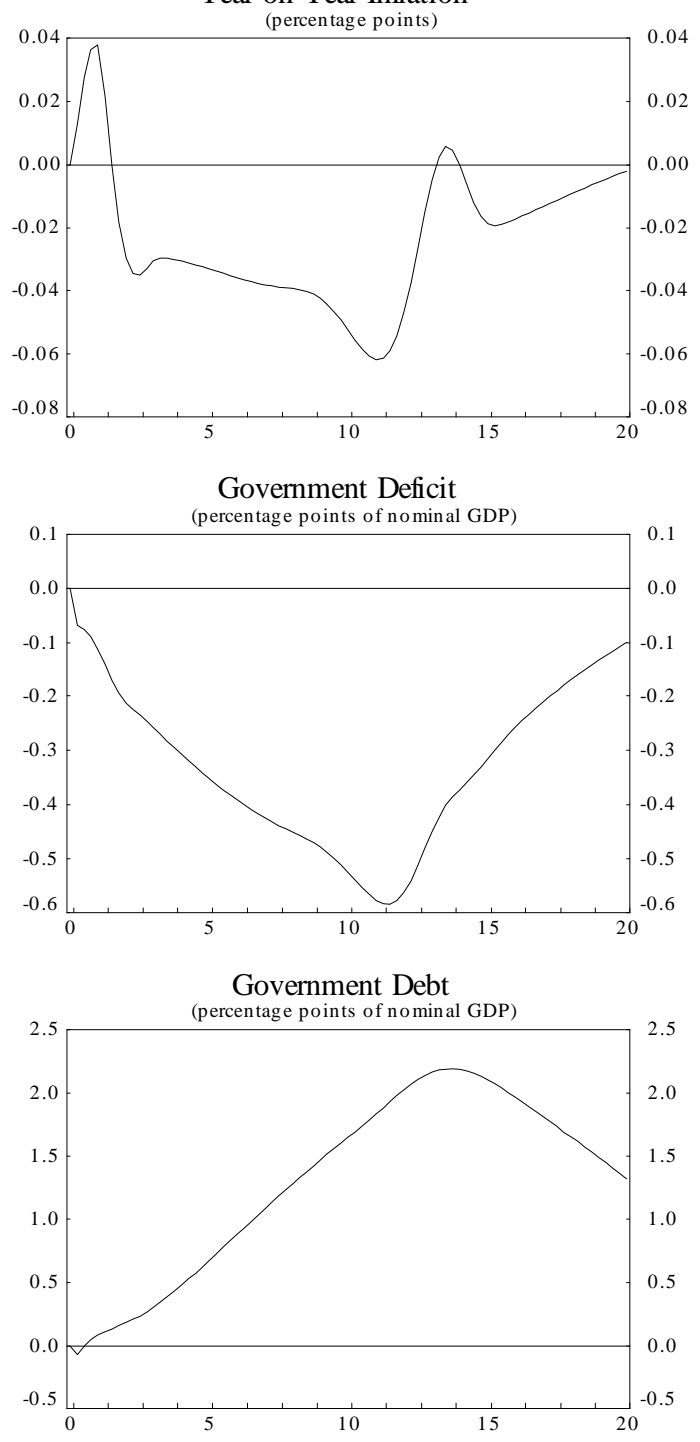
Figure 11: Rest of the World

Negative Productivity Shock in Japan and the Euro Area

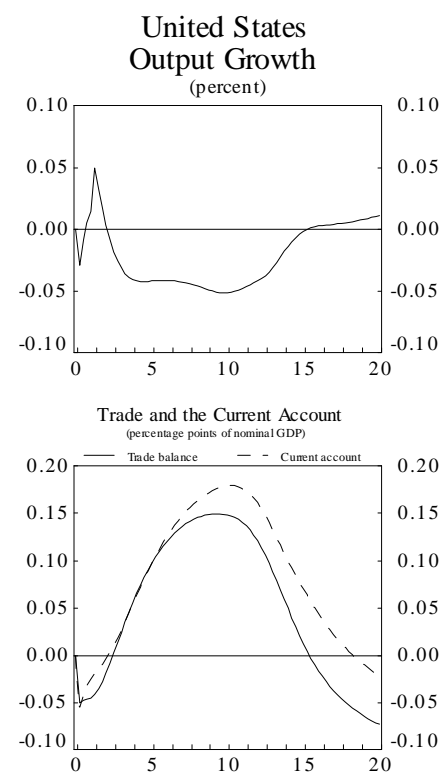

Real Effective Exchange Rate

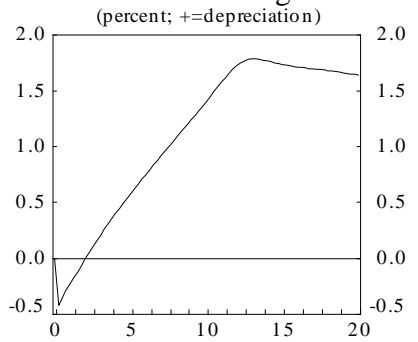

Real Interest Rates

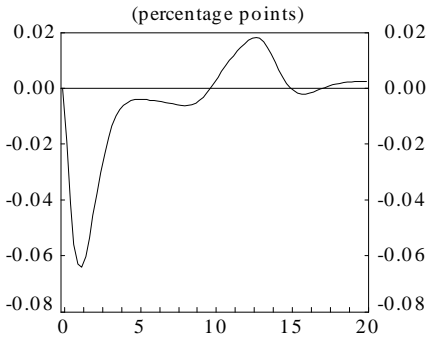

Year-on-Year Inflation

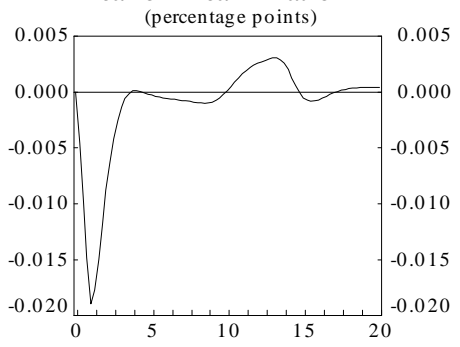

Emerging Asia

Output Growth

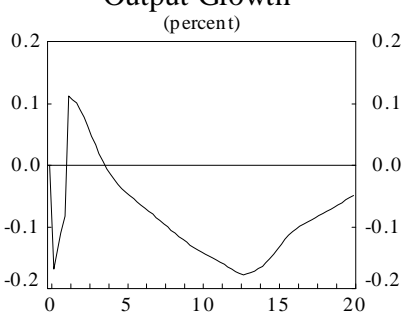

Trade and the Current Account
(percentage points of nominal GDP)

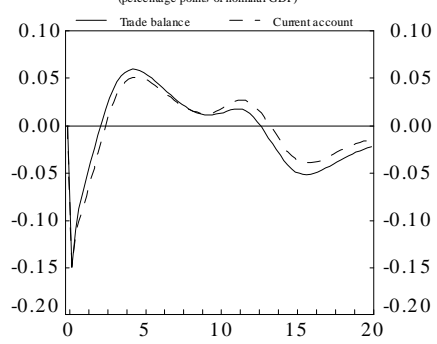

Real Effective Exchange Rate

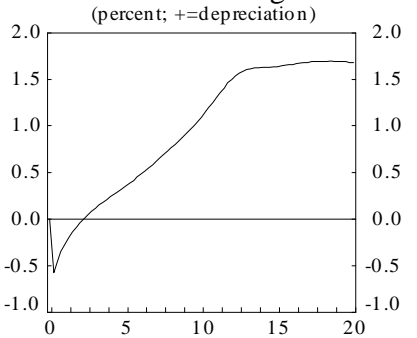

Real Interest Rates

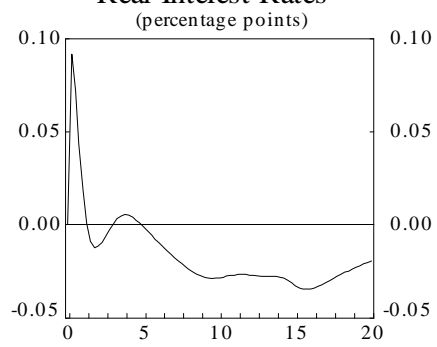

Year-on-Year Inflation

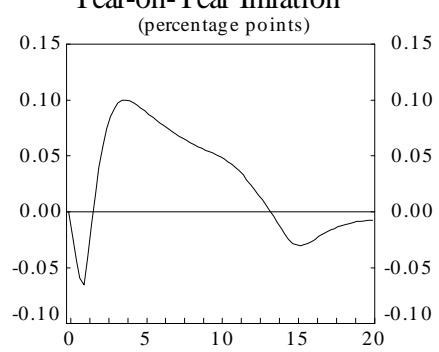

Remaining Countries

Output Growth (percent)

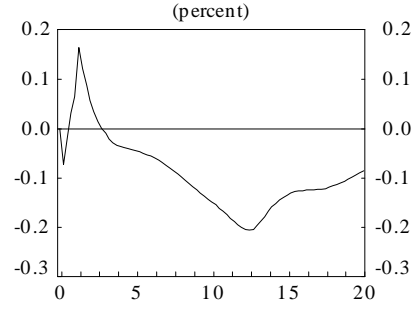

Trade and the Current Account
(perentage points of nominal GDP)

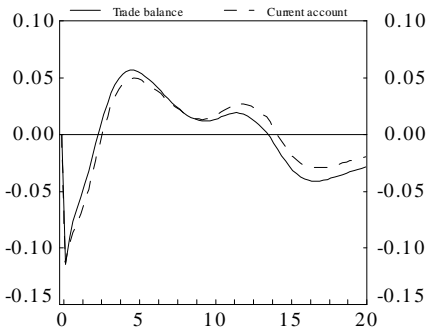

Real Effective Exchange Rate

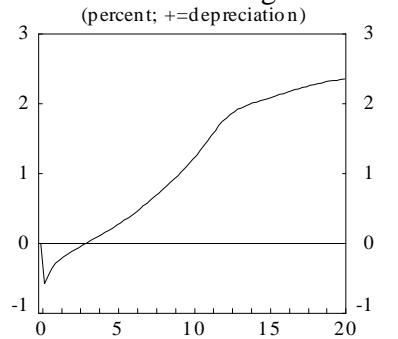

Real Interest Rates

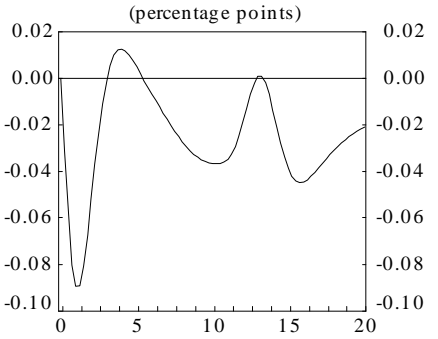

Year-on-Year Inflation

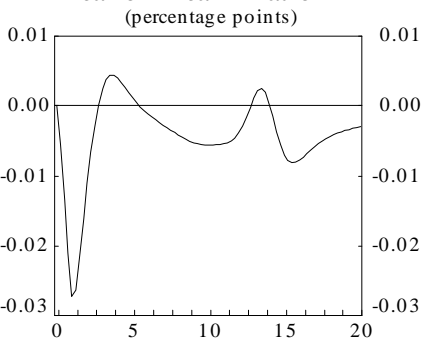


Figure 12: Emerging Asia

Positive Productivity Shock in Emerging Asia

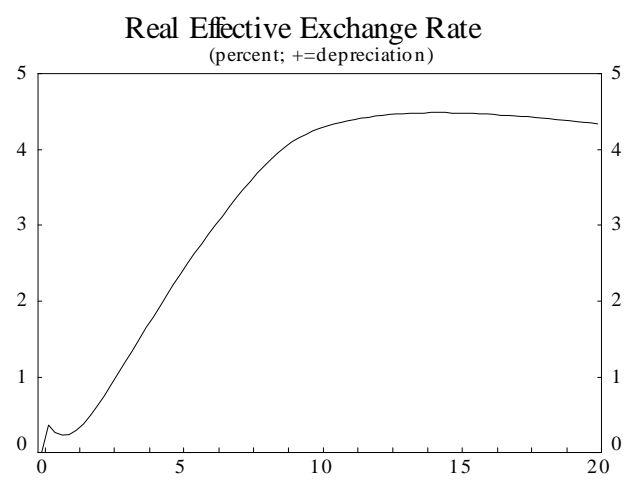

Real Interest Rate

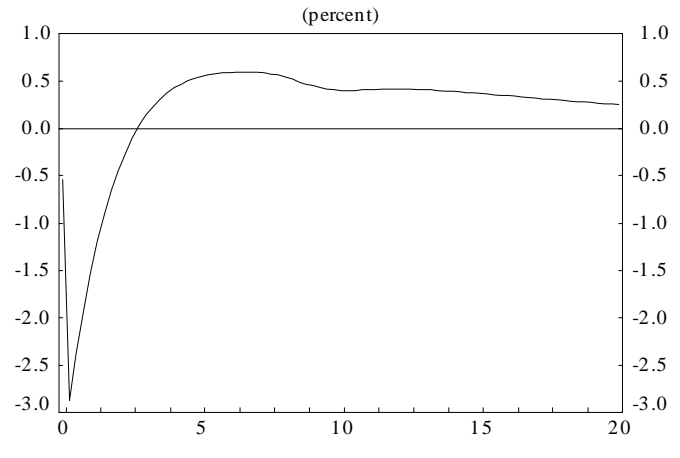

National Accounts

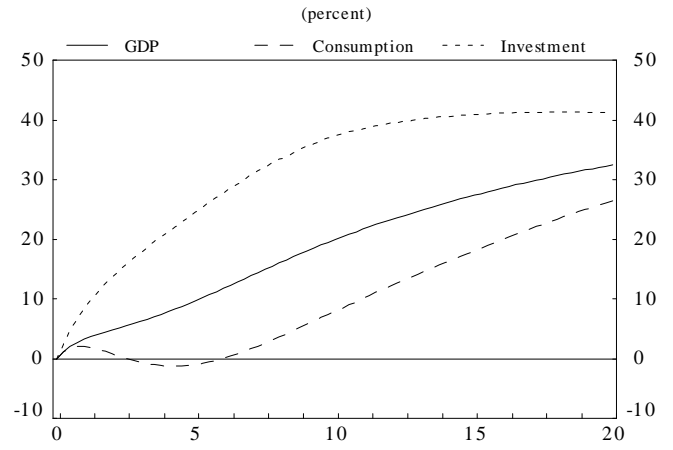

Net Foreign Liabilities

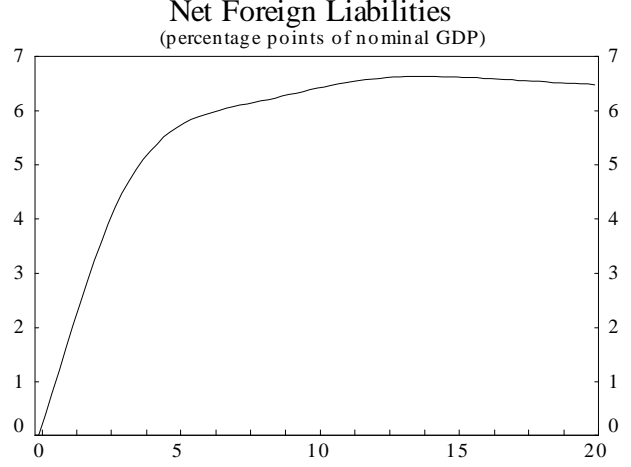

Trade Balance and the Current Account (percentage points of nominal GDP)

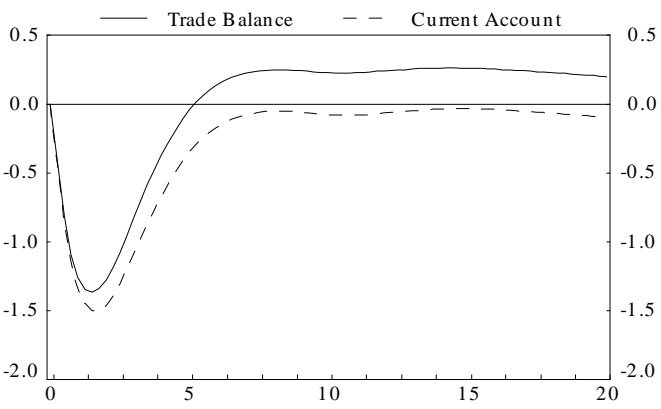

Year-on-Year Inflation

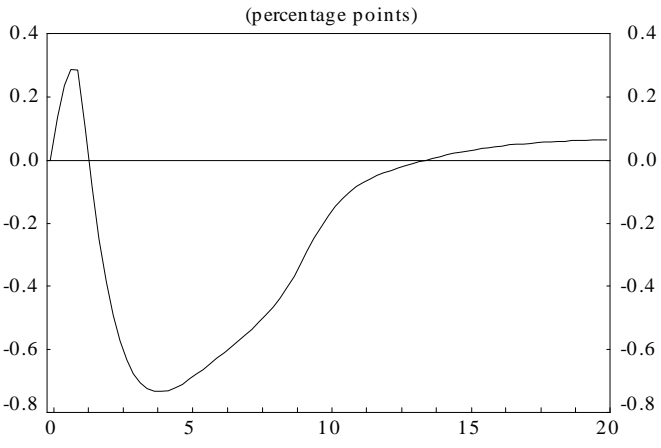

Government Deficit

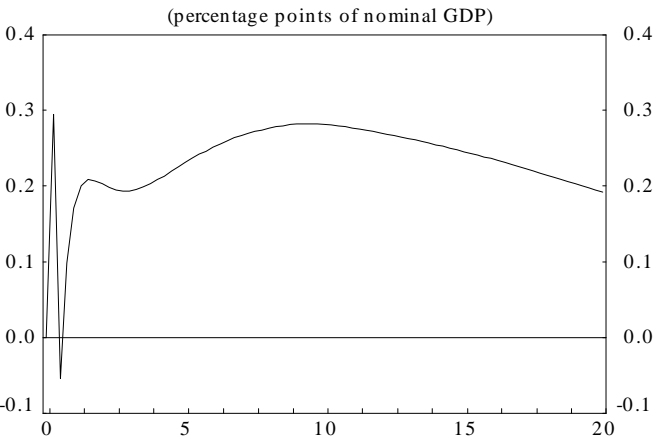

Government Debt

(percentage points of nominal GDP)

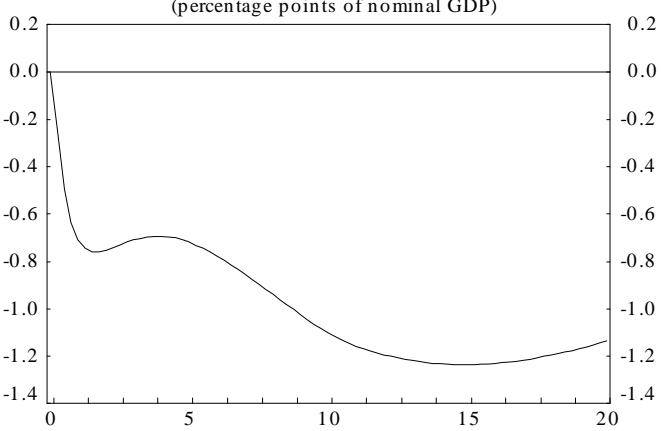


Figure 13: Rest of the World

Positive Productivity Shock in Emerging Asia

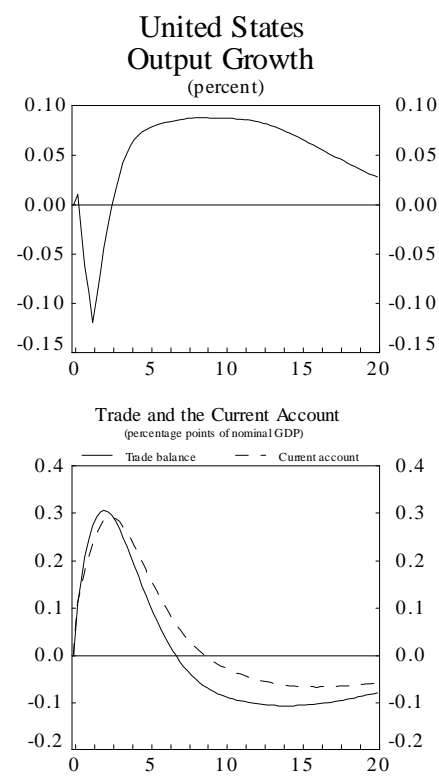

Real Effective Exchange Rate

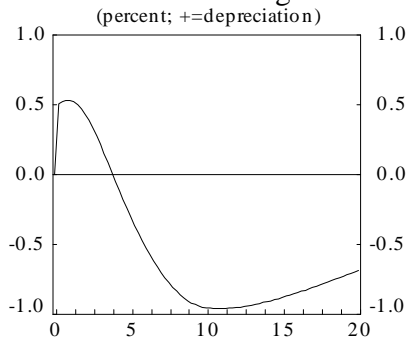

Real Interest Rates

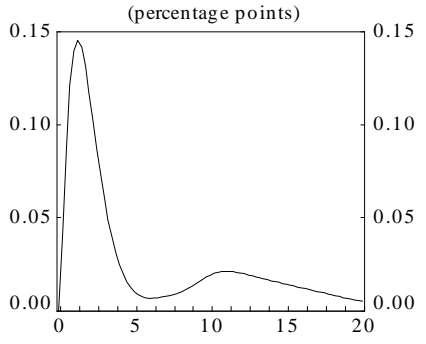

Year-on-Year Inflation

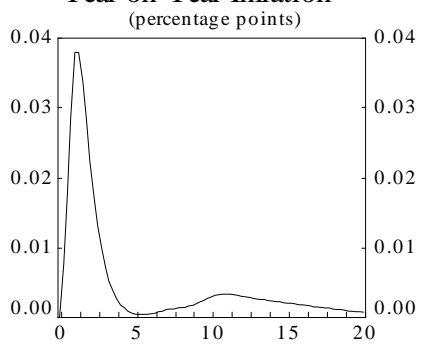

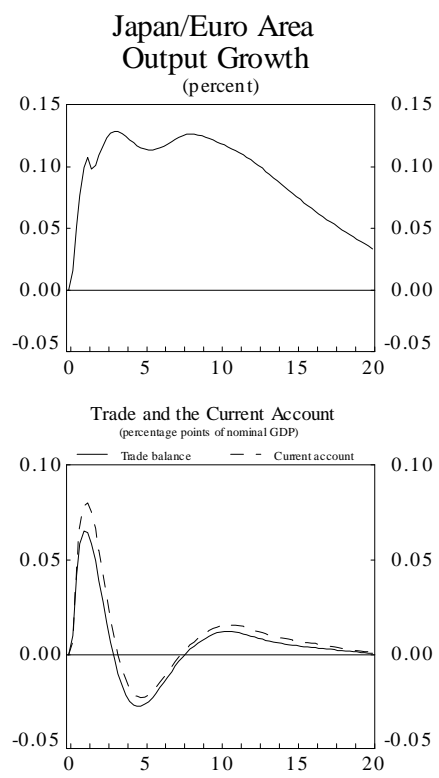

Real Effective Exchange Rate

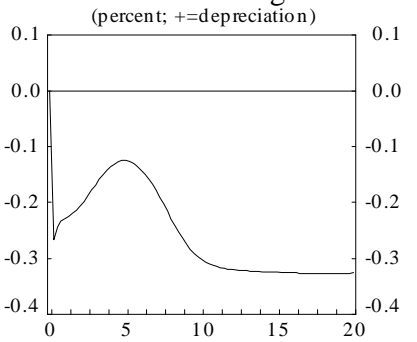

Real Interest Rates

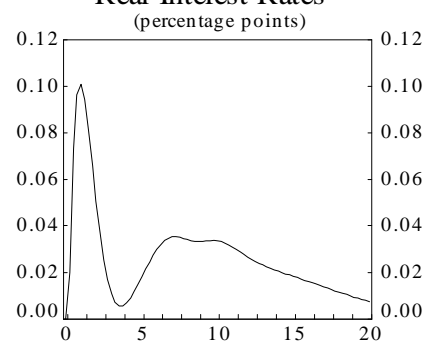

Year-on-Year Inflation

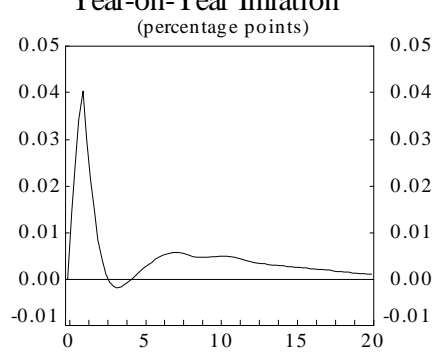

Remaining Countries

Output Growth

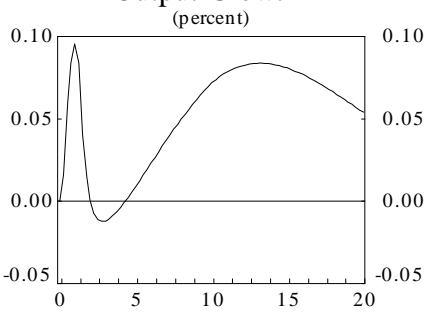

Trade and the Current Account
(percentage points of nominal GDP)

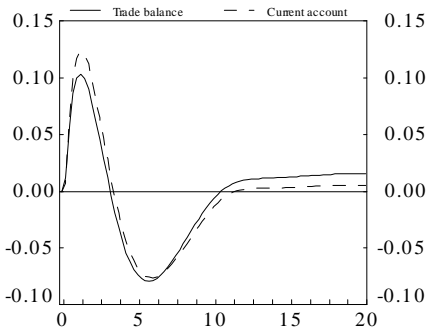

Real Effective Exchange Rate

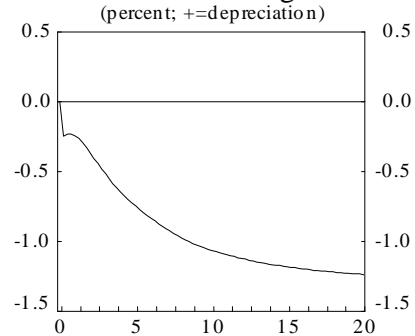

Real Interest Rates

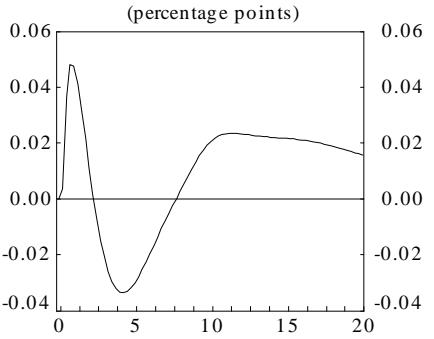

Year-on-Year Inflation

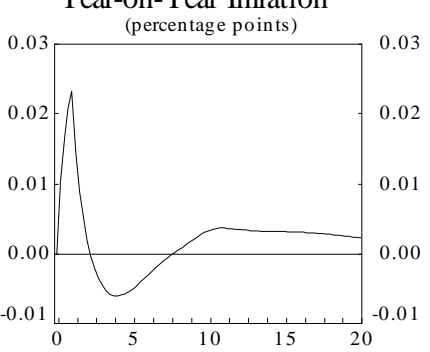


Figure 14: Emerging Asia

Positive Fiscal Policy Shock in Emerging Asia, including Export Subsidies
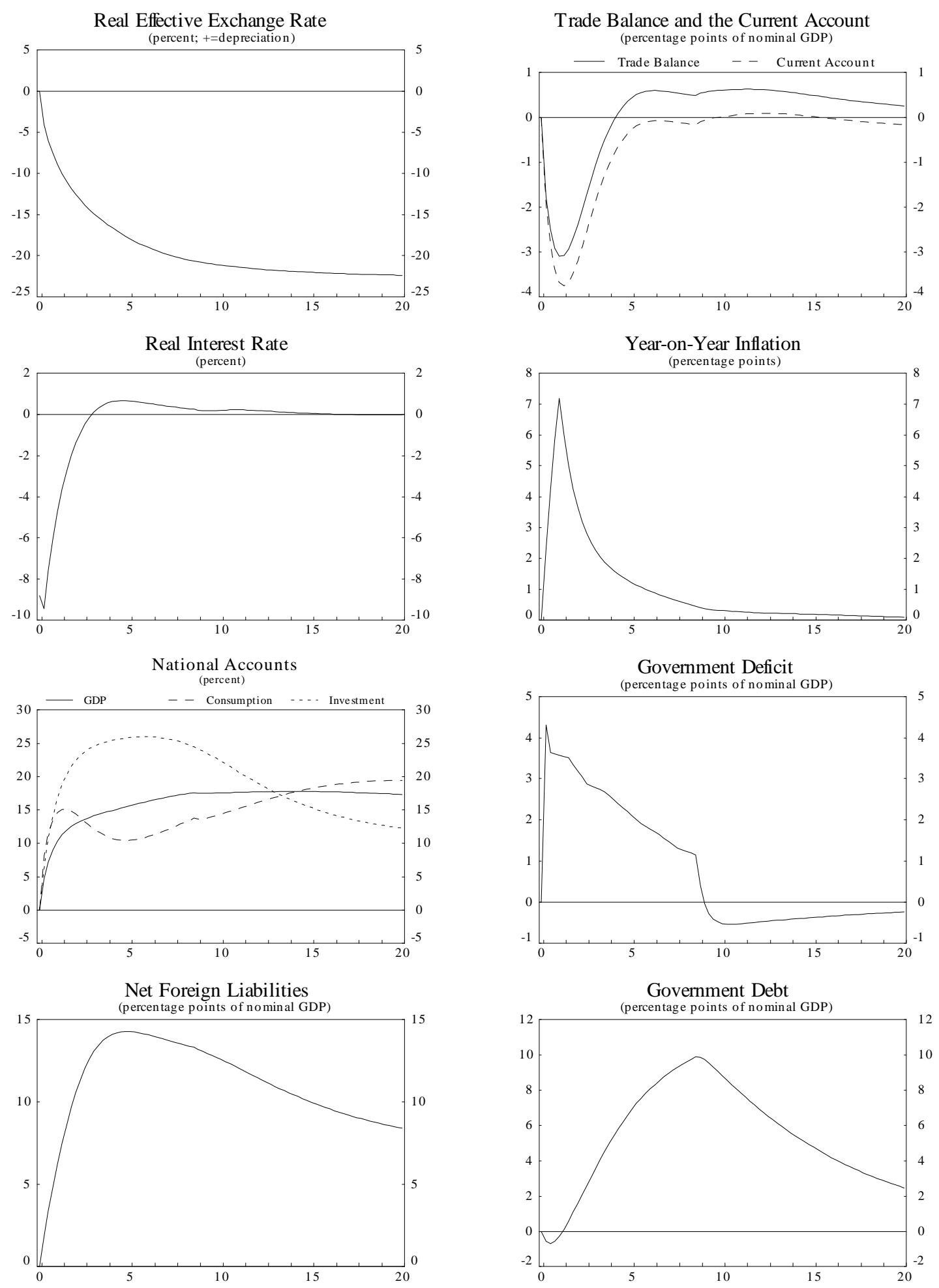
Figure 15: Rest of the World

Positive Fiscal Policy Shock in Emerging Asia, including Export Subsidies

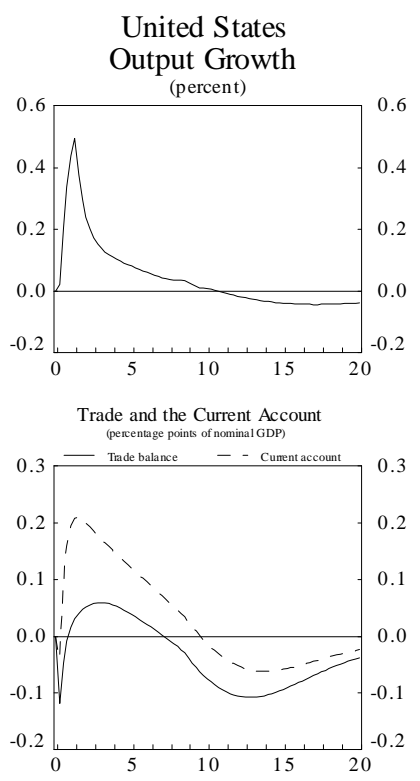

Real Effective Exchange Rate

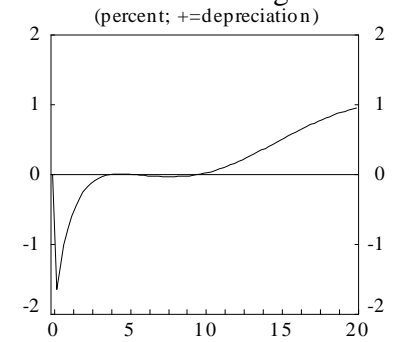

Real Interest Rates

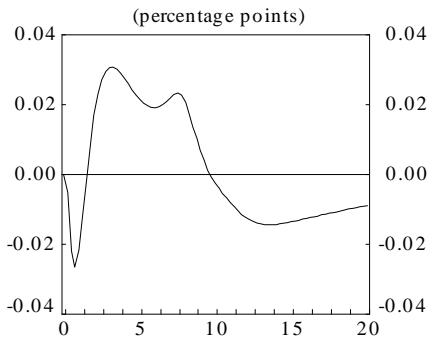

Year-on-Year Inflation

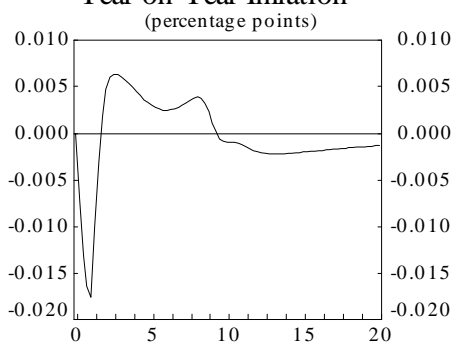

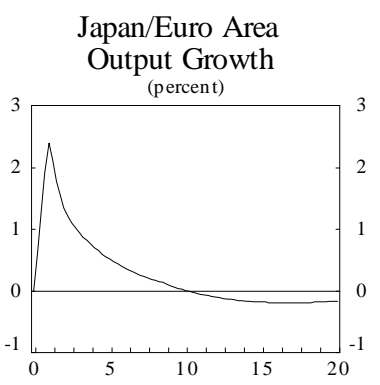

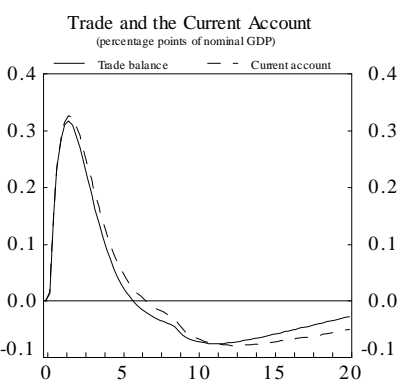

Real Effective Exchange Rate

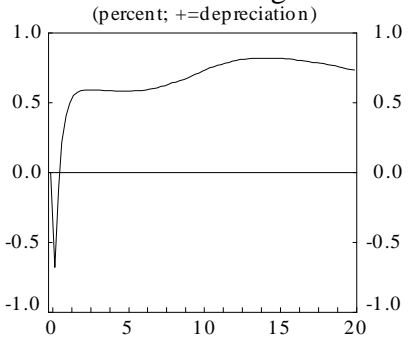

Real Interest Rates

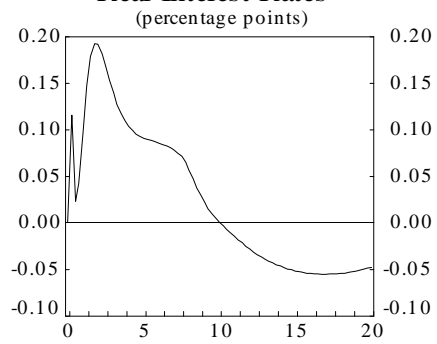

Year-on-Year Inflation

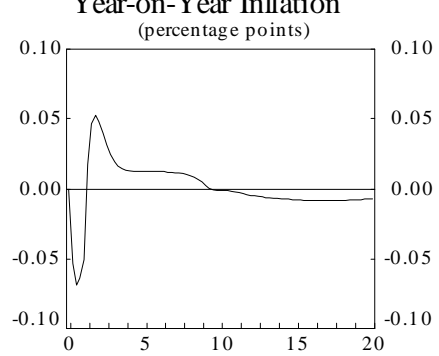

Remaining Countries

Output Growth (percent)

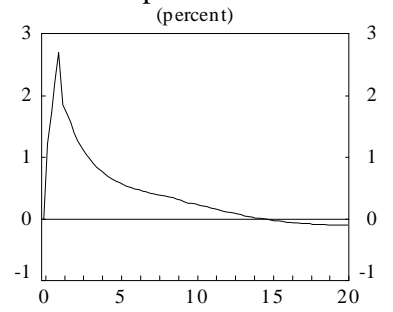

Trade and the Current Account
(percentage points of nominal GDP)

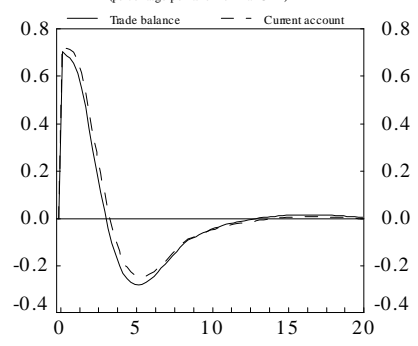

Real Effective Exchange Rate

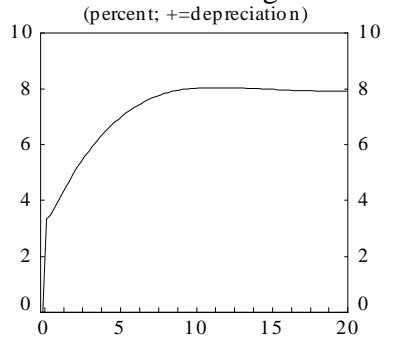

Real Interest Rates

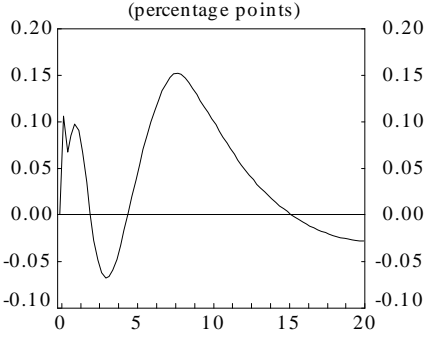

Year-on-Year Inflation

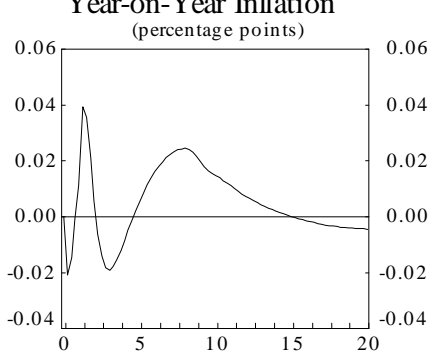


Figure 16: Forecasts from the IMF's World Economic Outlook, 1999 to 2005

\section{United States}
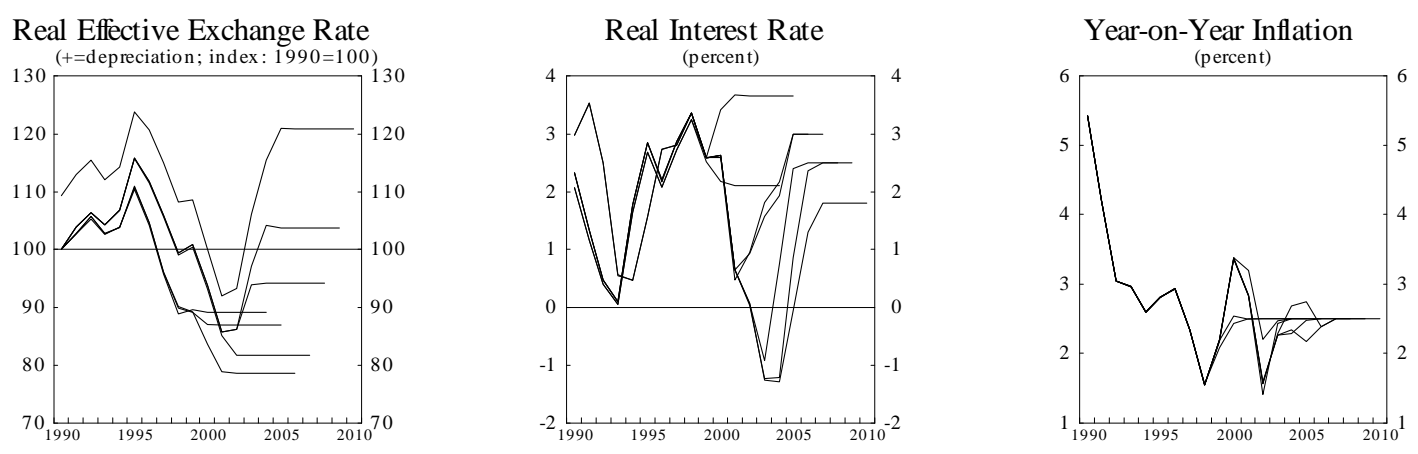

Trade Balance

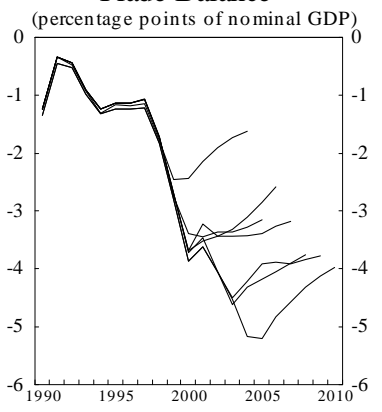

Government Debt

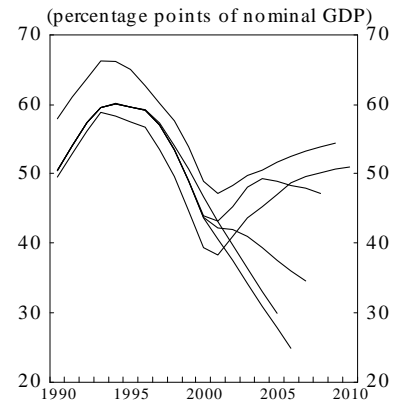

Current Account Balance

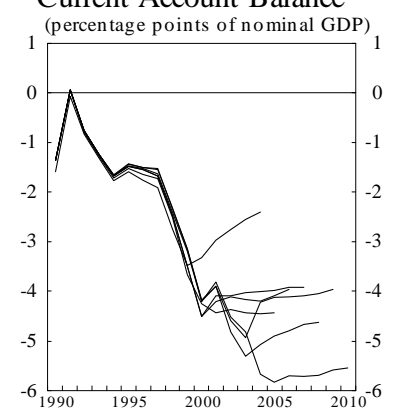

Consumption

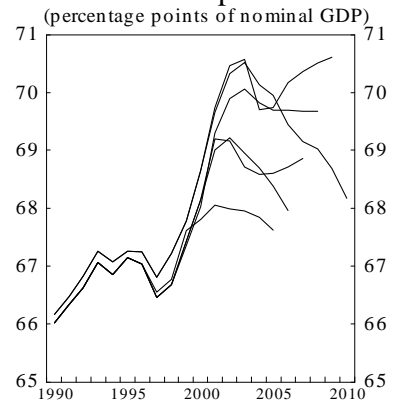

Government Deficit

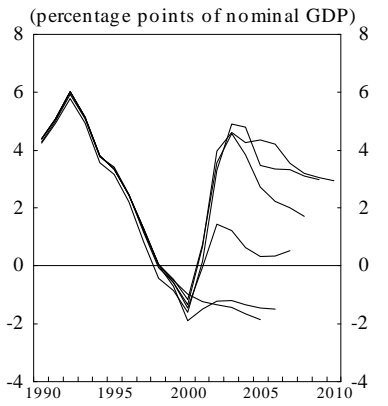

Investment

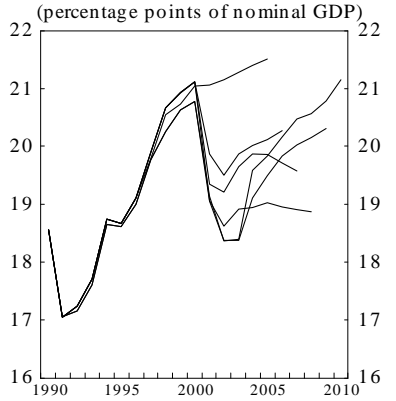


Figure 17: The Baseline Scenario - United States

(Levels)

Real Effective Exchange Rate

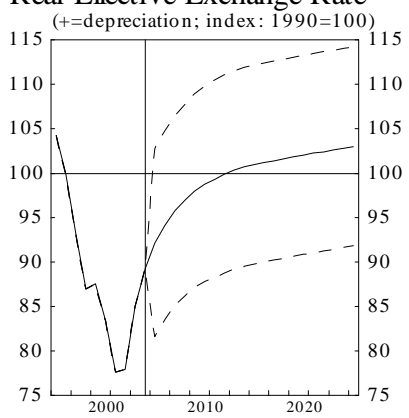

Productivity Growth

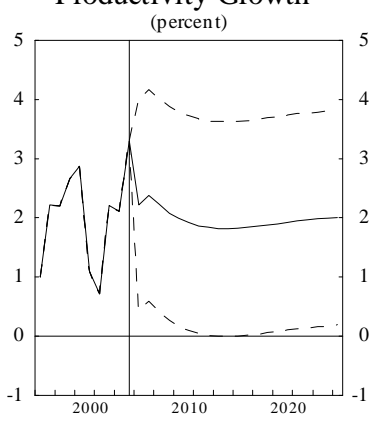

Trade Balance

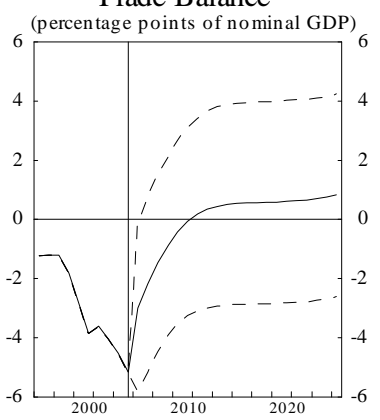

Government Deficit

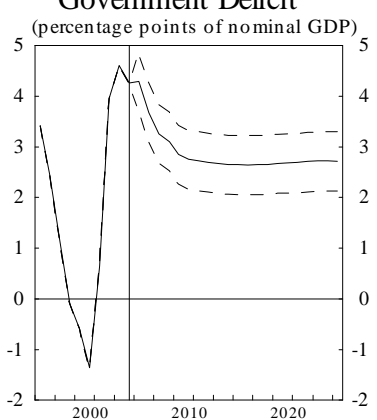

Real Interest Rate

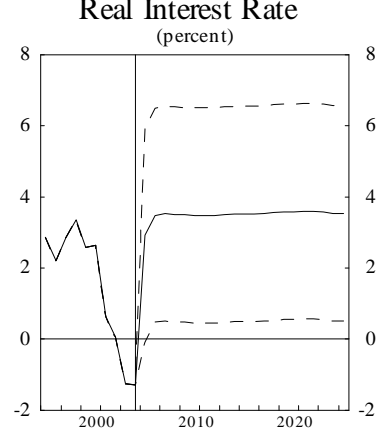

Consumption

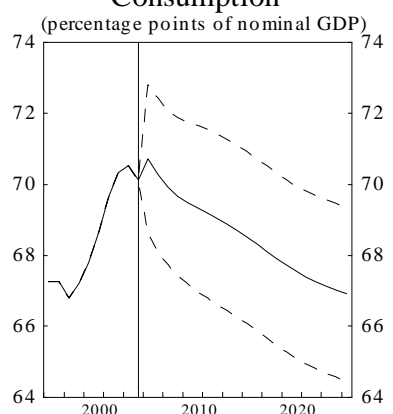

Current Account

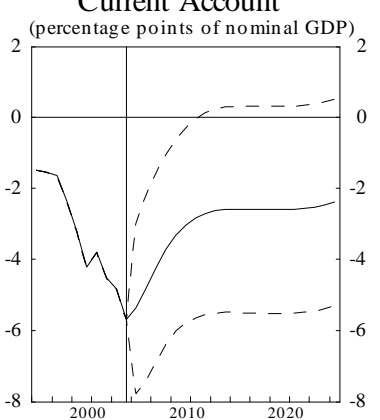

Government Debt

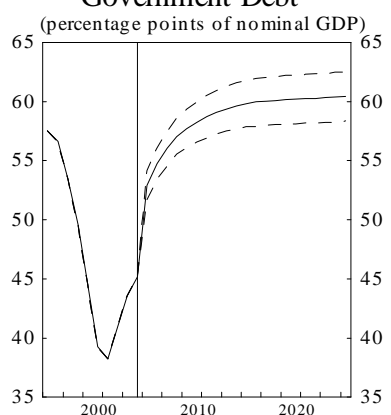

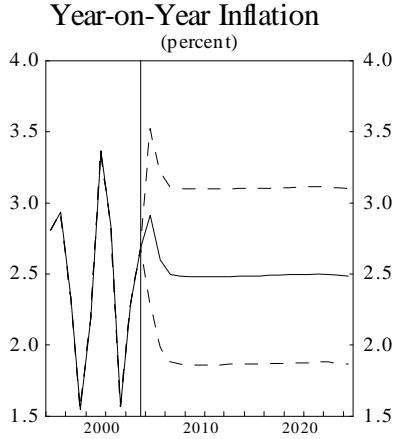

Investment

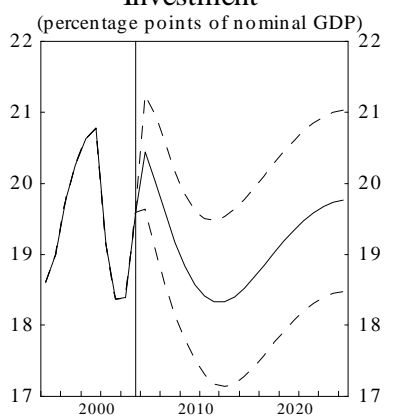

Net Foreign Assets

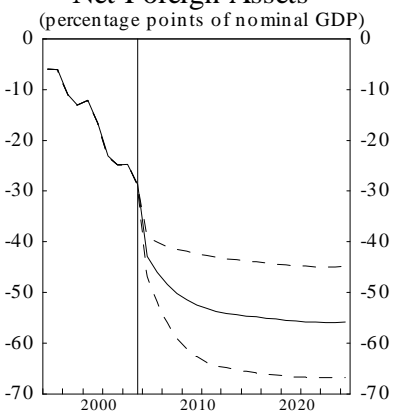


Figure 18: The Baseline Scenario - Emerging Asia

(Levels)

Real Effective Exchange Rate

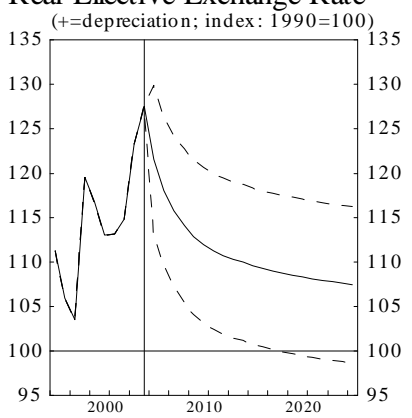

Productivity Growth

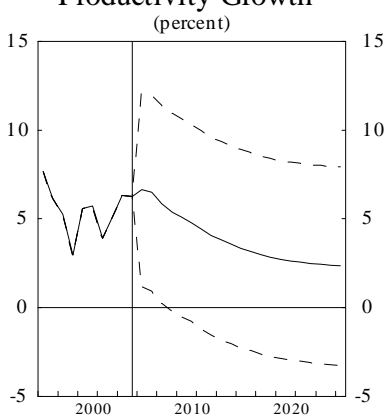

Trade Balance

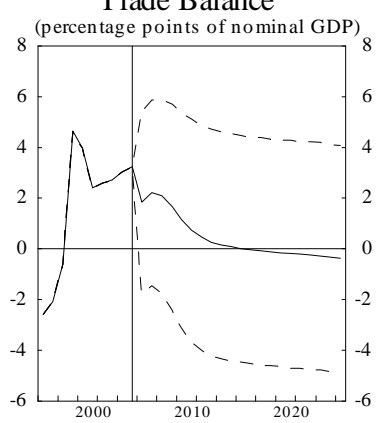

Government Deficit

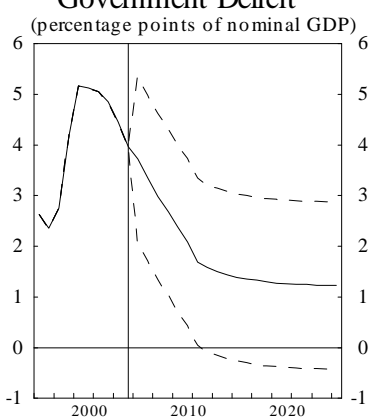

Real Interest Rate

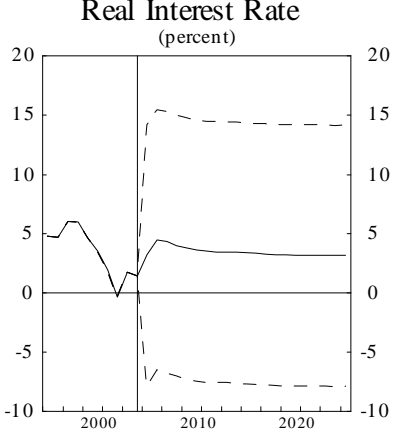

Consumption

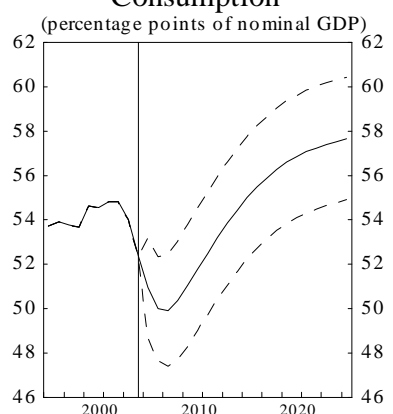

Current Account

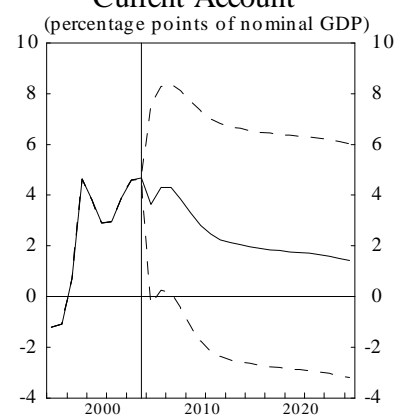

Government Debt

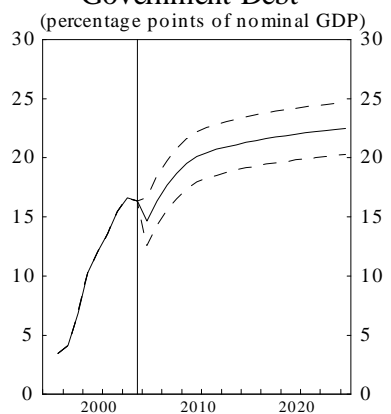

Year-on-Year Inflation

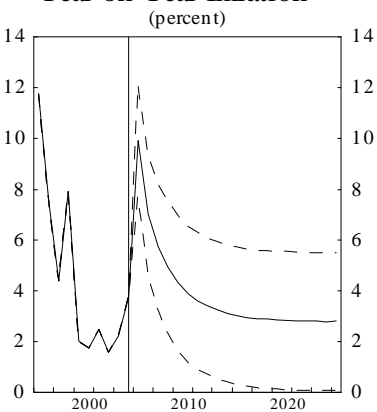

Investment

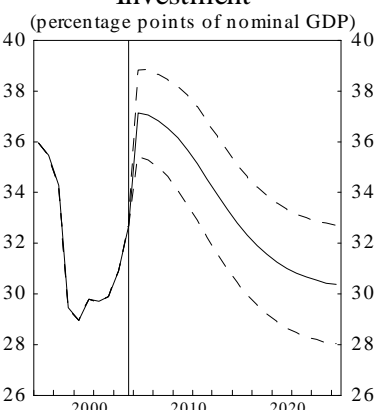

Net Foreign Assets

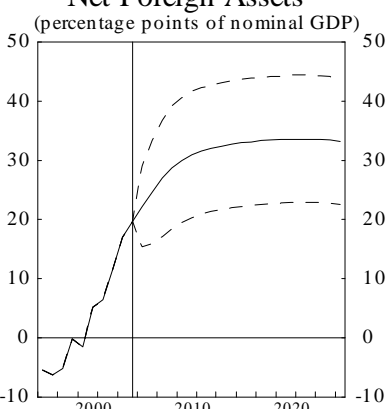


Figure 19: The Baseline Scenario - Japan and the Euro Area

(Levels)

Real Effective Exchange Rate

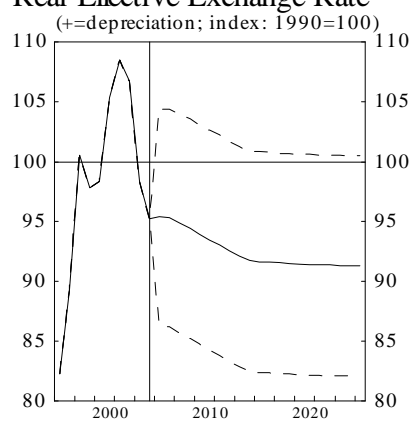

Productivity Growth

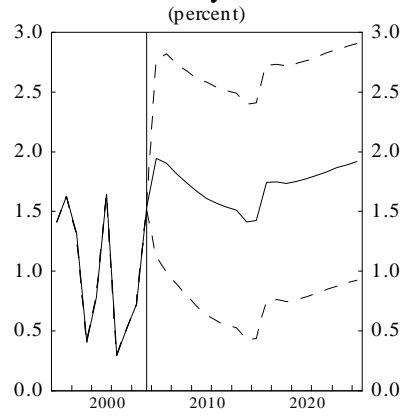

Trade Balance

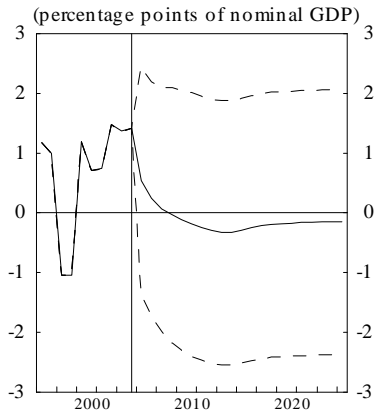

Government Deficit

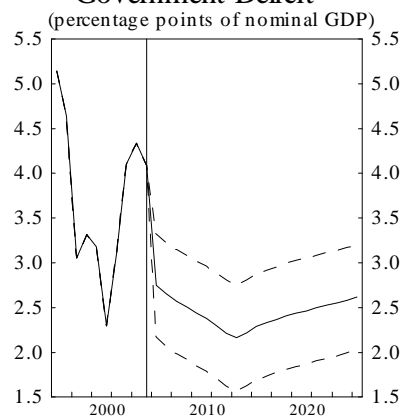

Real Interest Rate

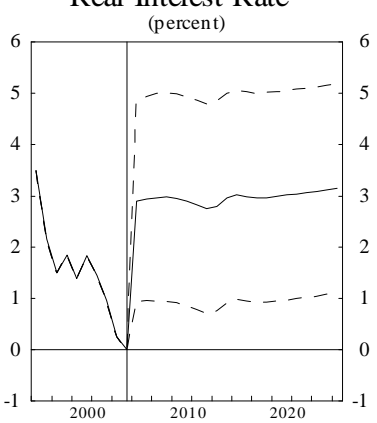

Consumption

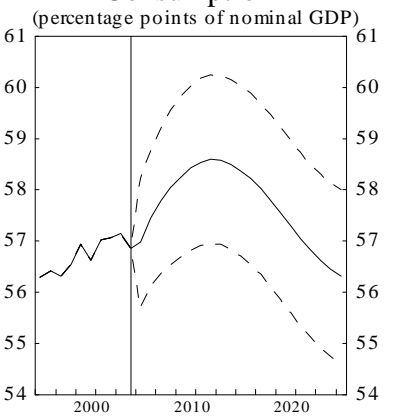

Current Account

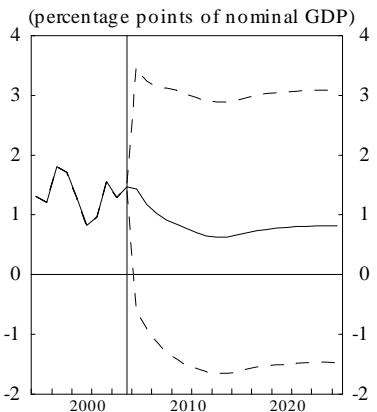

Government Debt

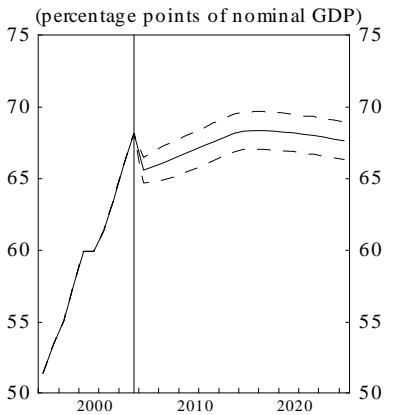

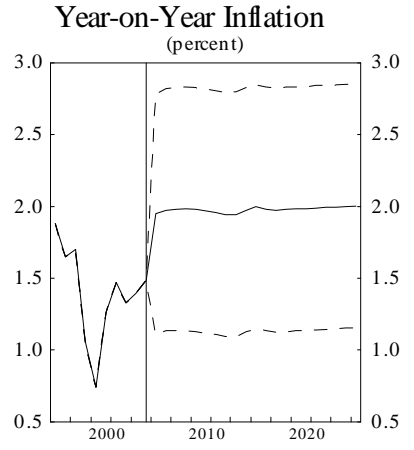

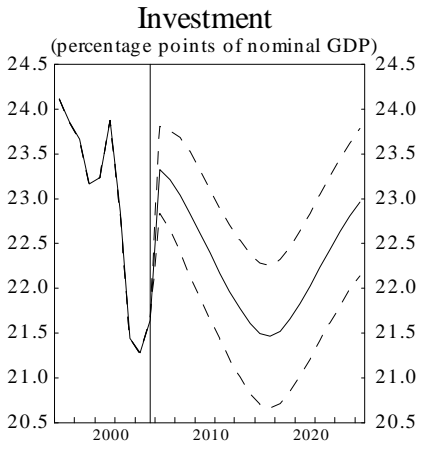

Net Foreign Assets

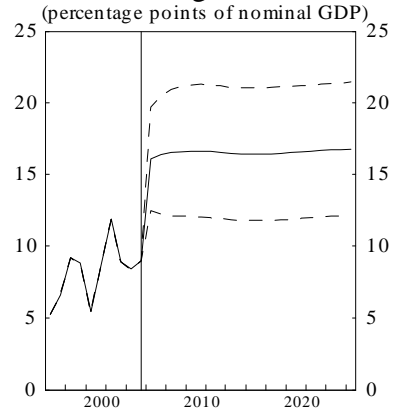


Figure 20: Loss of Appetite for US Assets - Benign Scenario Where the U.S. Current Account Deficit Declines by 1.5 Percentage Points: Exchange Peg in Emerging Asia (Solid Lines) and Move to Flexible Exchange Rates in Emerging Asia (Dashed Lines) [Deviation from baseline]
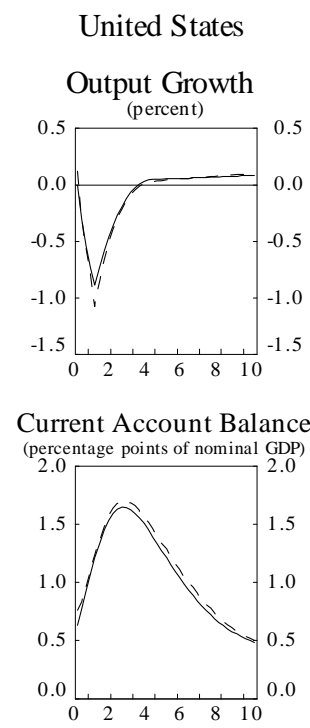

Real Interest Rates

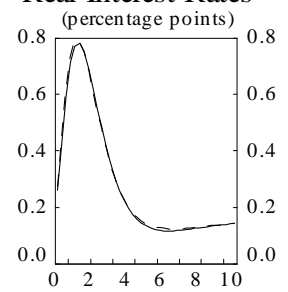

Real Effective Exchange Rate
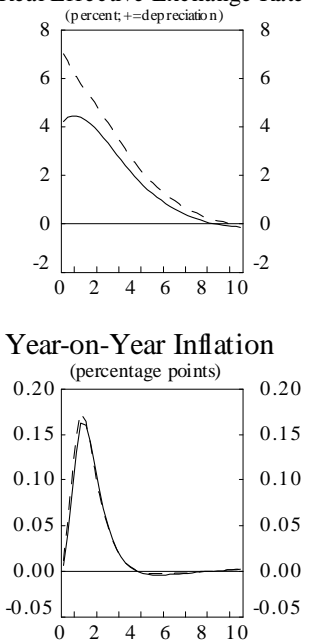

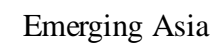

Output Growth

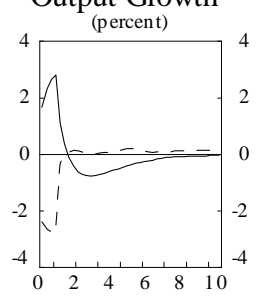

Current Account Balance (percentage points of nominal GDP)

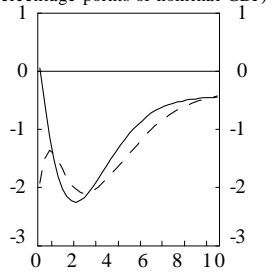

Real Interest Rates

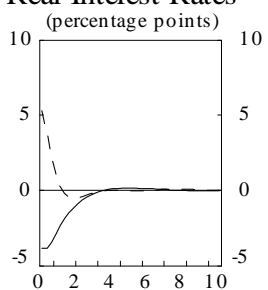

Real Effective Exchange Rate
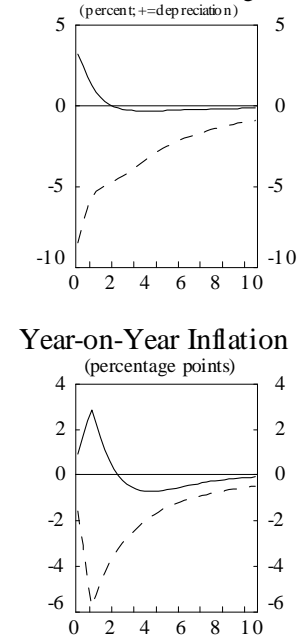

Japan/Euro Area

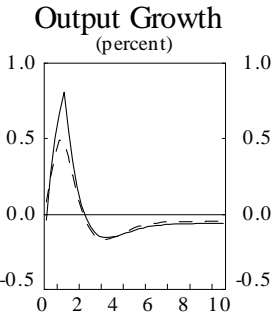

Current Account Balance (percentage points of nominal GDP)
0.0

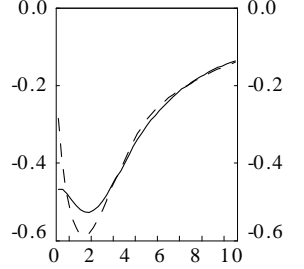

Real Interest Rates

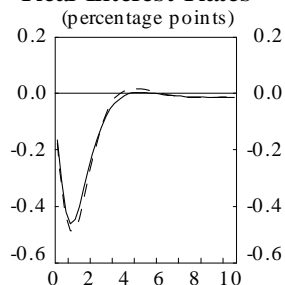

Real Effective Exchange Rate

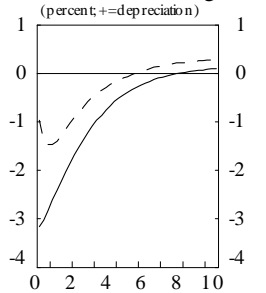

Year-on-Year Inflation

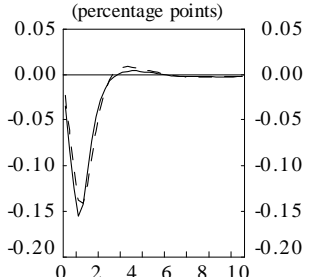

Remaining Countries

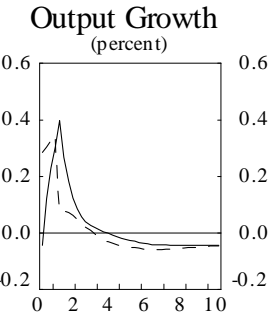

Current Account Balance (percentage points of nominal GDP)

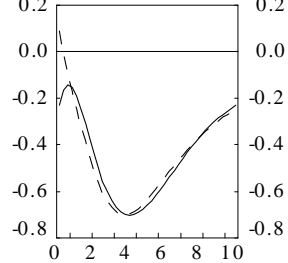

Real Interest Rates

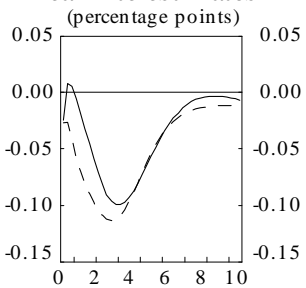

Real Effective Exchange Rate

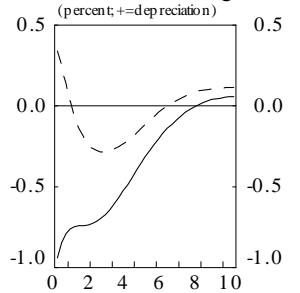

Year-on-Year Inflation

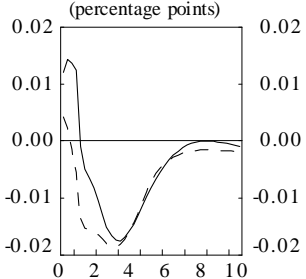


Figure 21: More Painful Current Account Reversal [Deviation from baseline]

United States
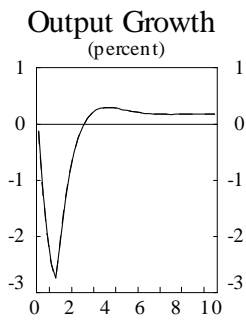

Current Account Balance (percentage points of nominal GDP)

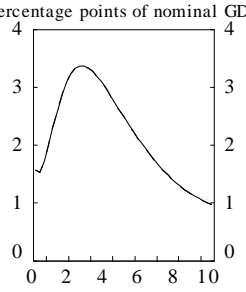

Real Interest Rates

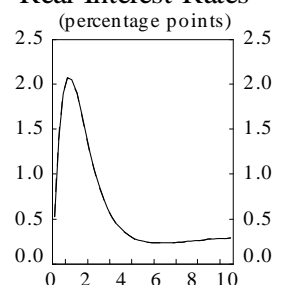

Real Effective Exchange Rate

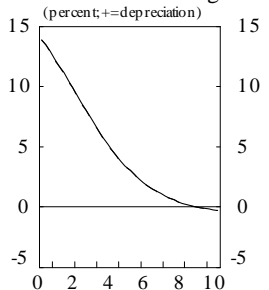

Year-on-Year Inflation

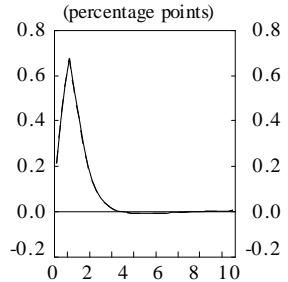

Emerging Asia

Output Growth

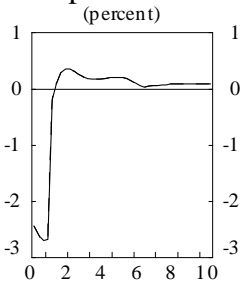

Current Account Balance (percentage points of nominal GDP)

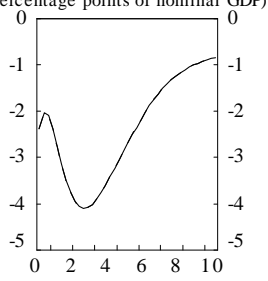

Real Interest Rates

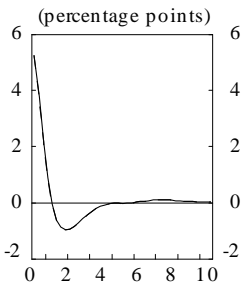

Real Effective Exchange Rate

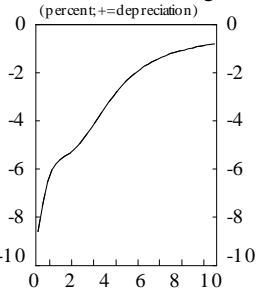

Year-on-Year Inflation

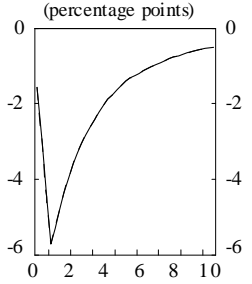

Japan/Euro Area

Output Growth

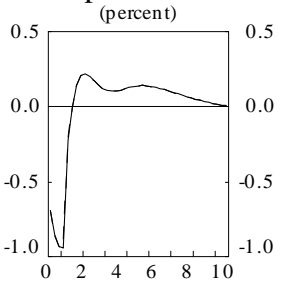

Current Account Balance (percentage points of nominal GDP)

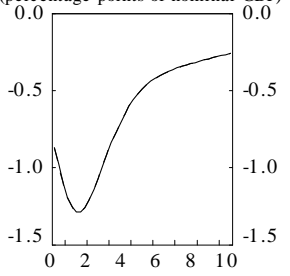

Real Interest Rates

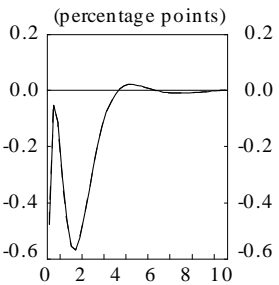

Real Effective Exchange Rate

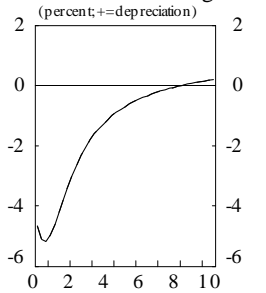

Year-on-Year Inflation

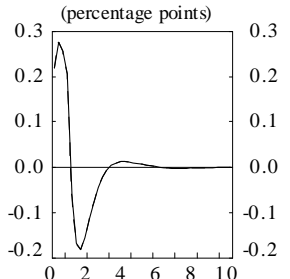

Remaining Countries

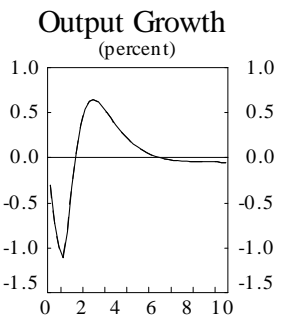

Current Account Balance (percentage points of nominal GDP)

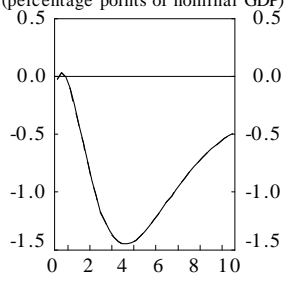

Real Interest Rates

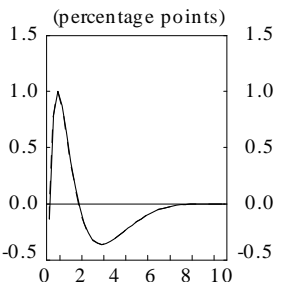

Real Effective Exchange Rate

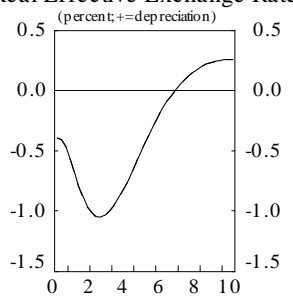

Year-on-Year Inflation

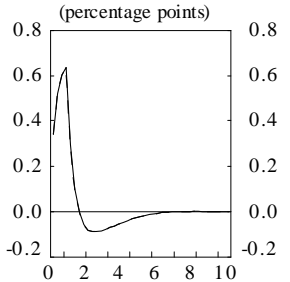


Figure 22: Effects of a Permanent Reduction in Government Debt through Tax Hikes: Exchange Rate Peg in Emerging Asia (Solid Lines) and Move to Flexible Exchange Rates in Emerging Asia (Dashed Lines) [Deviation from baseline]
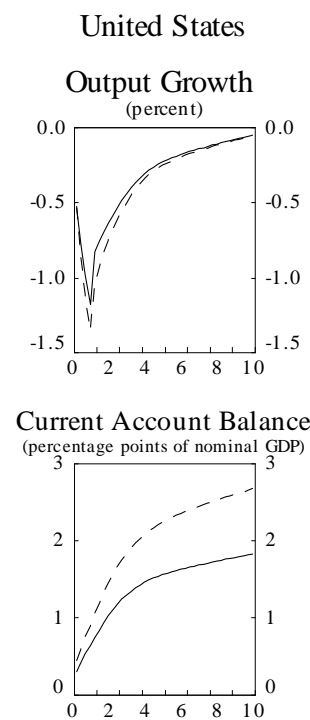

Real Interest Rates

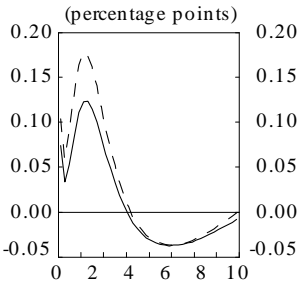

Real Effective Exchange Rate
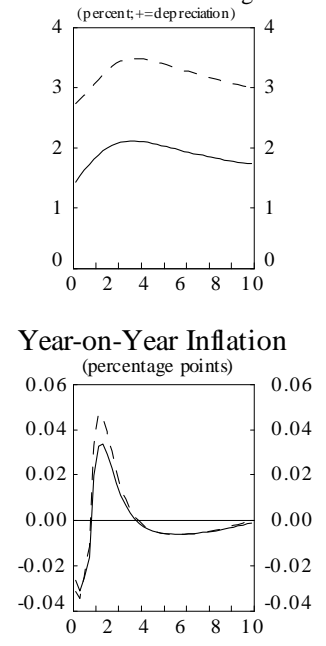

\section{Emerging Asia}

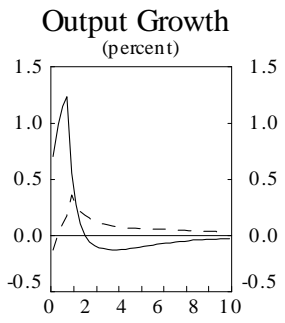

Current Account Balance (percentage points of nominal GDP)

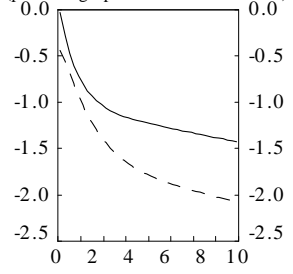

Real Interest Rates

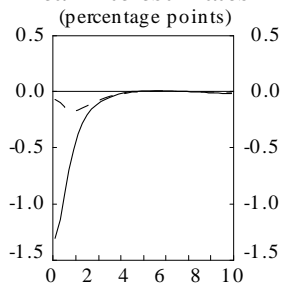

Real Effective Exchange Rate

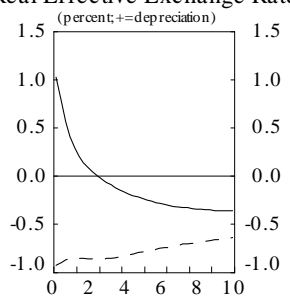

Year-on-Year Inflation

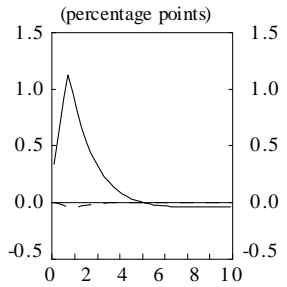

Japan/Euro Area

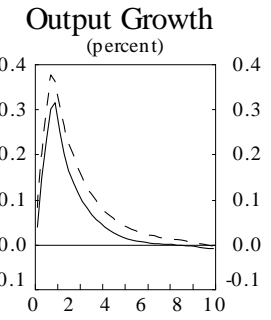

Current Account Balance (percentage points of nominal GDP)

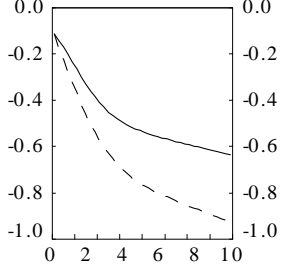

Real Interest Rates

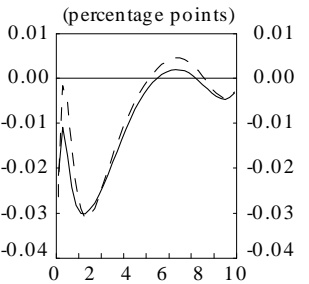

Real Effective Exchange Rate

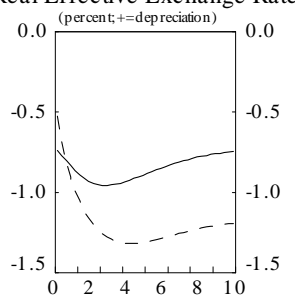

Year-on-Year Inflation

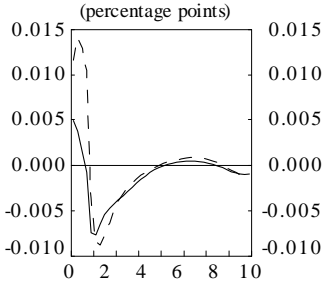

Remaining Countries

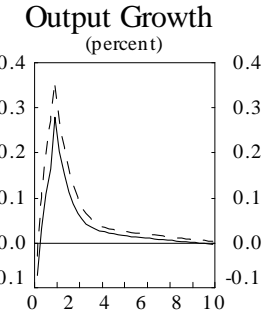

Current Account Balance (percentage points of nominal GDP)

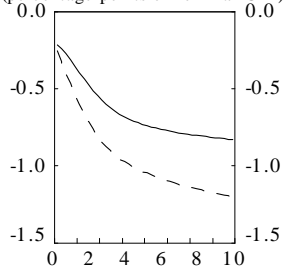

Real Interest Rates

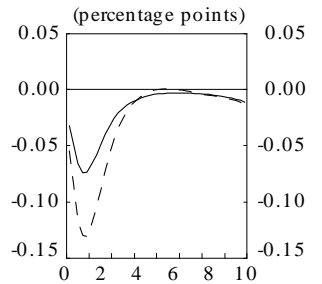

Real Effective Exchange Rate

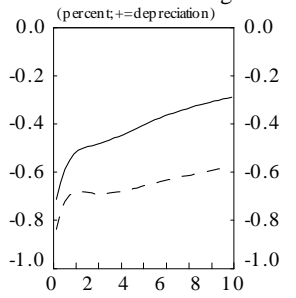

Year-on-Year Inflation

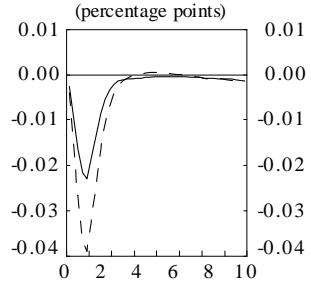


Figure 23: Effects of a Permanent Reduction in Government Debt through Tax Hikes: Sensitivity Analysis with Alternative Assumptions on the Link Between Government Debt and Net Foreign Liabilities [Deviations from baseline]

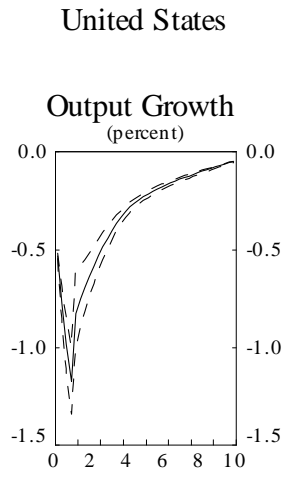

Current Account Balance

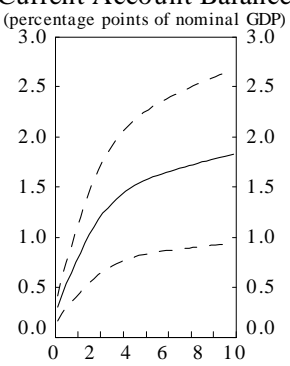

Real Interest Rates

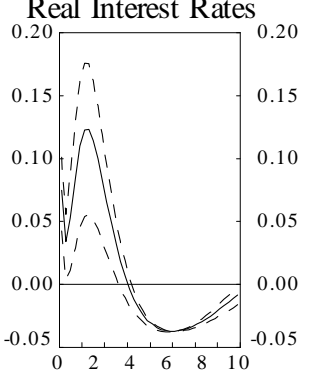

Real Effective Exchange Rate

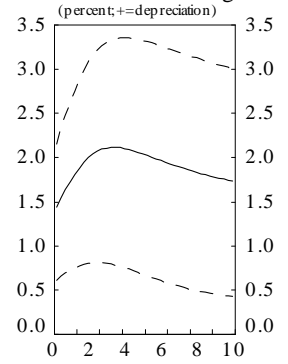

Year-on-Year Inflation

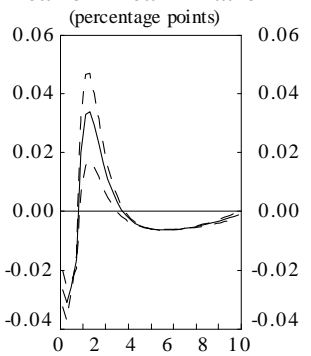

Emerging Asia

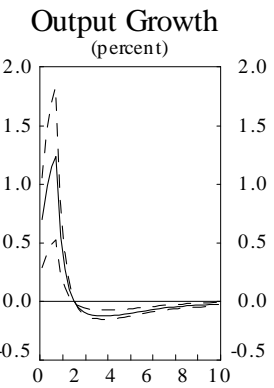

Current Account Balance (percentage points of nominal GDP)

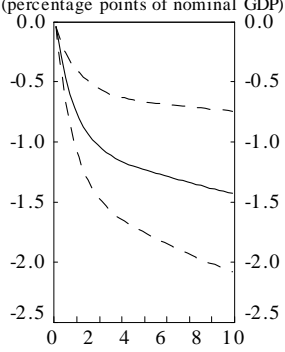

Real Interest Rates

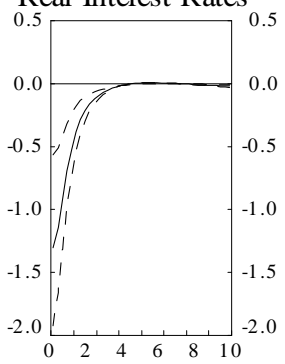

Real Effective Exchange Rate

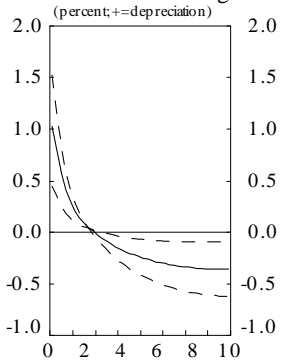

Year-on-Year Inflation

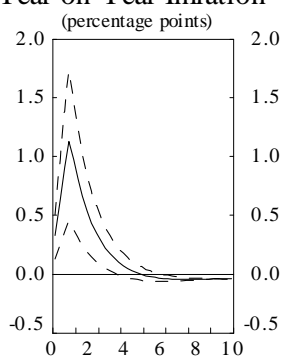

Japan/Euro Area

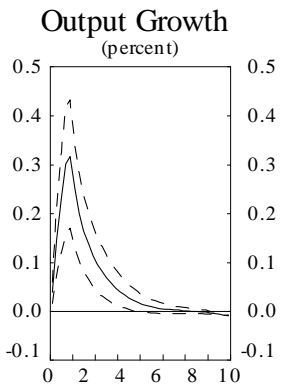

Current Account Balance (percentage points of nominal GDP)

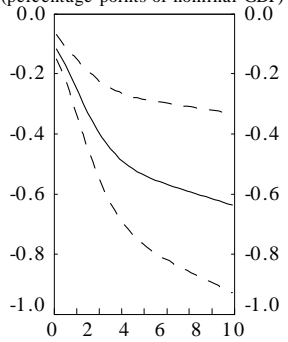

Real Interest Rates

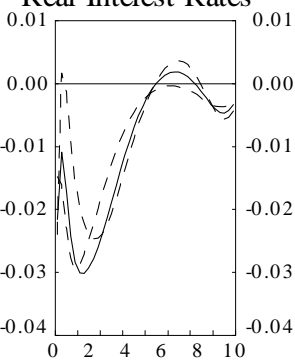

Real Effective Exchange Rate

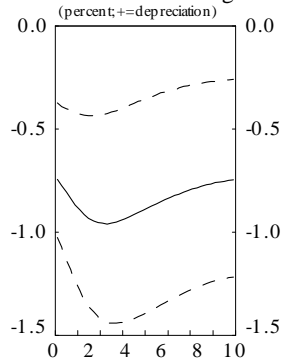

Year-on-Year Inflation

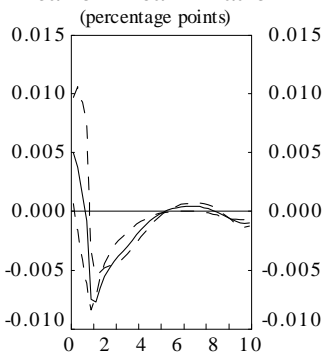

Remaining Countries

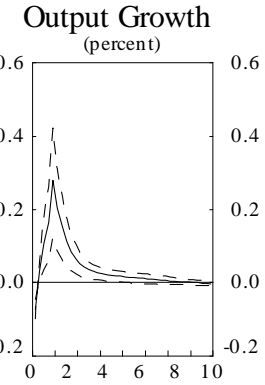

Current Account Balance (percentage points of nominal GDP)

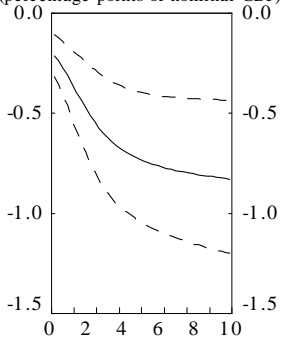

Real Interest Rates

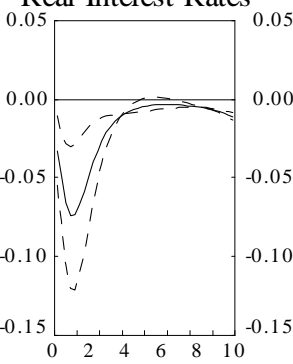

Real Effective Exchange Rate

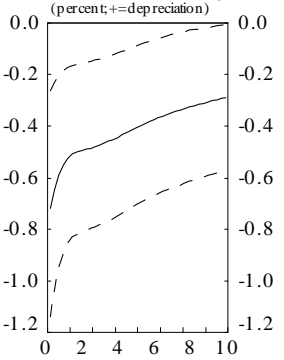

Year-on-Year Inflation

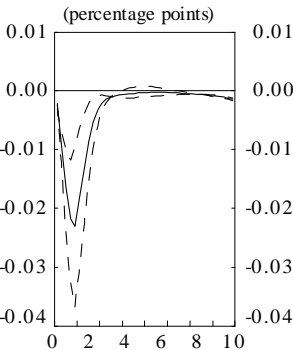


Figure 24: Effects of a Permanent Reduction in Government Debt through Tax Hikes: Sensitivity Analysis using GFM Comparing a Planning Horizon of 10 Years (Solid Lines) with a Planning Horizon of 20 Years (Dashed Lines) [Deviations from baseline]

United States

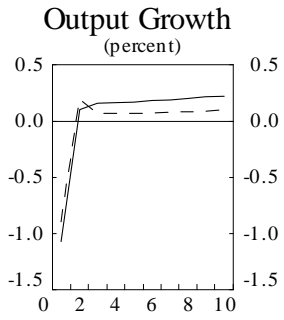

Current Account Balance $($ percentage points of nominal GDP)

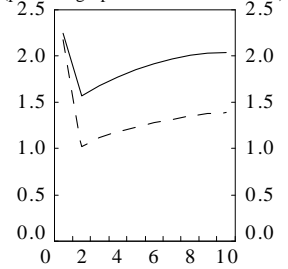

Real Interest Rates

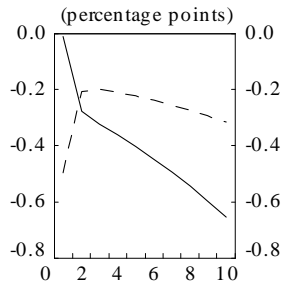

Real Effective Exchange Rate

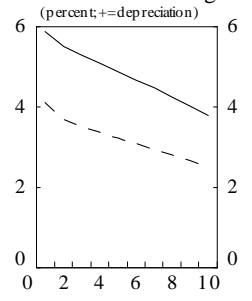

Year-on-Year Inflation

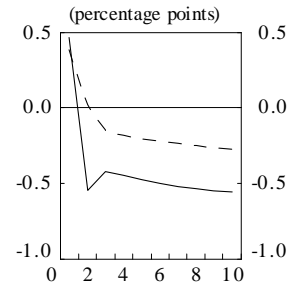

Emerging Asia
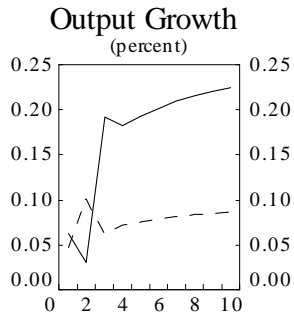

Current Account Balance (percentage points of nominal GDP)
0.0

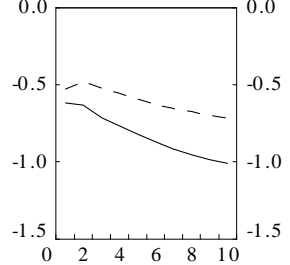

Real Interest Rates

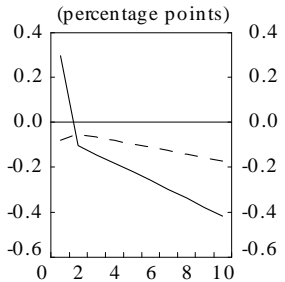

Real Effective Exchange Rate

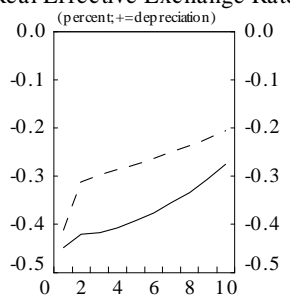

Year-on-Year Inflation

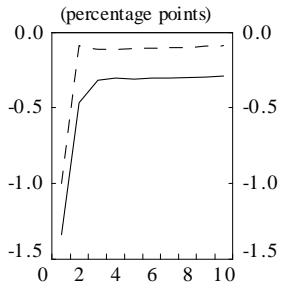

Japan/Euro Area

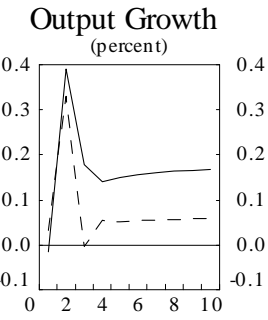

Current Account Balance (percentage points of nominal GDP)

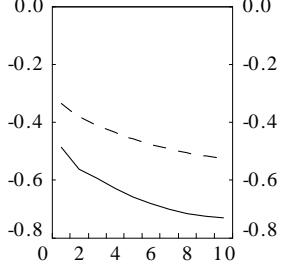

Real Interest Rates

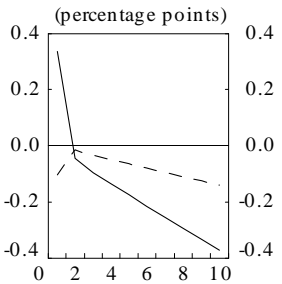

Real Effective Exchange Rate

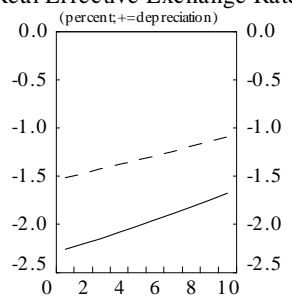

Year-on-Year Inflation

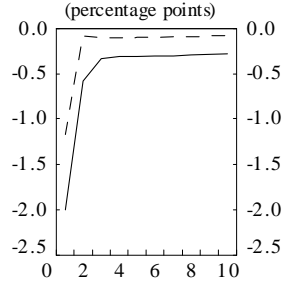

Remaining Countries

Output Growth

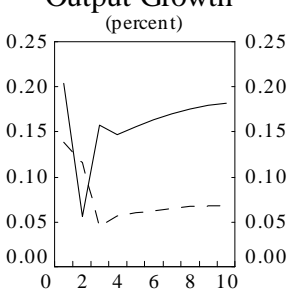

Current Account Balance (percentage points of nominal GDP)

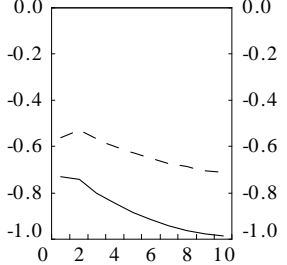

Real Interest Rates

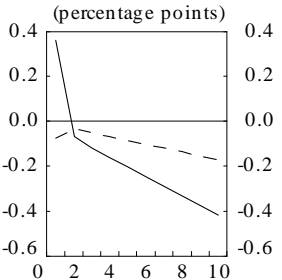

Real Effective Exchange Rate

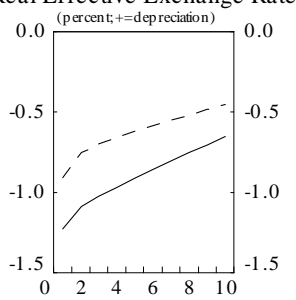

Year-on-Year Inflation

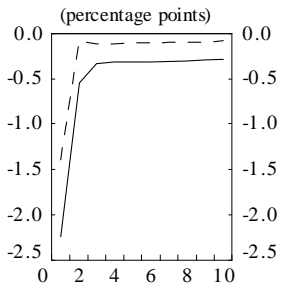


Figure 25: Effects of a Permanent Reduction in Government Debt through Tax Hikes (Solid Lines) and Expenditure Cuts (Dashed Lines) [Deviations from baseline]

United States

Output Growth

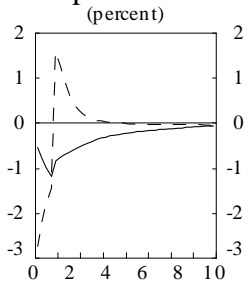

Current Account Balance (percentage points of nominal GDP)

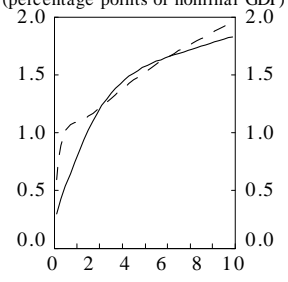

Real Interest Rates
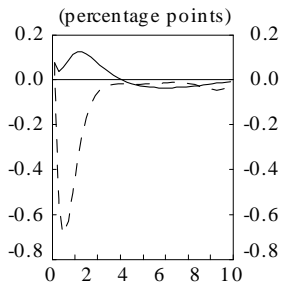

Real Effective Exchange Rate

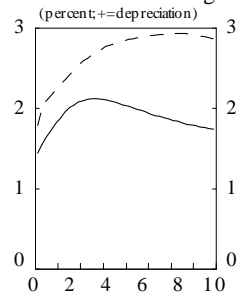

Year-on-Year Inflation

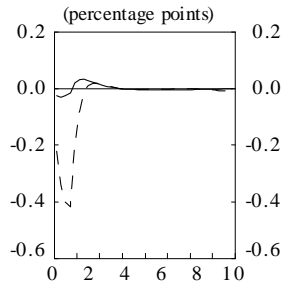

Emerging Asia

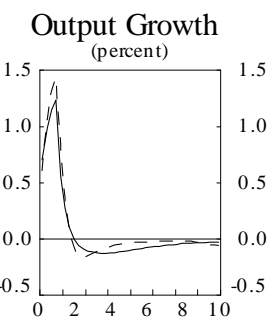

Current Account Balance
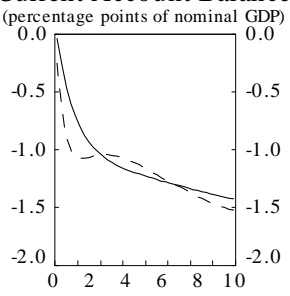

Real Interest Rates

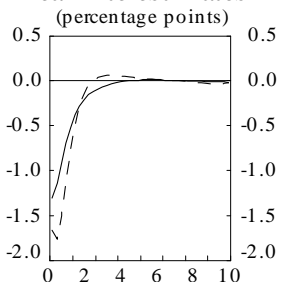

Real Effective Exchange Rate

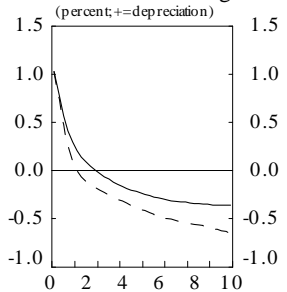

Year-on-Year Inflation

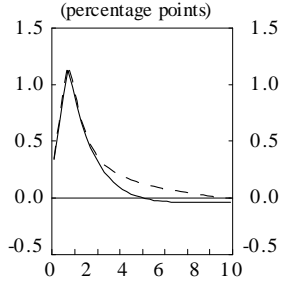

Japan/Euro Area
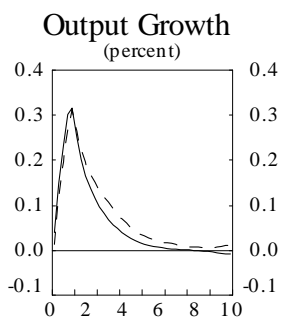

Current Account Balance (percentage points of nominal GDP)

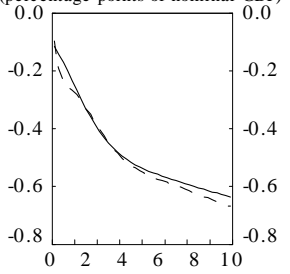

Real Interest Rates

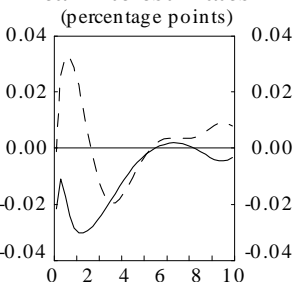

Real Effective Exchange Rate

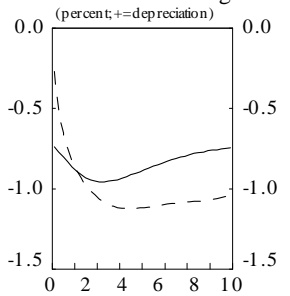

Year-on-Year Inflation

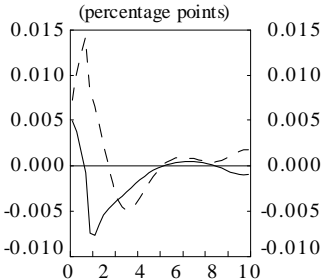

Remaining Countries

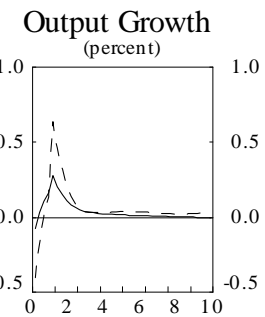

Current Account Balance (percentage points of nominal GDP)

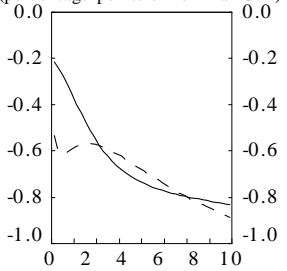

Real Interest Rates

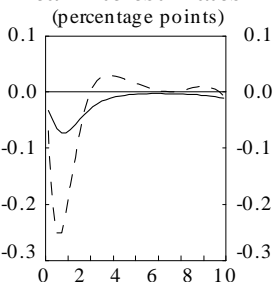

Real Effective Exchange Rate

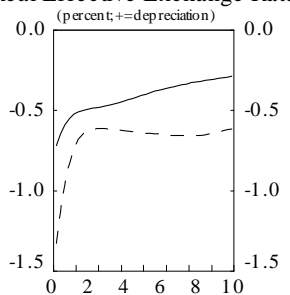

Year-on-Year Inflation

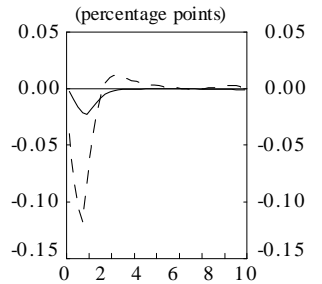


Figure 26: Estimated Effects of More Competition-Friendly Policies in Japan and the Euro Area: Financed by All Other Regional Blocs (Solid Lines) and Financed Only by the United States (Dashed Lines) [Deviations from baseline]

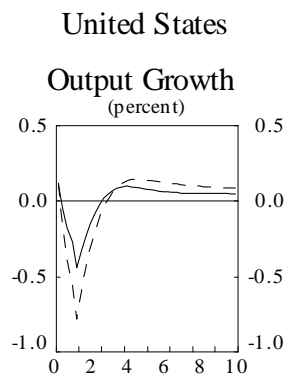

Current Account Balance

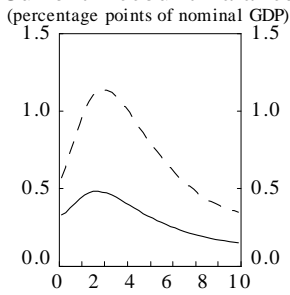

Real Interest Rates

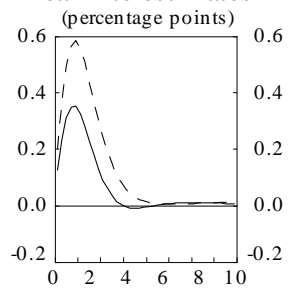

Real Effective Exchange Rate
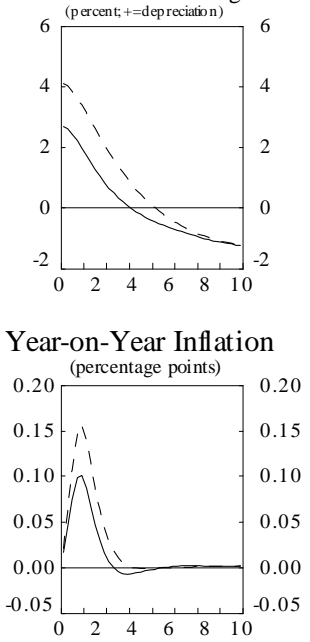

Emerging Asia

$\underset{\text { (percent) }}{\text { Output Growth }}$

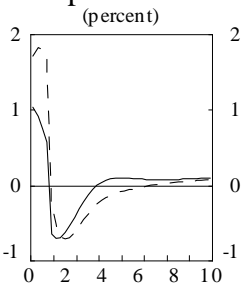

Current Account Balance (percentage points of nominal GDP)

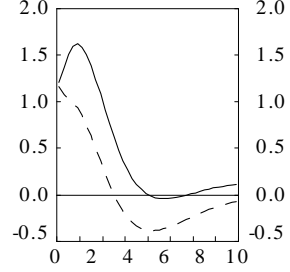

Real Interest Rates

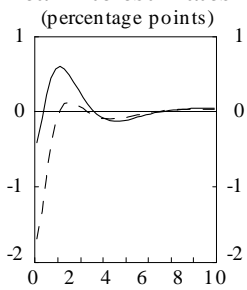

Real Effective Exchange Rate

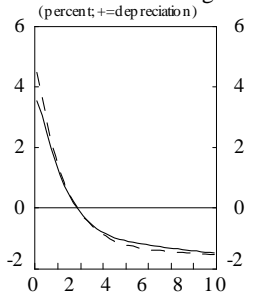

Year-on-Year Inflation

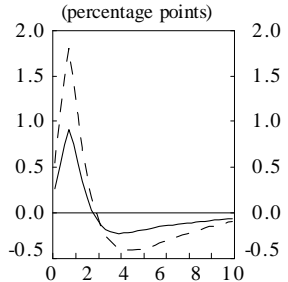

Japan/Euro Area
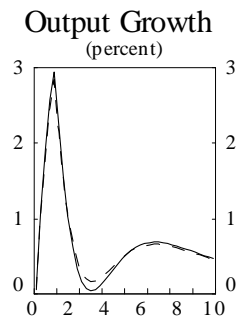

Current Account Balance (percentage points of nominal GDP)

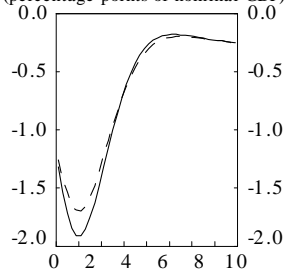

Real Interest Rates

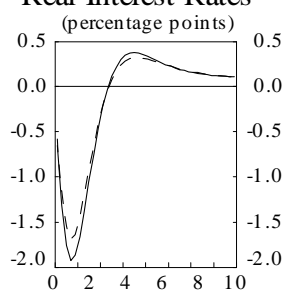

Real Effective Exchange Rate

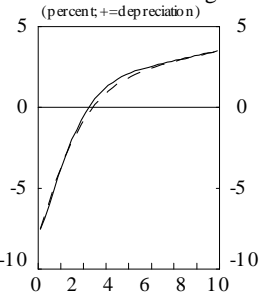

Year-on-Year Inflation

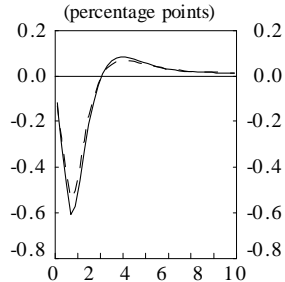

Remaining Countries

Output Growth

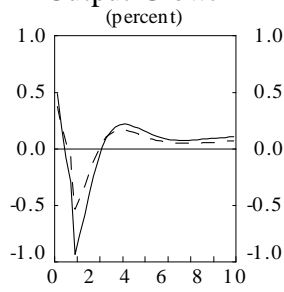

Current Account Balance (percentage points of nominal GDP)

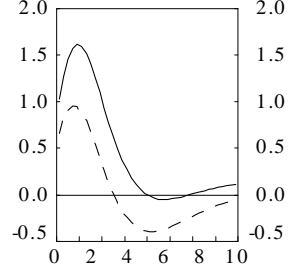

Real Interest Rates

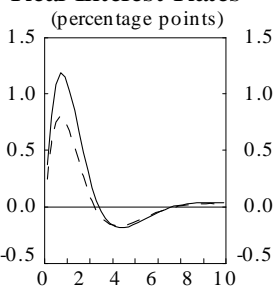

Real Effective Exchange Rate

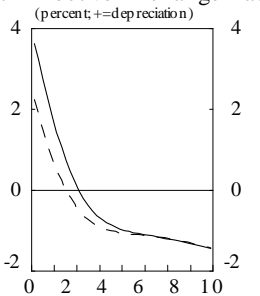

Year-on-Year Inflation

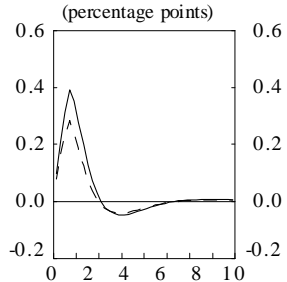

